Portland State University

PDXScholar

\title{
Toward a phenomenological-based perspective of acculturation with application to Scottish immigrants
}

Dorothy M. Sermol

Portland State University

Follow this and additional works at: https://pdxscholar.library.pdx.edu/open_access_etds

Part of the Interpersonal and Small Group Communication Commons, and the Speech and Hearing Science Commons

Let us know how access to this document benefits you.

\section{Recommended Citation}

Sermol, Dorothy M., "Toward a phenomenological-based perspective of acculturation with application to Scottish immigrants" (1983). Dissertations and Theses. Paper 3387.

https://doi.org/10.15760/etd.5274

This Thesis is brought to you for free and open access. It has been accepted for inclusion in Dissertations and Theses by an authorized administrator of PDXScholar. Please contact us if we can make this document more accessible: pdxscholar@pdx.edu. 
AN ABSTRACT OF THE THESIS OF Dorothy $M$. Sermol for the Master of Arts in Speech Communication presented July 12 , 1983.

Title: Toward a Phenomenological-Based Perspective of Acculturation with Application to Scottish Immigrants.

APPROVED BY MEMBERS OF THE THESIS COMMITTEE:

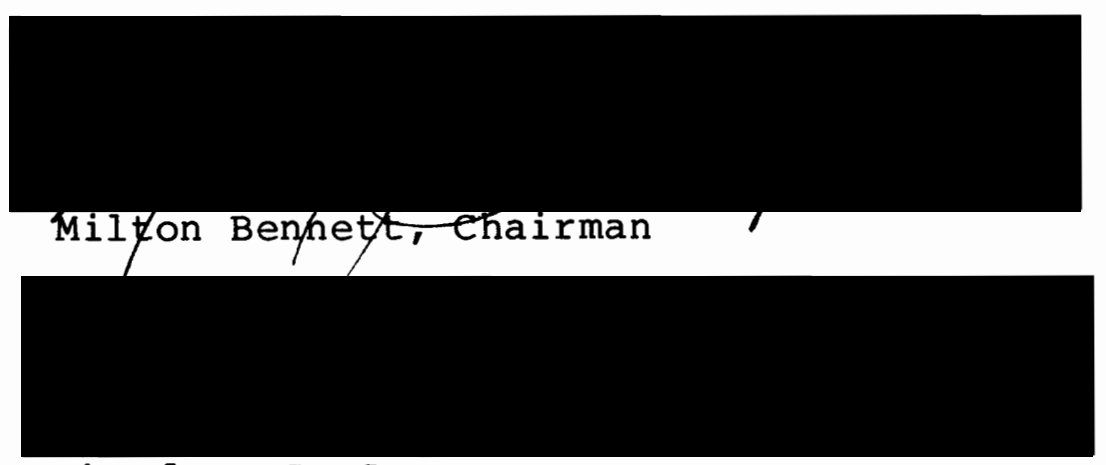

Theodore G. Grove

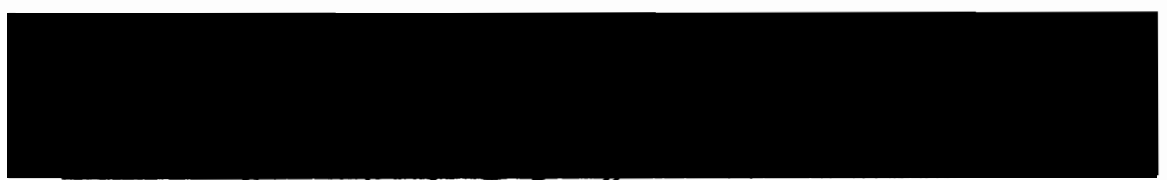

Alfred/Sugarmah
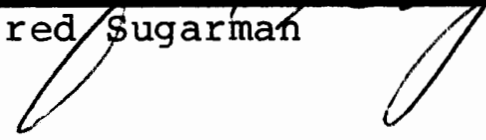

This thesis is an attempt to construct a perspective of the acculturation of immigrants drawing on certain communication-based phenomenological assumptions. From these phenomenological assumptions a Framework of Acculturation is constructed as a guide through which to examine the accul- 
turation process. The Framework of Acculturation is then applied to the particular group of scottish immigrants who live in the Northwest of the united States.

In order to look at acculturation in the context of both general and intercultural communication, the communiation-based phenomenological assumptions of relationship, subjectivity, and process are described and their relevance to the acculturation of immigrants is assessed.

A definition of acculturation is suggested that conforms to the phenomenological perspective. This definition considers acculturation as being a subjective experience in which an immigrant acquires and copes with the host culture. The immigrant interprets his new environment in relationship to a multitude of factors. The relationship is carried on through communication. Acculturation is also a dynamic process, in which elements of the process are interrelated with variable sequences.

Drawing on the aforementioned phenomenological. assumptions, a Framework of Acculturation, derived from selected Iiterature, is proposed to denote the conditions of acculturation and to act as a guide for the interview schedule used when questioning the subjects. The conditions of the Framework of Acculturation include transition, adjustment, identification with the host culture, biculturalism, multiculturalism, and assimilation. It is suggested that because of the "process" perspective, the conditions of acculturation are not static, linear, or fixed. The Framework of 
Acculturation is then applied to an inquiry about the process of the acculturation of eight Scottish immigrants. Immigrants were selected as subjects because they represent an idențifiable group of people who have engaged in long term cultural adjustment. Scots were selected because there is little information in the literature on this particular group. The subjective process of the acculturation of these immigrants is described by means of oral history interviews.

Insofar as acculturation is viewed from a phenomenological perspective, communication is the vehicle through which acculturation operates. Therefore, the subjects were queried about their intra- and inter-ethnic communication. It was found that intra-ethnic communication, in both formal and informal situations, was influential and persisted throughout the acculturation experience. Inter-ethnic communication, in the form of interaction with immigrants undergoing similar experiences, was found to be salient. Inter-ethnic communication with the host culture members was influential, particularly in work related activities.

The process nature of acculturation was evident. Although all subjects had experienced the condition of transition, thereafter they reported variable sequences or reversals of the conditions. The data showed that it was possible to describe the long term acculturation of immigrants using certain conditions of the Framework of Acculturation as a guide. The conditions of transiticn, adjustment to the 
host culture and identification with the host culture were particularly useful in analysis. However, the conditions of biculturalism and multiculturalism should be more clearly defined.

Finally, suggestions and hypotheses for further study are provided. Application of aspects of the acculturation process that would be of use in the communication training of immigrants are described. 


\title{
TOWARD A PHENOMENOLOGICAL-BASED PERSPECTIVE OF ACCULTURATION WITH APPLICATION \\ TO SCOTTISH IMMIGRANTS
}

\section{by}

DOROTHY M. SERMOL
A thesis submitted in partial fulfillment of the requirments for the degree of

\author{
MASTER OF ARTS \\ in \\ SPEECH COMMUNICATION
}
Portland state University
1983


TO THE OFFICE OF GRADUATE STUDIES AND RESEARCH:

The members of the committe approve the thesis of Dorothy M. Sermol presented July 12, 1983.

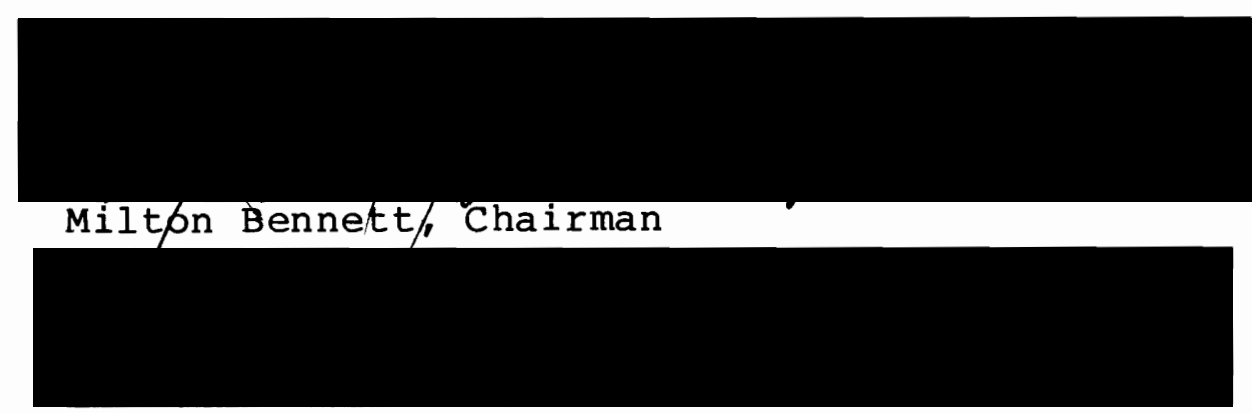

Theodore G. Grove

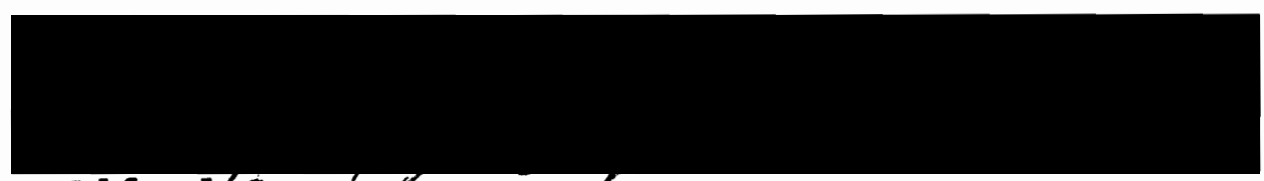

Alfred/sugatmán

APPROVED :

Theodore G. Grove, Chairman, Department of Speech Communication

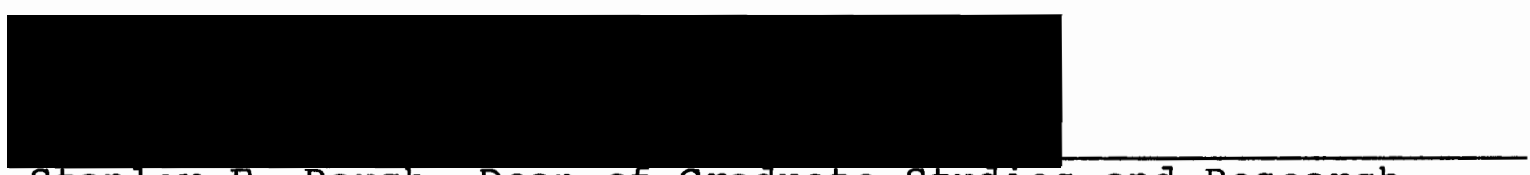

Stanley E. Rauch, Dean of Graduate Studies and Research 
Dedicated to

Hap, Luisa, Amanda

Isobel and Ewen 


\section{ACKNOWLEDGMENTS}

I emigrated from Scotland to the United States and much of my inspiration for writing this study stems from this experience. However, the guidance and encouragement that led me to complete this study came mainly from the following people.

For support, encouragement and many useful talks I am particularly indebted to Dr. Bennett, Dr. Grove, and Dr. Sugarman, whose responses put me in touch with what I was doing and whose comments, teachings, and and practical advice proved invaluable to me. Acknowledgment is also extended to Dr. Maynard, Mrs. Barna, Dr. Vogelsang, and Joan Maiers who patiently listened and who provided understanding and guidance. I am also indebted to Mrs. Vogelsang, whose editorial skills and friendship I appreciate.

Most importantly, I thank my loving family, who encouraged me to use my creative energies. Hap, your love, understanding, selflessness, and unbounded enthusiasm made this, and much more, possible. I thank my daughters, Luisa and Amanda for being fine company during all the working hours and for radiating sweetness and comfort to me. To my family, the biggest thanks of all, with love. 
TABLE OF CONTENTS

PAGE

ACKNOWLEDGMENTS

LIST OF TABLES

vi i

LIST OF FIGURES

CHAPTER

I AN OVERVIEW OF THE STUDY . . . . . . .

Purposes of this Study . . . . .

Description of the Communication

Based Phenomenological Assumptions

and Definitions . . . . . . . .

First Phenomenological Assumption:

Communication is Relational

Second Phenomenological Assumption:

Communication is Subjective... .

Third Phenomenological Assumption:

Communication is a Process . . . .

II ACCUlturation . . . . . . . . . . 35

Various Definitions of Acculturation 36

An Overview of Acculturation . . . 37

Acculturation is a Subjective Experience $\quad 39$

Acculturation is Relational . . . . 44

Acculturation is a Process . . . . 55

A Phenomenological Framework of Acculturation: The Subjective Experience of Immigrants in Relational Terms. . 
The Qualitative Perspective . . .

The subjects . . . . . . . . 77

Interview Procedures . . . . . . 80

The Interview Schedule . . . . . 81

IV DATA: THE ORAL HISTORY INTERVIEWS . . . 90

V ANALYSIS . . . . . . . . . . . 147

Analysis of the Subjective Experience According to the Framework of Acculturation .. . . . . . . .

The Effect of Communication on Acculturation . . . . . . . 160

Limitations of this Study . . . . . 172

VI IMPLICATIONS AND APPLICATIONS . . . . . 176

Implications . . . . . . . . 176

Applications .......... . 180

SELECTED BIBLIOGRAPHY . . . . . . . . 197 


\section{LIST OF TABLES}

TABLE

PAGE

I A Framework of the Acculturation Process.

64

II The Relationship of the Framework of

Acculturation to the Interview

Schedule . . . . . . . . . . .

87

III The Relationship of Other Factors of

Acculturation to the Interview

Schedule . . . . . . . . . . . 


\section{LIST OF FIGURES}

FIGURE

PAGE

1. Conceptual Flow Diagram for Thesis . . . ix 
CONCEPTUAL FLOW DIAGRAM FOR THESIS

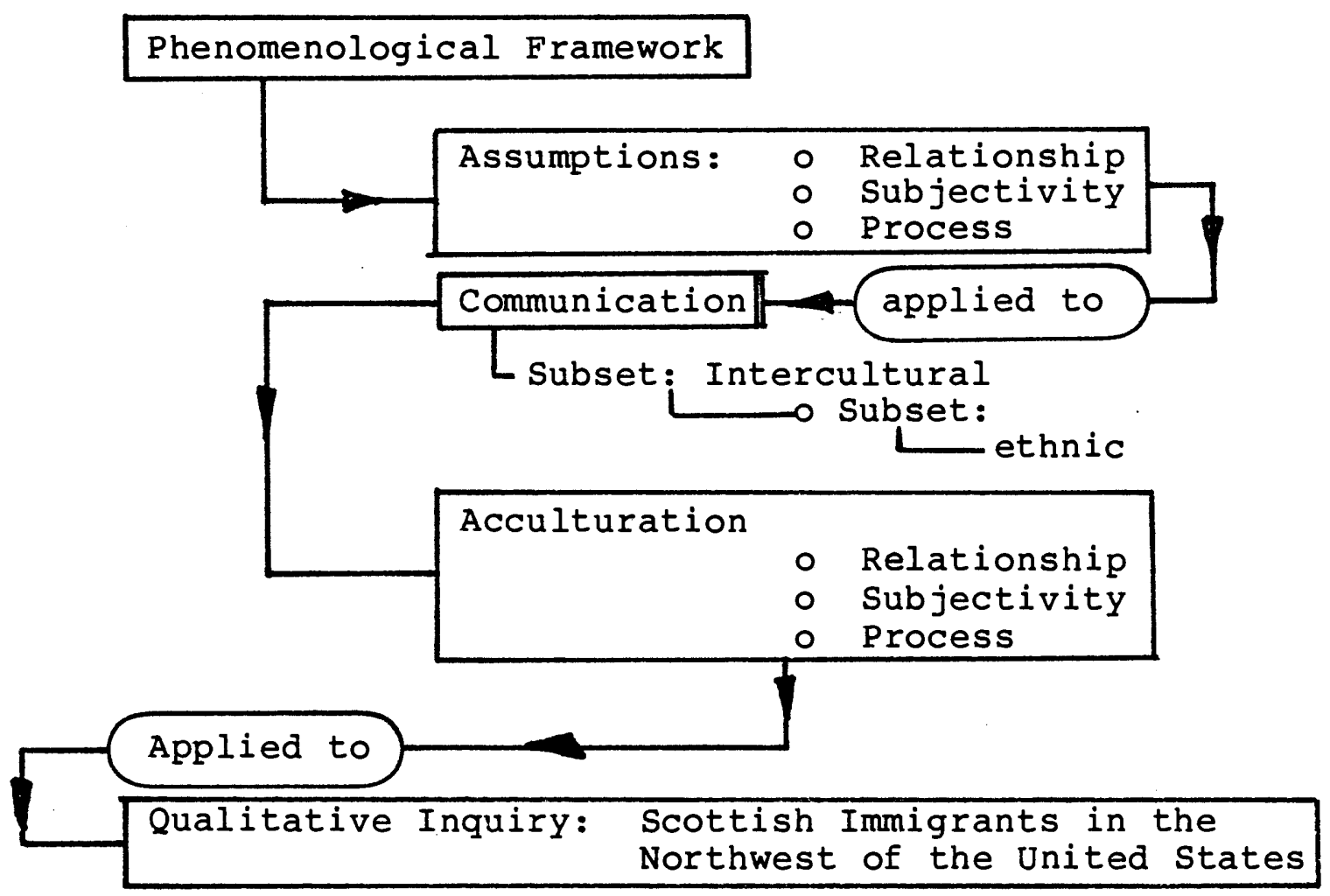

Figure 1. Conceptual flow diagram for this thesis

The flow diagram outlines the conceptual structure of this study. In order to look at acculturation in the context of communication, the communication-based phenomenological framework of relationship, subjectivity, and process is described. The three assumptions are applied to communication; a subset of communication, intercultural communication; and a subset of intercultural communication, ethnic communication.

The communication-based phenomenological perspective is then applied to a construction of acculturation in which acculturation is viewed as occurring through relationships, as subjectively experienced, and as a process. This construction of acculturation, in the form of a Framework of Acculturation, is then applied as a qualitative inquiry to the process of the acculturation of selected scottish immigrants. 
CHAPTER I

AN OVERVIEW OF THE STUDY

\section{PURPOSES OF THIS STUDY}

The main purpose of this thesis is to examine the process of the acculturation of immigrants in terms of intercultural communication concepts with an emphasis on certain phenomenological assumptions about the nature of the communication process. The acculturation of immigrants has been selected because immigrants represent an identifiable group of people who have engaged in long term cultural adjustment. In order to look at acculturation in the context of both general and intercultural communication, it is necessary to clarify some of the underlying assumptions of communication to assess their relevance to the acculturation of immigrants. In this regard, I will describe certain assumptions of phenomenology, as that perspective is used in communication, to show how these assumptions operate in the communication process. I will propose that the acculturation process is compatible with communication-oriented phenomenological assumptions, and will suggest a definition of acculturation that considers the phenomenological perspective. This phenomenological perspective will be applied to a construction 
of acculturation. A Framework of Acculturation will be developed that adheres to the suggested phenomenological perspective. The Framework of Acculturation will be specific to long term acculturation as exemplified by immigrants.

The second purpose is to apply the communication-based phenomenological perspective to the particular process of acculturation of scottish immigrants who now live in the Northwest of the United States, in order to examine the Framework of Acculturation. This is addressed in chapter three. This particular group has been chosen because the acculturation of scottish immigrants has not received a great deal of systematic study. In contemporary literature the immigration experience and consequent acculturation of Asian and Hispanic peoples has been amply documented (Brislin, 1981; Baldassini and Flaherty, 1982), but little is mentioned about scots. Perhaps this is because Scots have apparently acculturated without becoming an overt problem to the host society. However, the Scot must also contend with the various stresses of immigration and consequent acculturation which include uprootedness, change and adaptation.

The third purpose is to describe the influence of intra- and inter-ethnic communication on the process of the acculturation of scottish immigrants. The above mentioned Framework of Acculturation will, in part, focus on ethnic communication, which is a subset of intercultural communica- 
tion. It will be suggested that insofar as we view acculturation from a phenomenological perspective, communication is a vehicle through which acculturation operates. The immigrant acquires knowledge and understanding of the host culture through communication with members of the host culture and immigrants from other cultures (inter-ethnic communication), as well as with immigrants from his own culture (intra-ethnic communication) (Brislin, 1981; Kim, $1977)$.

The benefits of intra-ethnic communication in the acculturation process has been noted for other groups in various situations. Intra-ethnic communication provides a network of support that may otherwise not be available in the host society. For example, Richard Brislin (1981) reports that Peace Corps personnel in South America alleviate the stress of cultural adjustment through intra-ethnic communication. Harding and Looney (1977) found Vietnamese immigrant children in Los Angeles, who received intra-ethnic support from family members and fellow immigrants, adjusted positively to their new environment, whereas those without group support experienced severe adjustment problems.

Similarly, inter-ethnic communication is a consideration in the acculturation of immigrants because during the acculturation process the immigrant builds a new life in a culture different from his own. He establishes new friendships, and copes with unfamiliar aspects. He strives to 
learn to adapt to the new cultural patterns and norms of the host culture (Kim, 1977).

The fourth purpose of this thesis is to provide suggestions for further study, and application of aspects of the acculturation experience.

\section{DESCRIPTION OF THE COMMUNICATION-BASED \\ PHENOMENOLOG ICAL ASSUMPTIONS}

AND DEFINITIONS

In this section, three phenomenological assumptions about the communication process that are relevant to this study are described: communication is relational; communication is subjective; communication is process. Each assumption is applied to communication in general, and then to the subsets of communication, namely, intercultural communication and ethnic communication. See Figure 1, p. ix the Conceptual Flow Diagram for this Thesis, for an outline of this format. Definitions that pertain to this study are also indicated in this section. In chapter two, I will attempt to establish that the construct acculturation is compatible with these communication-based phenomenological assumptions.

As used in communication, phenomenology is the study of human behavior and experience from the point of view of the person who is behaving and experiencing (Fausti and Luker, 1972; Laing, Phillipson, and Lee, 1966; Stewart, 1978 ). Phenomenology focuses on the relational and 
subjective interpretation of experience. Interpretation and understanding are considered to be a dynamic process.

A phenomenological approach to communication has been explicitly applied in various speech communication studies including organizational communication (Jehenson, 1973); interpersonal communication (Phillips and Meztger, 1976; Stewart, 1973, 1978); communication theory (Bemis and Phillips, 1964); the speech act (Lanigan, 1977); discussion (Fausti and Luker, 1972); rhetoric (Gresson, 1978); language (Deetz, 1973); and intercultural communication (Metzger, 1977 ).

\section{FIRST PHENOMENOLOGICAL ASSUMPTION: COMMUNICATION IS RELATIONAL}

\section{General Communication}

An important communication-based phenomenological assumption is the primacy of relationship (stewart, 1978). Relationship implies that knowledge is derived from a person's subjective perception in relation to the object he is perceiving rather than the person's internal and subjective perception in isolation. According to stewart, knowledge "emerges in the meeting of, or relationship between the subject and object in consciousness" (p. 186). The object could be a person, thing, or idea (Lauer, 1965). Moreover, stewart has asserted that, in order to understand the object, one must meet the object and experience it. 
The Scottish psychiatrist Ronald D. Laing (1967), has written extensively about experience and its manifested behaviors in relational terms. He states that "behaviour is a function of experience; and both experience and behaviour are always in relation to someone or something other than self" (p. 9). For example, parenthood as a concept can be understood only in relational terms because it identifies the relationship between parent and child (Stewart, 1978). It is the relationship that is subjectively experienced by both. The assumption of relationship points out that "the terms of the subject-object relationship are intelligible only through each other" (Lauer, 1965, p. 66). Communication is the primary mode through which the subject-object relationship becomes meaningful.

Bemis and Phillips (1964) say that "communication, in phenomenological terms means 'interchange of meaning'" ( $p$. 263). According to stewart (1978), the phenomenological study of communication focuses on the communication relationship. Leonard Hawes (1973) states that communication is relational because it is "not something we do but something in which we engage with others" (p. 14). He indicates that communication functions to transmit messages via symbols, but more importantly, it defines "the nature of the relationship binding the symbol users" (p. 15). For example, if a person, (a symbol user), in a relationship perceives that 
information is being concealed rather than disclosed by the other person, the nature of their relationship is changed.

Fausti and Luker (1972) also emphasize that communication is relational when they write: "Each man must work with, co-operate with and associate with other members of the society whether he wants to or not" (p. 125). In the same vein, John stewart (1978) posits that it is the relationship between people that is of prime importance to communication.

From this discussion we may realize that communication is an act of relationship. Alfred Schutz (1970) succinctly sums up the relational view of communication when he says that when we communicate with others, if even for a moment, "We grow older together" (p. 207).

\section{Subset: Intercultural Communication} is Relational

The relational view of communication is particularly important to intercultural communication. Intercultural communication is broadly defined by Samovar, Porter, and Jain (1981), in their book, Understanding Intercultural Communication, as communication that occurs whenever "a message producer is a member of one culture and a message receiver is a member of another culture" (p. 27). Richard Prosser (1978) describes intercultural communication as "that interpersonal communication on the individual level between members of distinctly different cultural groups" ( $p$. 
xi). This form of communication includes verbal and nonverbal components. Culture is viewed as having a major influence on the communication process. (See page 12 for a definition of culture that is used in this thesis).

The intercultural communication relationship takes place through the process of communication in which differences in language, nonverbal behaviors, attitudes, values, and the meanings attributed to them define the relationship (Pusch, 1979). Because people from different cultural backgrounds have differences in their perceptions, expectations and experiences, interaction between people from different cultures is generally considered to be fraught with misunderstandings and difficulties (Harris and Moran, 1982; Prosser, 1979; Singer, 1982).

As well as people to people relationships, intercultural communication theory emphasizes the individual's relationship with his culture. According to Watzlawick, Beavin, and Jackson (1967), the experience of reality is formed by relationships and patterns of relationships which are created from a point of reference. Man's culture is that reference point and man defines himself in relationship to it (Schutz, 1970).

Edward Hall (1973) writes that "Men cut nature up, organize it into concepts, and ascribe significances" ( $p$. 123 ) according to the common agreement of the culture. These common agreements are the values, beliefs, and biases of the 
culture which man accepts as truth and reality (Singer, 1982). His whole life becomes meaningful according to these patterns of relationships. However, Hall points out the fixity of man's culture. He tells us that, generally, man is controlled by his culture, that he is "bound by hidden rules and is not master of his fate" (p. 119). According to Hall, man believes his culture's version of reality to be the only reality and that his culture's version of truth to be the only truth. Because of this, he tends to block out what is contrary to his definition of reality.

This phenomenon, of being bound to a cultural reference point, is generally defined as ethnocentrism (Harris and Moran, 1982). Ethnocentrism may lead to misunderstanding of another's reality, to prejudice, and to conflict. In general, people are unaware that people in other cultures have different reference points (Harris and Moran, 1982). This lack of awareness is the single greatest problem in all forms of communication (Samovar, Porter, and Jain, 1981).

Subset: Ethnic Communication

is Relational

Contained within the perspective of intercultural communication are such subsets as inter- and intra-ethnic communication (Prosser, 1978). Inter-ethnic communication emphasizes the interaction among members of different ethnic groups, or as prosser states, "with members of the ethnic groups and members of the dominant society" (p. 67). Intra- 
ethnic communication stresses the interaction among members within the same ethnic groups (Prosser, 1978). Ethnic communication, in general, is characterized as being that form of communication in which the source and the receiver are of the same race but of different ethnic origins and backgrounds (Samovar, Porter, and Jain, 1981).

As the group to be studied in this thesis are the Scots, a distinct national group from northern Europe, ethnicity is viewed as being based on national, linguistic, and ancestral characteristics. Religious or racial ethnicity is not a consideration.

\section{Conclusion}

The importance of the assumption of relationship for this present study is that the adjustment to a new culture should be viewed in a context which takes into account the many forms of relationships an individual maintains with his new environment. Processes of adjustment to a new culture will constantly be modified by the particular configuration of these relationships. One form of relationship is ethnic communication. As previously mentioned, one purpose of this study is to describe the influence of inter- and intraethnic communication in the acculturation of immigrants. 
SECOND PHENOMENOLOGICAL ASSUMPTION:

COMMUNICATION IS SUBJECTIVE

\section{General Communication}

The relationship between subject and object is interpreted by the experiencing person according to his unique frame-of-reference, private world, or "reality." Fausti and Luker (1972) state that phenomenology is a method that "attempts to understand behavior from the behaver's point of view" ( $p .124$ ). The authors say that subjective behavior, from the point of view of the behaver, is always purposeful even if it seems irrational to an observer. Also, they posit that all behavior is determined by the perceptual field of the behaver.

In the phenomenological terms used by John Stewart (1978), man's perceptual field, or his reality, exists in the subject's perception and interpretation of the subjectobject relationship. Interpretation is then the subjective element. Interpretation is subjective because it derives from a private frame of reference which is based on the person's conscious knowledge, whether implicit or explicit.

May Brodbeck (1968) writes of the subjectiveness of interpretation when she reminds us of wittgenstein's question, "What is left over if I subtract the fact that my arm goes up from the fact that I raise my arm?" (p. 58) The something "left over" is the meaning or interpretation of 
the movement. This meaning or interpretation is dependent upon the subject's personal frame of reference.

But, what is the derivation of this frame of reference? The frame of reference that provides the implicit or explicit conscious knowledge is derived from the previous experience of the person as contexted by his cultural setting. For the purposes of this study of acculturation in which intercultural communication is emphasized, the definition of culture that Richard Brislin (1981) offers will be used because it emphasizes cross-cultural contact. Brislin proposes that culture can be defined in two ways. The first is "the actual unfamiliar people with whom an individual interacts" ( $p .4$ ) as, for example, the interaction of individuals with people who possess any of the following indications: different color, language, ethnicity, or political allegiance. The second definition, a more abstract concept, focuses on people's characteristic behavior, ideas, and values. That is to say, members of a given culture feel comfortable with the traits, everyday behavior, standards (e.g., of beauty, success, intelligence), and norms of morality which are considered proper and correct. Members of the given culture become intolerant of people, from within or without, who deviate from the accepted ways. According to Brislin, this second, more abstract definition, allows for - - analysis on how culture affects the behavior of its members and an analysis of how subsequent contact with others (affected by a different culture) can be problematic (p. 7). 
The advantage of considering simultaneously these two perspectives on the meaning of culture allows us to explore both the subjective culture of the individual, and the objective culture from which the subjective culture is mainly derived. This dual perspective is, of course, a common sociological approach, as exemplified by Berger and Luckmann's (1967) discussion of subjective and objective culture.

In this study, emphasis will be placed on the derivation of the subjective interpretations that man attributes to his experience from his objective culture. This subjective interpretation of culture affects a person's behavior. As Fausti and Luker (1972) tell us, "All behavior, without exception, is completely determined by, and pertinent to, the perceptual field of the behaving organism" (p. 124). Therefore, behavior is clearly connected to both the concepts of culture discussed earlier by Brislin.

The crucial point from this discussion for this study is that if objective culture changes, there needs to be appropriate behavior change. In order to understand the adjustment of immigrants who find themselves in a new cultural setting, we need to consider, not just different behaviors, but differences in the subjective culture associated with these behaviors.

As previously stated, our knowledge is construed from the influence of our personal experience derived from our cultural setting. (Kelly, 1963; May, 1958). We convey our 
own essentially personal knowledge, its thoughts and perceptions, through verbal and nonverbal communication. Thus, communication is subjective (Bemis and Phillips, 1964). According to John Stewart (1978), subjectivity in communication has the quality of essentially human self-reflexiveness, contrary to a mere selfish focus on self. Stewart, following the phenomenological perspective, maintains that man, by virtue of consciousness, is uniquely capable of selfreflection and of making decisions. Self-reflexiveness facilitates the communication process, in such areas as, for example, self-disclosure and empathy.

Phenomenological communication studies, therefore, emphasize the subjectivity in man and stress that, in order to understand the communication process, we must realize that people subjectively perceive their world and that they act according to these perceptions.

However, it goes beyond the purely subjective. As previously suggested, the emphasis in communication is that a person attributes meaning according to his private frame of reference but also according to his understanding of the object he is perceiving. Dean Barnlund (1970) speaks of this when he says that communication is "not a reaction to something, nor an interaction with something, but a transaction in which man invents and attributes meaning to his purposes" (p. 88).

stewart (1973) defines transaction as ongoing feedback 
in which "who we are emerges out of the event itself" ( $p$. 19). We define self in relation to the other involved, in an act of inter-subjectivity. The implication of intersubjectivity is that human communication is an ongoing process of transactions in which meaning emerges in the mutual understanding between the communicators. In other words, "who the persons are--their 'existence and nature' --emerges out of their meeting with each other" (Stewart, p. 20) with the focus on the meeting rather than the meeters.

\section{Subset: Intercultural Communication}

and Subjectivity

In intercultural communication terms, this phenomenological emphasis on the subjectivity of the person is an important consideration. Of special interest is how a person subjectively interprets the relationship with people of other cultures.

A distinction is made between being purely subjective and being subjective in relationship. A purely subjective perceptual field might be if one thinks that one's own cultural values and beliefs are right and all others are wrong. Harris and Moran (1982) state that a belief in the inherent superiority of one's own culture accompanied by a belief that other cultures are inferior is defined as ethnocentrism.

Because of the negative aspects of ethnocentrism, intercultural communication theory emphasizes the phenome- 
nological notion of intersubjectivity. Intercultural communication is facilitated and ethnocentrism is reduced if one avoids imposing one's cultural attitudes on others, and if one respects the cultural differences of others (Harris and Moran, 1982). Again, the focus is on the meeting rather than the meeters.

According to intercultural communication theory, cultural self-awareness, which means being aware of one's own cultural self, reduces ethnocentrism and facilitates intercultural communication (Prosser, 1978; Pusch, 1979; Samovar, Porter, and Jain, 1981). Pusch states that cultural selfawareness is the subjective "process of looking inward to find our culturally conditioned perceptions of reality" ( $p$. 17). The existence of this form of cultural self-awareness, or self-reflexiveness, implies that a person becomes conscious, becomes aware, that his behavior is influenced by cultural conditioning. An awareness that one's own value system and world view is unique to one's own culture, and that other cultures have values and Weltanschauungen relevant to their needs, but different from one's own, ideally may lead to intercultural communication understanding.

According to Richard Prosser (1978) in his text, The Cultural Dialogue, cultural self-awareness is a component in increasing effective intercultural communication. It ultimately allows us to identify cultural differences and similarities between ourselves and people of other cultures. 
Samovar, Porter, and Jain (1981) note that cultural self-awareness serves to alleviate the hardships of culture shock and is an aid in the adjustment of people who move to a new culture. In the process of adjusting to the new culture, a person interprets his relationship to his new environment, and people therein, according to his subjective frame of reference which, as previously mentioned, is mainly derived from his home culture. Samovar, et al. suggest that people who communicate interculturally, as for example immigrants in the host culture, soon discover that many of their interpretations do not fit the new culture. Frustrations and misunderstandings may often ensue. However, if the immigrant is able to decipher and identify differences, and, more importantly, the reasons for them, he may be able to cope with these differences in a positive way. In terms of this present study, it is anticipated that immigrants have experienced some form of misunderstandings, cultural differences, and culture shock in their adjustment to the host culture.

However, the differences are not experienced and interpreted by only the immigrant: the host culture members subjectively interpret the immigrant according to the host culture frame of reference. Jonathan Sarna (1978) speaks of this host culture interpretation of immigrants in his ascription theory. He tells us that an immigrant is often perceived by host culture members as being "different," 
because of such attributes as different language, appearance, or behavior.

\section{Subset: Ethnic Communication}

\section{and Subjectivity}

Ascription, then, is the subjective judgment of immigrants by the host culture members. The immigrant on arrival in the host culture is immediately categorized by the host society as belonging to a particular ethnic group. James sauceda (1982), in his writings on ethnicity, states that ethnic membership is created by "stereotypic classifications imposed by the mainstream American society" (p. 191). Little consideration is given to regional differences within the immigrant's home culture. Thus, an Italian from sicily is classified as being the same as an Italian from Bologna, although the people from these areas are culturally and, often physically, very different. Furthermore, a Canadian is a Canadian in the eyes of the host culture, whether he comes from Montreal or Vancouver; a Jewish Lithuanian is not distinguished from a Galician Jew (Sarna, 1978). A Scot from the rural north or outer islands of scotland is not distinguished from his urban compatriot from the industrialized and cosmopolitan west. In fact, most people from the British Isles appear to be classified together by Americans with few considerations for the cultural and historical differences among the various groups. It is assumed that ascription 
occurs not only in the United States, but in all countries which have accepted immigrants.

Classifications, by their very nature, can be dangerous because they could lead to harmful stereotyping and prejudice on the part of host culture members, and feelings of ill-will and discomfort on the part of the immigrant. Moreover, effective inter-ethnic communication may be hampered by such classifications.

Effective inter-ethnic communication involves both the immigrant and the host culture members recognizing and coping with ethnic differences. Andrew Greeley (1974) writes that there have been conflicting views in the United States over the question of ethnicity and the absorption of immigrants into American society. One view is that ethnic differences should be eliminated into a common melting-pot, as in assimilation; whereas, an opposing view is that assimilation should not be pursued and that "many different cultures may flourish under the American umbrella" (Greeley, 1974 , p. 293), as in pluralism.

Assimilation occurs if, and when:

- . the immigrants and their descendents eschew the development of their own institutions and organizations, and any sense of distinct ethnic identity, and enter the "general" American structure of institutional life (Gordon, 1964, p. 104).

In other words, the immigrant rejects his own cultural heritage and blends so completely with members of the host cui- 
ture that there is no perceptual ethnic difference between himself and members of the host culture (Brislin, 1981).

Adherents of the theory of assimilation insist that American ways must be adapted to as quickly as possible by the immigrants. However, according to Broom and Kitsuse (1955), it is not only the immigrant who is involved in the outcome of assimilation. Validation by the host culture must occur. Validation occurs in inter-ethnic situations where the immigrant is willingly accepted by members of the host culture as an American. The price of assimilation is "the disappearance of the ethnic group as a separate identity and the evaporation of distinctive values (Gordon, 1974, p. 81 ).

However, assimilation is a most unlikely condition in first generation immigrants (Greeley, 1971; Ting-Toomey, 1981). Possibly, it could be said that assimilation is a future generational occurance that can happen only if an ethnic individual's primary learning has taken place within the host culture. Intercultural communication theorists generally consider assimilation to be an undesirable condition because it inhibits cultural diversity (Prosser, 1978).

Glazer and Moynihan (1970) reject the afore-mentioned assimilationist view. They say, "The point about the melting-pot is that it did not happen" (p. 290). Andrew Greeley (1974), who upholds this position in his study of ethnicity in the United States, says, "It is clear that boundaries 
exist despite a flow of personnel across them" (p. 2). According to these authors, cultural differences can, and do persist, and the United States is, today, a culturally pluralistic society.

Cultural pluralism, as used in this study, describes the multi-ethnic character of American society in which ethnic awareness is emphasized. It is based on the theory of cultural relativity in which differences between groups of people are accommodated (Prosser, 1978). Ideally, the members within a pluralistic society recognize that each ethnic group has different frames of references and the contribution of each group is mutually encouraged and maintained by members of the society. Intercultural communication theorists generally embrace the pluralistic viewpoint with the tenet that no one culture is better or worse than the other, in terms of providing a coherent world view for its members (Prosser, 1978; Pusch, 1979).

\section{Conclusion}

Any process of adjustment to a new culture, then, includes becoming aware of and coping with differences. This factor of recognizing differences is an overall one in the study of intercultural communication. Edward stewart, in his overview of intercultural communication, proposes that "it is on this issue of differences, either naturally 
or by acquisition, that intercultural communication rests its claim for identity" (cited in Prosser, 1978, p. 11).

Clearly, the phenomenological aspect of man's subjective understanding of himself in relationship to both his indigenous culture and to others, and of identifying and coping with differences, is an important consideration in intercultural communication and to the process of long term cultural adjustment.

THIRD PHENOMENOLOGICAL ASSUMPTION:

COMMUNICATION IS A PROCESS

General Communication

A person's subjective interpretation and understanding of $\mathrm{his}$ experiences depend on the situation and are based on process. Stanley Deetz (1973) proposes that we interpret objects according to their serviceability; according to the situation and how we view its possibilities.

For example, in a situation in which a prisoner contemplates escape, a guard or a barred window is interpreted in different terms than in a situation in which the prisoner prefers to be rehabilitated. His interpretation is dependent upon his perception of the situation. In one situation the prisoner may view the guard as an enemy, the window as a barrier. In the latter situation the prisoner may see the guard as someone to get along with, the window as a fresh air inlet. 
The ability to interpret similar situations differently suggests fluidity and flexibilty of interpretation. This ability implies process as that term is applied to communication.

Communication, when viewed phenomenologically, is a process. According to Leonard Hawes (1973), communication is a fluid stream of interconnected acts. He suggests that communication should be viewed holistically. This means that it is an on-going, nonstatic activity which cannot be completely understood in terms of discrete isolated units. Nor is communication linear. Prior to 1960 , communication was frequently written about as though it were a linear act, in which information was transmitted from a subject to an object in sequential steps. However, David Berlo (1960), in his book, The process of Communication, was influential in synthesizing the concept that communication is a dynamic, interactive process. By "process" he meant that communication does not have a beginning, an end, or fixed sequences of events. Rather, communication is an act of reciprocity, in which sender and receiver mutually affect each other and the relationship. Communication as a process has no fixed cause-and-effect because it is believed that no outcome is caused by any single person or action. In fact, Paul watzlawick et al. (1967) emphasize that a cause-and-effect mentality in people is at the root of many communication problems. 
Watzlawick et al. write that trying to find cause-andeffect in relationships encourages blaming and conflict. Any attempt, in conflict situations, to "punctuate the sequence of events" (p. 96) ignores the relationship in process. An example of the futility of applying cause-and-effect mentality to an interpersonal communication situation is that of the husband who says he avoids going home because his wife is always unpleasantly drunk. She is always drunk, she says, because he comes home so late. They both blame each other for their respective behaviors. It is this blaming which leads to disagreements of who started what, to communication distortion, to frustration, conflict, and if carried to extremes, to the end of the relationship. It really does not matter which act prompted which reaction. Berlo (1960) states that it is dangerous to assume that one ingredient of communication precedes another or that they are independent of each other. It is the whole process which should be examined by the communicators.

in terms of this present study, it is anticipated that immigrants who perceive a sense of dissatisfaction with the host culture may be reacting inflexibly to the host culture with the type of cause-and-effect mentality discussed above. Phenomenology considers this perspective of process or flexibility in the notion of intentionality, which also considers the relational and subjective perspective. However, for the purposes of the assumption of process, as 
used in this study, intentionality will be viewed from the process perspective in this section. In the following discussion of intentionality, scholars from disciplines other than communication are referenced in order to clarify the connection of process to intentionality. An explanation is also given to the relationship between the notion of intentionality and this present study.

Intentionality means that man is conscious of his experience and that this consciousness is inherently conscious-of. Colin Wilson (1980) explains intentionality by saying:

I do not merely see something; I fire my attention at an object as I might fire a rifle at a target. If I do not do this, then I am not conscious of what I am looking at (p.59).

In other words, consciousness is intentional.

The notion of intentionality is salient to the speech communication discipline (Lanigan, 1979). According to Lanigan, the applicability of intentionality to communication concerns the fluidity of human communication. We are conscious beings engaged in the communicative activities of perception and expression. This communication activity is reversible: through the act of speech communication we can convert perception into an expression, and vice versa. Lanigan goes on to say that of particular interest to speech communication is: 
- . the ability of human communicators to switch back and forth between speaking and listening, to do both simultaneously, to remove the spatially real into memory or to project the conceptually real into time as a future expectation all suggest the way in which communication is an object of consciousness (p. 34 ).

Husserl (1962), the father of phenomenology, calls consciousness "inward experience" (p. 138). The person is viewed as being a complex of conscious, changing processes. Moreover, the person has the capacity to become aware of, or conscious of, these processes in spacio-temporal relationships. Rollo May (1958) expresses this condition as the Dasein (Boss, 1963) (being there):

Dasein indicates that man is the being who is there and implies also that he has a "there" in the sense that he can know he is there and can take a stand with reference to that fact. The "there" is moreover not just any place, but the particular "there" that is mine, the particular point in time as well as space of my existence at this given moment. Man is the being who can be conscious of, and therefore responsible for, his existence (p. 5l).

Husserl calls the "there" that May mentions the "natural standpoint," the point from which man construes or interprets his world. He tells us that man is conscious-of the world around and moves freely within it. He moves freely because he can shift his standpoint in space and time, and "turn temporally forwards and backwards" (p. 94). His consciousness of the world is in what he construes as existing really or supposedly in "a world of values, a world of goods, a practical world" (p. 93). 
We assume that the world about others and the world about ourselves, the Umwelt are one and the same world (May, 1958). However, according to May, this is erroneous because man exists, not only in the Umwelt, but in the meaning he construes of his relationships with others in the world. May states that these relationships are of the Mitwelt and Eigenwelt. Each is construed subjectively by the individual, and all three, Umwelt, Mitwelt, and Eigenwelt are simultanously experienced. Phenomenologically, this subjective interpretation is intentional because man is conscious of, or aware of his world. Moreover, man construes or designs his world. According to May, "To be aware of one's world means at the same time to be designing it $(p .60)$.

Mitwelt is the "with-world," of being with others. It includes the meanings we construe of our relationships with other people. As relationships are not static, meanings are not static or fixed, but change according to the relationship or the encounter and also to the individual's intention.

Eigenwelt, "own world", is concerned with an individual's subjective interpretation of events. However, it is of the relationship the person has with self and is manifested in his subjective reactions to the world at large, as in, for example, how he interprets the meaning of "what something in the world--this bouquet of flowers... means to 
understanding is dependent upon the intentionality of the person. This intentionality, according to Colin Wilson (1980), changes according to the situation.

These three modes of world seem to be particularly appropriate to the process of an immigrant's adjustment to a new culture. The immigrant finds that his cultural setting, his Umwelt, has changed. This change in cultural setting influences his interpretations of his relationships with others, his Mitwelt, as well as his subjective reaction to the process, his Eigenwelt.

The above description of intentionality is much like George Kelly's (1963) constructive alternativism theory. Kelly believes people to be creative, non-static beings with the capacity to abstract meanings from the world about them (the Umwelt) and to impose their own interpretations on it (Eigenwelt). Moreover, this interpretation is not restricted to a one time event. It can change and is permeable, much like the previous discussion of the Mitwelt. Kelly says that people have freedom to choose alternative constructions in dealing with their world: "No one needs to paint himself into a corner; no one need to be completely hemmed in by circumstances; no one need to be the victim of his biography" (p. 15).

Kelly emphasizes that people make sense out of their world by predicting events, although he posits that it is not from the events as they actually happened that people 
derive meaning--it is from their construing of the experiences. Previous experiences are receiving additional interpretative meanings in the light of additional experiences and their interpretations. In other words, people interpret their present experience in relation to past experience. Most important to this is that it is from each person's past experience, and the construing of that experience, that he derives meaning, not the events as they actually existed. Therefore, the person construes meanings not fixedly, but in relationship to the situation and to a construal of experiences, as in the phenomenological notion of intentionality. Man's past experience is derived from his cultural frame of reference, as previously stated, but even his culture is construed subjectively.

It follows that if intentionality is applied to experience, we see that people are capable of acting with intentionality which operates on their own cultural assumptions. People, also, are capable of construing their own interpretive systems to themselves. Thus, intentionality implies that man has the choice to respond to situations with flexibility. In terms of this present study, it is anticipated that immigrants have responded to their new situation with flexibility, and have adjusted to the host culture by intentionally construing their way out of their home culture frame of reference and adapting to aspects of the host culture. 
Subset: Intercultural Communication

and Process

In intercultural communication the situational and process approach is of prime importance. The specific focus is on flexibility and fluidity of interpretation with the realization, made possible by cultural self-awareness, that an individual can transcend Hall's fixity of culture, mentioned on page 8 . From the preceeding discussion of intentionality, we see that people intentionally construe meanings and place their own interpretation upon their world. Taking culture as an object, as that term is used in phenomenology, we do not have to think of culture as being rigidly interpreted. If, in phenomenological terms, people view culture as if it were an object, in the sense that we have a relationship with it, we can assume that this object has no fixed status except as its meaning is sustained through indications and definitions that people make of it. Remembering the phenomenological notion of intentionality and that people are continually construing and reconstruing their world, according to the situation and definition of self, we can see that the fixity of culture, as Hall supposes, contains a subjective element and that interpretations are, in fact, not static. Therefore, it may be possible to say that man is indeed able to transcend his cultural reality. It is this ability which provides the base for the experience of ethno-relativity. 
It might also be surmised from this discussion that ethno-relativity is a positive factor in the facilitating of communication between immigrants and host culture members and is, perhaps, conducive to some aspects of the acculturation process. If people realize that they are not "fixed in" to culturally ordained beliefs and attitudes, intercultural communication problems may be alleviated. People may, reciprocally, be more able to understand each other's point of view. Ultimately, this leads to an empathic act, which Milton Bennett (1979) describes as occurring if a person is flexible enough to imaginatively, intellectually, and emotionally participate in another person's experience.

The process approach can be applied to intercultural communication on yet a different level in what is called multiculturalism. According to Adler (1982), this name

- . suggests a human being whose identifications and loyalties transcend the boundaries of nationalism and whose visions are pinned to a vision of the world as a global community" (p. 389).

A multicultural person is one who is flexible enough to accept the fundamental differences between cultures while being committed to the "universality of the human condition" (p. 390$)$.

Adler posits that the multicultural person views the world as a dynamically moving process. Moreover, a multicultural person is situational in his relationship to cultures. He is able to modify his own cultural frame of 
reference; to incorporate those of other cultures. Although he has a firm grasp of his own cultural reality, cultural boundaries to him are indefinite. He is adaptable and responsive enough to be able to redefine them according to the context in which he finds himself.

\section{Subset: Ethnic Communication}

\section{and Process}

In ethnic communication too, the process perspective is important. For example, the ethnic institutions where intra-ethnic communication channels are readily available, have not remained static but have changed, in part, according to the needs and attitudes of the members while on American soil (Steinberg, 1981). Often the change is so great that, according to Jonathan Sarna (1978), ethnic ties which are developed only in America, make the ethnic institutions that evolve often "as foreign to the immigrants as to the natives" (p. 370). Steinberg (1981) proposes that often there is such an incongruity between the culture of the home country and the ethnic culture developed in the United States that the customs and behaviors of the ethnic group become mere caricatures of those of the home culture.

However, if ethnic institutions and customs are viewed from a phenomenological perspective, they may be seen, not as caricatures, but as institutions construed to meet the changing experiences of immigrants transplanted to a different cultural frame of reference. All that is left of the 
home culture are memories which change or are revalued according to the different cultural experiences and needs in the host culture. In other words, faithful repetition of the home culture is impossible.

of importance to the process perspective of ethnicity is that, in spite of the differences between the home culture and the ethnic group culture, in the United States, ethnicity and ethnic groups and enclaves have persisted, albeit in hybrid form. There are still scottish clans, German Vereine, and British-American societies which are unlike anything found in the home culture, but members of the group have construed and reconstrued the group to meet the needs of the situation.

\section{Conclusion}

The application of the assumption of process to this study concerns the fluidity of acculturation and the potential control individuals may be able to exercise over that process.

In summary, the phenomenological approach to communication offers a model which: 1) emphasizes the relational framework 2) allows for the subjective interpretation of the communication event, according to the relationship 3) offers a non-linear, process approach.

As we have seen, the phenomenological perspective applies also to the subsets intercultural communication and 
ethnic communication. It enables us to focus on intercultural communication relationally (i.e., person to person, person to culture), and gives a further dimension to the theories of cultural relativity, cultural self-awareness, cultural differences, cultural empathy, and multiculturalism. 


\section{CHAPTER II}

\section{ACCULTURATION}

In this chapter, salient components in the acculturation process will be delineated to be used as a basis for this study. A definition of acculturation will be suggested that is consistent with the communication-based phenomenological assumptions mentioned previously. Selected theories and studies of acculturation will be considered as they pertain to this definition. Finally, a Framework of Acculturation will be offered in which conditions of the acculturation process will be described, and which will be used as a basis for the interview schedule and analysis for this study. It should be noted that the review of selected literature acts as a guide to the general understanding of the acculturation phenomenon as it pertains to immigrants, to support the definition, and to explain the Framework of Acculturation. In chapter 4, the Framework of Acculturation will be applied to the process of the acculturation of scottish immigrants who now live in the Northwest of the United States in order to examine the Framework of Acculturation. Although the studies reviewed in this section have not been explicitly labelled "phenomenological" by their authors, they have been selected for their suitability to this thesis 
according to the criterion of either a subjective, relational, or process perspective of acculturation.

\section{VARIOUS DEFINITIONS OF ACCULTURATION}

The following examples are representative of the variety of the definitions of the acculturation of immigrants to be found in selected literature and show the differing perspectives from which acculturation has been studied. According to Weinstock (1974), acculturation concerns changing attitudes, behaviors, and values. It is "the process of becoming more American-like" (p. 322), in which the immigrant moves from an idealized home culture pole of a theoretical continuum toward an idealized American pole. Baldassini and Flaherty (1982), who studied changing values and the behavioral consequences, define acculturation as the process whereby "all immigrants confront a new cultural reality that affects and often changes their lives in the host culture" (p. 127). Herberg (1982) includes ethnicity in her definition which is "the process of cultural adaptation, both behaviorally and in terms of ethnic consciousness and identity" ( $p$. 155). Acculturation is defined by Dyal and Dyal (1981) as "adaptation to a new culture" (p. 302 ), and Marden and Meyer (1968), who are concerned with trait acquisition, define acculturation as "the change in individuals whose primary learning has been in one culture and who takes over traits from another culture" (p. 35). 
The above definitions show the differing perspectives from which the acculturation of the individual has been viewed. However, in order to look at the acculturation of the immigrant from a communication-based perspective, the following definition is suggested. The specifics that support this definition will appear in the rest of this chapter.

\section{Definition of Acculturation}

For an immigrant, acculturation is here defined as the process of acquiring and coping with the host culture. Acculturation is subjectively experienced by the immigrant who has to adjust his perceptual field in order to cope with encountered differences in the new culture. Acculturation is a relational experience in which an immigrant interprets his experiences in relationship to a multitude of factors in his perceptual field. The relationship is carried on through communication. Acculturation is a dynamic process in which elements are interrelated, with no fixed sequence of events. If one element of the process changes, other elements may be affected.

\section{AN OVERVIEW OF ACCULTURATION}

From earliest time, mankind has migrated from one place to another: for example, Israelis migrated to Egypt; 
the Romans invaded and stayed in Northern Europe; the British settled in their colonies. In the last century it is estimated that approximately sixty five million Europeans left their country of origin in search for a better life; the largest influx being between 1880 and 1930 at which time twenty three million Europeans emigrated to the United States (Burkey, 1978).

In our time, contact between individuals from different cultures has greatly increased. Business and industry have assumed international proportions, satellites beam communication instantly between nations, and people still emigrate. Consequently, there is need for a broader understanding of the acculturation process as it pertains to modern society.

Much information is available about the construct "acculturation." It has been written of, researched and studied in many disciplines including anthropology, sociology, history, psychology and, to a lesser extent, intercultural communication. Because of this varied treatment there is some inconsistency in the use of the term "acculturation" for it has been used interchangeably with related constructs such as "assimilation," "accommodation," "culture contact," "modernization," "fusion," "absorption," and "Americanization" (Gordon, 1964 ; Rose, 1981; Teske and Nelson, 1974; Weinstock, 1974). 
Moreover, acculturation has been approached and analyzed in various contexts, such as in groups of people being subjugated by dominant cultures (e.g., the American Indians by white settlers or Scots by English conquerers); groups of people migrating because of political or religious persecu-tion (e.g., Jewish refugees); the individual who makes temporary long term residence abroad (e.g., the foreign student, the business $\operatorname{man})$; or the individual who by choice, leaves his or her homeland to live in another country because of economic ambition, envisaged increased opportunity, or perhaps a drive for independence (e.g., the immigrant).

It is this latter category, that of the individual immigrant, that is of interest in this study.

\section{ACCULTURATION IS A SUBJECTIVE EXPERIENCE}

This thesis is concerned with the phenomenological subjective experience of acculturation of immigrants. Certain literature on acculturation focuses on the acculturation experience of the individual, whereas other literature considers the acculturation of groups of people (Metzger, 1977). Teske and Nelson (1974) in their comprehensive review of acculturation theories summarize the importance of the individual in acculturation by saying: 
It is axiomatic that acculturation may be treated as either an individual phenomenon, a group phenomenon, or both, providing care is exercised to define at which level of analysis the scholar is operating (p. 352).

Accordingly, the review of selected literature in this study pertains mainly to the individual immigrant with emphasis on the subjective dimension of acculturation.

Different people experience acculturation in a variety of different subjective ways. Variables in the acculturation experience include, among others, the immigrant's age, motivation, social status, marital standing and personality (Dyal and Dyal, 1981; Kim, 1982). Often the experience of acculturation is dependent upon the environment from whence the immigrant came or in which he settles (Brislin, 1981).

These factors are but a few of the more important variables which combine to form, what is known as, an individual's "perceptual field." The immigrant's perception of the host culture is a function of this perceptual field. The point was made in chapter one that a large part of one's perceptual field is derived from one's home culture's frame of reference. This frame of reference is the immigrant's subjective reality, which is formed in the following way.

The person becomes a member of a specific society, internalizing and absorbing the meanings of that society through interaction with other members. According to George Kelly (1963) our cultural identity is that aspect of our personal system of constructs, shaped by the wider cultural 
group, which are formed to explain life's experiences. The individual accepts the biases and persuasions of his culture as being "truth." Berger and Luckmann (1967) posit that we have no option but to believe that these ascribed meanings are indeed reality and the world as our group understands and interprets it becomes firmly entrenched in our consciousness. The result is, to use Alfred Schutz's (1970) words, "thinking as usual" (p.81).

The immigrant, travelling far from home, initially interprets the new social environment in terms of his home culture. However, in dealing with many unfamiliar and different aspects of the new culture, he soon finds his own interpretive scheme to be inadequate for coping with his new experiences and cross-cultural interactions. It may not be possible in the immigrant's adjustment to the host culture to continue his "thinking as usual," or behave according to what is acceptable in his home culture. Rather, according to schutz, the immigrant needs to gather explicit knowledge of the elements of the new culture. He needs to consciously identify differences between home and host cultures to deal effectively with the new culture (Prosser, 1978; Broome, $1981)$.

In phenomenological terms, during acculturation the immigrant needs to consciously reconstrue his world so that he may eventually grasp the meaning of the host culture and acquire "knowledge of the elements of the approached cul- 
tural group" (Schutz, 1970, p. 93). Acculturation, then, is a time of coping with the encountered differences in which the immigrant's relationship to home culture and host culture is redefined. Differences may refer to the perception, language, non-verbal expressions, and Weltanschauung of the people from the cultures involved.

It is anticipated that the scots in this study have had to deal with unfamiliar aspects of life in the host culture, and have had to adjust their perceptual field to cope with these encountered differences. Remembering our previous discussion that behavior is related to a person's perceptual field, it is anticipated that any adjustment of the perceptual field will probably have resulted in behavioral changes of some kind.

The initial subjective experience of differences in language, or other communication clues, is frequently labelled as culture shock which, according to Richard Brislin (1981), refers to the accumulated stresses and strains of being forced to meet one's everyday needs in unfamiliar ways and of the continued need to grope for new behaviors. Culture shock is a transitional condition in which the immigrant may lose his cultural bearings. It is often accompanied by feelings of frustration, alienation, and helplessness (Barnlund, 1982). These feelings may be accompanied by a rejection of the host culture, withdrawal into intra-ethnic relationships, and a strong chauvinistic 
relationship to the home culture (Oberg, 1979). Robert Kohls (1979) adds that culture shock includes the subjective experience of homesickness, boredom, and generally strange behavior. This behavior often leads to communication problems such as defensiveness and "is a major obstruction in intercultural communication" (Bennett, 1977, p. 46).

Even in cultural groups that are seemingly very alike, such as, the British and the Americans, there is a component of "differences," and culture shock can be encountered. Neither group shares the same experience nor do they share the same perceptions (Samovar, Porter, and Jain, 1981).

The factor of encountered differences in communication is especially important in the subjective acculturation of the immigrant. In order to cope with his new environment the immigrant should realize that the encountered strange behaviors are simply differences, should be recognized as such, and dealt with positively (Adler, 1975). According to Alfred Schutz (1970), coping with a new cultural setting is not easy:

- . the cultural pattern of the approached group is to the stranger not a shelter but a field of adventure, not a matter of course but a questionable topic of investigation, not an instrument for disentangling problematic situations but a problematic situation itself and one hard to master (p. 93).

However, George Kelly (1963) states that if a person is prepared to perceive events in new ways, to be adaptable, he broadens his horizons and gives new and valid meanings to 
his experience. The immigrant has opted to live in a different culture and therefore he must develop new techniques of survival, and change former ones.

The factors mentioned above, concerning the subjective experience of immigrants, will be seen in the analysis of the immigrants in this study and serve to help in understanding the analysis of the immigrant's experiences. It is anticipated that the scots of this study, in the process of acculturation, will have experienced some form of encountered differences and culture shock.

\section{ACCULTURATION IS RELATIONAL}

An important phenomenological assumption is is the relational aspect of experience, by which is meant that subjective interpretations are made in relationship to a multitude of factors in a person's perceptual field. Insofar as we view acculturation from a phenomenological perspective, it should not surprise us to see that communication is the vehicle through which acculturation operates in a relational context. In acculturation, an immigrant leaves his own culture and has to learn the ways of a new culture through communication channels.

In the previous chapter, communication was discussed from a phenomenological perspective. It is now suggested that acculturation occurs within a communication framework because, if acculturation is a relational process, the rela- 
tionship is carried on through communication. Therefore, it can be said that communication is a relational factor in acculturation.

Several studies and theoretical articles in the communication field support the view of acculturation being a relational experience occurring through communication. Young Yun Kim (1982) describes acculturation as "the process of developing communication competence in the host sociocultural system" (p.361). In her previous article (1979), "Toward an Interactive Theory of Communication/ Acculturation," Kim observes that acculturation occurs through interrelationships as the individual lives in the host environment and interacts with host subjects. She states that communication and acculturation are inseparable, with communication being the process through which the immigrant acculturates. The more an individual is involved in communication and interrelates with the host culture, the more his acculturation. Kim's work is important to intercultural communication as she explicitly delineates acculturation from the communication point of view.

Another study that links acculturation to communication is Jin Kim's (1980) "Explaining Acculturation in a Communication Framework: an Empirical Study." He contends that communication "as a vehicle of social integration, is a major determinant of the acculturation level a foreign [sic] immigrant achieves" ( $p .155$ ). One of Kim's findings from a 
study of 196 Korean immigrants in Los Angeles County shows that the higher an immigrant's occupational status, the more he will interact with the host culture. This interaction, in turn, has a positive effect on acculturation. In other words, if a Korean immigrant has high occupational status it apparently causes him to participate in intercultural communication activities. It is interesting to note that in this study the effects of occupational status on acculturation did not appear until the immigrant has been in this country for some time.

Kim's other findings show a heavy dependence on ethnic institutions, which are mainly organizations perpetuated by the ethnic community for members of the ethnic group. He notes that intra-ethnic communication has a damaging effect on the acculturation of Koreans in the long run.

other studies show intra-ethnic communication is not a damaging factor in acculturation. Stella Ting-Toomey (1981), in her study of ethnic communication and friendship patterns of Chinese-American students, discusses ethnic identity as a relational phenomenon:

Every individual has the basic need of relatedness, through socio-cultural bonds. It is the sense of "locating" oneself in a larger frame of reference that ethnic identity is held as a primary process found in the core of each individual (p. 383).

This "sense of locating oneself" is found in the immigrant, who, uprooted from his cultural milieu, oftentime suffering loneliness and helplessness, feels a need to relate 
to those members of his own cultural group within the larger society to which he has immigrated. The immigrant "reaches for some arm to lean on" (Handlin, 1974, p. 152). This arm is often found in the immigrant's own ethnic group (Rose, 1981; Sarna, 1978).

George Kelly (1963) suggests that people need to feel accepted and to know that they are understood by others. Kelly, in his Commonality Corollary, suggests that people belong to the same cultural group "not merely because they behave alike, nor because they expect the same thing of others, but especially because they construe their experiences in the same way" (p. 94). In other words, people like to be with people whom they believe have similar experiences to theirs. Kelly's theory would tend to explain the immigrant's need for intra-ethnic relationships.

In considering Scottish ethnics in the United States, intra-ethnic relationships often take place in formal institutions and societies, such as Scottish Clans, insurance societies, Burns' clubs, and st. Andrew's societies. In these institutions, intra-ethnic communication is actively participated in, and new immigrants are made welcome and to feel "at home" by other Scottish ethnics. The Scottish societies mainly function as social clubs, but may also serve as networks for finding employment, renewing and maintaining old customs and traditions, and for allowing the freedom to speak in the mother dialect. 
From this discussion we see that intra-ethnic communication has been viewed as either a hindrance or a help to the long term cultural adjustment of immigrants. For example, Shibutani and Kwan (1965) reported in their study of ethnicity that belonging to an ethnic group serves to strengthen ethnicity and because of this, delays entrance to the host society and hence, delays acculturation. In the same vein, the effect on acculturation of intra-ethnic communication is discussed by Leonard Broom and John Kitsuse (1955), who state that ethnic institutions provide a "relatively safe place in which acculturation forms may be rehearsed" ( $p, 45)$. But, according to the authors, ethnic institutions may retard the acculturation of members of the ethnic group because they prevent the individual from functioning in the host society without protection from his group. However, at the beginning of the acculturation experience, according to the authors, intra-ethnic communication is supportive to the individual.

This fact of ethnic institutions retarding the process of acculturation seems to be a double bind situation for the immigrant. It implies that intra-ethnic communication is a buffer against sudden exposure to unknown cultural patterns, while at the same time, acculturation to the host culture is impeded by such intra-ethnic communication because it may prevent the immigrant from fully participating in interethnic communication. It may be suggested that intra-ethnic 
communication, thus, tends to minimize inter-ethnic communication.

Accordingly, one could extrapolate from the aforementioned discussion that acculturation into the host culture best occurs if the preservation of different ethnic cultural values in the host culture is discouraged. However, this conclusion does not correlate with the observation that during acculturation a person can maintain strong relationships with home and host culture and function successfully in both, as manifested in the bicultural person (Kim, 1977).

What is germaine from these aforementioned studies is the recognition that, through the fundamental process of communication, acculturation occurs.

Richard Brislin (1981) fits acculturation implicitly into a communication framework, particularly inter-ethnic communication. This intercultural specialist, in his recent book, Cross Cultural Encounters, discusses long term cultural adjustment, which includes the experience of the adjustment of immigrants. He cites that an immigrant's complete adjustment is marked by four developments: cultural adjustment, identification, cultural competence, and role acculturation.

Brislin states that successful cultural adjustment is partly dependent upon establishing ties, through work or social groups, with the host culture in order to feel comfortable in the host society. We may infer from this that 
these ties are created and maintained through inter-ethnic communication.

Identification occurs when the immigrant feels a strong sense of relationship to the host culture. He feels at home, without concluding that he really belongs there. He perceives that his fate is linked with the host culture and that both have shared concerns. Often this development includes the requesting and granting of citizenship, buying property, taking leadership positions in the host society, and sending offspring to schools typical of the host society. Cultural adjustment and identification are closely linked in that people who are culturally adjusted feel a strong sense of identification with the host culture and vice versa. Thus, it may be said that identification with the host culture requires the use of some host culture patterns which an immigrant can acquire only through some form of inter-ethnic communication.

Cultural competence, according to Brislin, is when the immigrant feels competent functioning within the host society. This competence is based on meeting everyday needs through interaction with the members of the host culture in a variety of situations. Although Brislin stares that cultural competence involves knowledge of the language and the ability to behave appropriately in different situations, other intercultural specialists note that a sense of cultural competence also includes nonverbal competence and an 
understanding of host culture values (Kim, 1982; Prosser, $1978)$.

Brislin's final consideration in cultural adjustment is role acculturation. This includes "an increasing sense of convergence between one's attitudes and values and those held by a large number of hosts" (p. 286). Thus, in role acculturation immigrants feel that they are behaving appropriately, not because they are forced to, or because it is convenient, but because the host culture's beliefs are internalized into their personality. I suggest that the effect that this development of cultural adjustment has on communication is to draw host culture members into more natural forms of communication with the immigrant since the host culture members do not perceive the immigrant as being significantly different. From Brislin's discussion, we may conclude that cultural adjustment occurs within an interethnic communication framework. His writings imply that communication is the mechanism for interaction of host with immigrant. Moreover, communication of the immigrant with host society members enables the host to, reciprocally, become part of the acculturation process.

The importance of reciprocal communication is noted in a study of immigrants by Leonard Broom and John Kitsuse (1955). These authors believe that there comes a point in acculturation when immigrants have acquired enough knowledge of the host culture to function efficiently within the 
system. But, acculturation is not a one way process concerning only the immigrant. Rather it is dependent upon the immigrant's interaction with members of the host society, and the host culture members' acceptance of the immigrant. The acculturation of the immigrant is validated only by members of the host society. Validation is described by the authors :

It is in inter-ethnic situations that accuituration is validated as an instrument of adjustment, the ethnic individual's level of acculturation is tested, and the distance he must yet travel to assimilation is measured ( $p .45)$.

Another relational consideration in the subjective experience of acculturation offered by the phenomenological assumption of relationship is the variability of time as a factor in the development of acculturation. It raises the question: Do immigrants acculturate at approximately the same rate during the same period of time?

Most of the acculturation studies reviewed for this present study treated time as a linear flow which provided the constant backdrop for all immigrants' experiences. This view runs counter to the phenomenological assumption of relationship, which implies that people are capable of interpreting the importance of time differently. As noted earlier, different interpretations lead to different behaviors in relationship to the interpretation of phenomena. Therefore, 
it may not be appropriate to assume time as a constant in the development of acculturation.

Two examples of studies of acculturation which seem to deal with time as a linear constant in acculturation are by Breton (1964) and Young Yun Kim (1977). Breton revealed that interaction of the immigrant with members of the host group increased substantially between seven to twelve years. This happened especially for those immigrants who, because of an informal or loosely defined ethnic network, were forced to interact with members of the host culture.

Linear time as a function of acculturation was also considered by Young Yun Kim (1977) in her study of Korean immigrants in Chicago and their friendship networks. Her study revealed, for example, that during the first year the average immigrant had four times more intra-ethnic intimate friends than American. At seven to nine years there was a steady increase of both American and Korean friends. But, after nine years American friendships continued to grow while the number of Koreans dropped to the point where the average Korean immigrant had an almost equal number of ethnic and American friends.

A study which seems to support time as a function of interpretation is Weinstock's (1974) study of Hungarian immigrants. His study showed that the amourt of acculturation was not influenced linearily by the amount of time spent in the United States. He selected a group of Hungar- 
ian immigrants $(N=53)$ and then traced fifty of these immigrants two to three years later. He then re-tested them to assess the amount and nature of information regarding American culture that each subject now possessed. He finally concluded that perhaps the relationship between the amount of time spent in a given country and the progress of acculturation was not a linear function. He posited that time is of vital importance to acculturation only in the first few months when every week counts. However, soon other factors will predominate, such as reading the American press, close friendship with host members, high achievement orientation and strong manipulative tendencies. I assume that factors such as the ability to read and comprehend English, and to form new relationships with host members implies familiarity with the host culture that can be achieved only with the passage of time beyond the period of "a few months."

In this present study, it is anticipated that the rate of acculturation will be different for different people. It is the rate at which people respond to the influence of time that is of importance. The duration of acculturation is no guarantee for uniformity of experience because some people learn a great deal from only one experience, whereas others must repeat the experience over and over again before the experience becomes meaningful (Kelly, 1963). 


\section{ACCULTURATION IS A PROCESS}

Communication-based phenomenological assumptions posit that experience and behavior are processes in the sense that they are dynamic, non-static, continuous, with no fixed sequence of events. Each experience affects all other experiences. As acculturation involves acquiring new behaviors and experiences, it may be useful to look at it from a process perspective, as this term is used in communication.

Recently, Teske and Nelson (1974) specifically defined acculturation as a process. They say that it is a process in that it is a dynamic phenomenon that is neither static nor a unitary event. The implication of this is that acculturation is an ongoing activity which may change according to situations or the needs of the immigrant. Process also implies the dynamic interrelationships of events within the process in which each event affects all of the others, which will be explained more fully.

In support of the dynamic process approach, James and Ruth Dyal (1981) point out that we should remain open to the fact that acculturation is "not necessarily a linear process in which new cultural elements are substituted for old" but rather it "involves adding new behaviors that are context or situation specific" (p. 310) in which individuals shift back and forth from their original cultural patterns to the host cultural patterns depending on the context of the situation. 
Acculturation has not always been considered a dynamic process, as process is defined in this study. In some studies acculturation has been described as being a discrete subset within a greater cultural adaptation phenomenon. For example, according to Maureen Mansell (1981), acculturation is a subset of what she terms "the transcultural experience." Acculturation occurs when the immigrant feels a strong identification with the host culture. At this time, a sense of belonging to the new culture is often expressed, along with a relative tolerance for differences between ideological systems. According to Mansell, acculturation is often characterized by a lack of desire to maintain contact with the home culture.

Another theorist, Milton Gordon (1978), proposes that acculturation is actually the first of a seven variable assimilation scale. He calls acculturation "cultural or behavioral assimilation" in which only the cultural behavior patterns of the host culture are absorbed by the immigrants. In other words, Gordon's model treats acculturation as a discrete condition of the assimilation process. The criticism suggested here of Gordon's model does not depend on his particular definitions of acculturation and assimilation, which are different from those used in this study. Rather, exception is taken to the notion of any lock-step developmental model of cultural adaptation. While it is recognized that, in the acculturation of immigrants, certain events may pre- 
cede others, I suggest that the conditions of acculturation are permeable and that an immigrant, who experiences one condition of acculturation does not necessarily move on to the next condition until a point of completion is reached. Acculturation, in phenomenological terms, neither follows sequences nor does the immigrant move through set categories from stage to stage as Gordon or Mansell suppose.

However, a process perspective of acculturation helps to explain that the conditions of acculturation (as will be explained further on in this chapter) may be reversible and may vary from situation to situation. A combination of influences may necessitate a shift to a previous condition of acculturation. For example, changes in the perception of host culture members toward people of other cultures may affect acculturation. The phenomenological notion of intentionality implies the people's perceptions of similar situations may change according to what is perceived by them as relevant intentional events.

An intercultural communication example of such a perceptual change is the United States' attitude, at various times, toward Japanese and Iranian people. During World War II, Japanese-Americans were interned in concentration camps by the American government. Generally, they were viewed with hostility and anger as the enemy. Attitudes toward Iranians were neutral. 
Nowadays, the situation has changed. Japanese-Americans are considered to be fine upright citizens, whereas many Iranians in the United States feel compelled to conceal their identity because of the hostage crisis and host culture dissatisfaction over spiraling oil prices. New modes of coping have to be adopted by the immigrants, then, in answer to the various changes in host culture perceptions and attitudes. This remains true, no matter what stage of development or other state, posited by some authors, that the immigrant may be in.

In this study, it is anticipated that immigrants have altered methods of coping as they may have perceived changes in host culture attitudes. From the above discussion we may infer that a process perspective enables us to see that events or situations are interrelated and if one element of the process changes, other elements may also be affected.

The process perspective also enables us to see that acculturation is not an "either-or" phenomenon, in the form of rejection of the home culture, as some theorists suppose. For example, Warner and Srole (1945), in their study of ethnic groups, state that the new members "unlearn" what they have been taught of their original culture in order to learn "the new ways of life necessary for full acceptance into the host society" (p. 28).

Rejection is mentioned by Maureen Mansell (1981), who claims that during acculturation immigrants may either 
reject the original culture by saying such phrases as "I'm glad I got out when I did" or stating that when the family is gone they doubt they would ever want to visit their former homeland.

The process nature of experience assumed in the phenomenological perspective does not imply the need to reject the old in order to acquire something new. Rather, process implies that no experience is separable from other experiences. Such being the case, an immigrant does not forget or reject the home culture, or elements of it, but reconstrues his experience to suit the demands of the situation. According to Schutz (1970), former experience is not forgotten but "has now another meaning" (p. 304).

From this discussion, it may be said that the immigrant does not necessarily reject the home culture. Rather, the immigrant, in the process of acculturation, learns new ways and adopts new behavioral patterns and builds upon former ways. Even if the immigrant finds some former ways practically useless, he still may remember them if need be, and may be able to implement them in the appropriate situations. He also may be able to adapt the former ways to suit the new culture.

The process of acculturation is much like learning a new language. When one learns a new language, one learns haltingly, but as practice and understanding increase, facility ensues. Eventually one may be able to think in the 
learned language and to speak just as well as those to whom the language is indigenous. In other words, one becomes bilingual. However, this does not mean that one has forgotten or rejected the original mother tongue. It takes only a short time to recall former words and phrases, if indeed they are ever forgotten.

The acculturation process may operate in a similar fashion. In the new culture, one learns new strategies of life, and adapts former ways to suit the new culture. As practice and understanding increase, facility of operating in the new culture ensues. Eventually one may be able to operate in and understand the new culture just as well as those to whom the culture is indigenous. In other words, one may become bicultural or multicultural.

Ideally, the bicultural or multicultural person is able to step across cultural boundaries depending upon the situation. He moves freely from the inter-ethnic environment to the intra-ethnic environment and participates in both.

To review, in phenomenological terms, then, the experience of acculturation can be said to be a non-linear process which changes according to the situation, and to the needs of the immigrant. The immigrant learns what is right or appropriate for him in a certain situation. The immigrant, himself, is part of this process, forever slipping in and out of situations, construing new meanings according to 
the situation, and participating and withdrawing as he sees fit. He acquires new symbols, new patterns of behaviors. Former ones are discarded or fall into disuse, but are not rejected or unlearned. In other words, the possibilities of the situation dictate the use of patterns of behavior.

Acculturation, when viewed within a phenomenological perspective, offers an approach in which inter- and intraethnic relationships change as needs and situations change, but the overall process is ongoing and never ending. We do not have to think of acculturation as being an "either-or" phenomenon or as a sequence leading to any particular end condition such as biculturalism or assimilation. It is suggested that the process of acculturation for immigrants is a developing of an ongoing relationship with the host culture and its members according to circumstances and situations while, at the same time maintaining intra-ethnic relationships. The focus is on the intentionality of the immigrant-"What this situation means to me"--with the understanding that the immigrant is flexible enough to have relationships with whatever group is meaningful for him according to his needs. Remembering Deetz (1973), who said that we understand things "directly in terms of their possibility for our acting in the World" (p. 43), we see that the immigrant has the choice to respond positively to the immediate situation whether it is in intra- or inter-ethnic communication. One neither interferes with the other, nor decreases the quality 
of an immigrant's adaptation to the host culture. Rather, successful acculturation occurs if appropriate meanings are construed from both intra- and inter-ethnic relationships.

The phenomenological perspective supports the view that maintaining intra-ethnic relationships does not mean that the immigrant cannot successfully maintain inter-ethnic relationships. This relational viewpoint would tend to support theories of biculturalism and multiculturalism.

\section{A PHENOMENOLOGICAL FRAMEWORK OF THE PROCESS \\ OF ACCULTURATION: THE SUBJECTIVE \\ EXPERIENCE OF IMMIGRANTS \\ IN RELATIONAL TERMS}

\section{Overview}

The following section will conceptualize the process of acculturation within a phenomenological Framework of Acculturation. This Framework has been devised in order to delineate salient conditions in the long term acculturation process of immigrants to be used as a basis for the interview schedule and the analysis of this study.

To develop a generalized framework is a complicated problem because acculturation is a subjective experience. To add to the problem is one particular phenomenological assumption that has been suggested; namely, that acculturation is a process, as previously discussed. It was suggested that acculturation did not consist of categories of sequences through which an immigrant automatically moves. 
Nor is it a linear sequence in which the immigrant substitutes new cultural elements for old ones, forgetting the old ones. Consequently, it is difficult to establish a framework which, by its very nature, tends to categorize.

However, for the purposes of this present study certain conditions have been delineated that seem to occur within the process, as shown in Table I.

The listing of these conditions should not imply that they are static, nor are they completed at fixed times. Moreover, being in one condition does not necessarily mean the next condition will automatically follow. Although it is acknowledged that perhaps certain conditions may precede others, it is assumed because of the process nature, that the order of conditions may vary or may switch to different conditions in a non-linear way. Therefore, it should be kept in mind that the Framework of Acculturation contained herein describes conditions of the process but within a forced order and limited perspective. It is not a complete picture, nor can it reproduce the dynamic process itself.

The conditions that have been subdivided out of the process are based on the literature in this area. I have borrowed heavily from Brislin and his writings on long-term adjustment, as presented previously, but I have added to them, in order to give a phenomenological description. Care has been taken to include the primacy of relationship, as used in this study, as a unifying factor. 


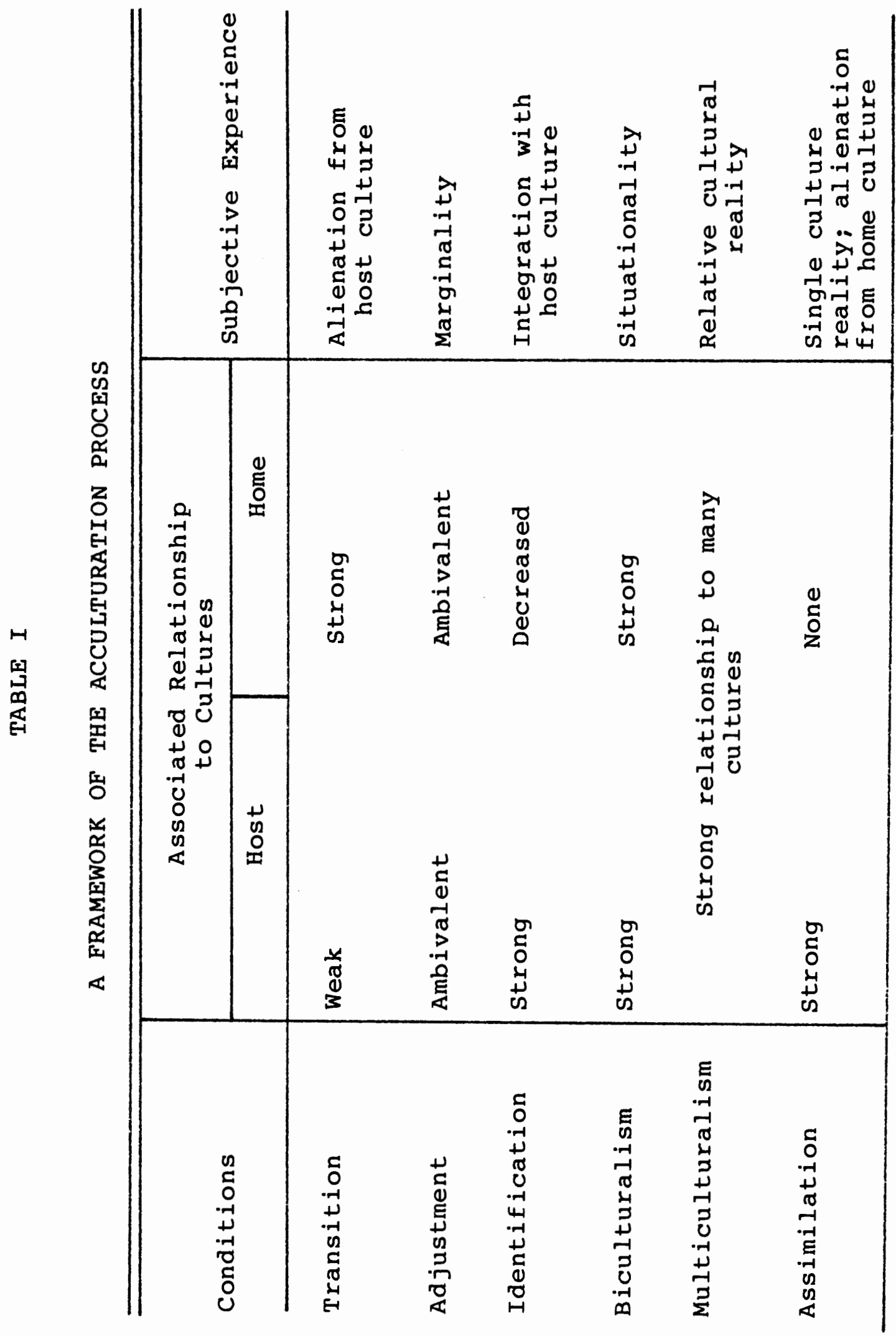


The Framework has been used as a guide in developing the interview schedule for use in the oral history interview sessions of the subjects of this study. The relationship of the Framework to the interview schedule is given on page 87 . The interview schedule is found on page 88 . 
DESCRIPTION OF THE FRAMEWORK OF ACCULTURATION

The process of acculturation is a subjective experience which varies with each individual. It consists of the following possible conditions within the process:

1. Transition

2. Adjustment

3. Identification with the host culture

4. Biculturalism

5. Multiculturalism.

6. Assimilation

\section{Transition}

Transition is a condition of acculturation in which an immigrant experiences:

1. Change and uncertainty in the host culture

2. Feelings of alienation toward the host culture

3. Feelings that intra-ethnic communication is important

4. Increased positive relationship for the home culture As previously mentioned, one's culture equips one with value orientations and belief systems through which one's social reality is constructed. In a situation in which an immigrant is uprooted from this reality through immigration, he is faced with the realization that he cannot interpret his new social environment with his habitual "thinking as usual" (as that term is used by Schutz, 1970, p. 88). The 
immigrant encounters many differences which may produce subjective feelings of insecurity, uncertainty, and culture shock. Conflict may occur, so much so that, according to Peter Adler (1975), the individual's struggle starts out as an encounter with another culture but eventually becomes an encounter with the self.

In other words, the condition of transition occurs when the immigrant, exposed to the new culture, experiences the above mentioned feelings. The immigrant acts with uncertainty and has to develop new techniques of survival, or change former ones. He quickly learns that his own "cultural baggage" is not directly applicable to conditions in the host society. Often, anticipated and expected results do not materialize because the immigrant's perceptual field has not adjusted to cope with the encountered differences.

This condition may be accompanied by a desire to return to the home culture and a need for communcation with one's own culture group, or intra-ethnic communication. Although this condition of transition may frequently occur at the beginning of an immigrant's experience, it may last a short time, a long time, or may reoccur in any situation at subsequent points of an immigrant's experience. 


\section{Adjustment to Host Culture}

Adjustment is a condition of acculturation in which an immigrant experiences:

1. Feelings of cultural ambivalence

2. The progress of inter-ethnic relationships

3. Meaningful intra-ethnic relationships

The immigrant is in a situation in which his loyalties are split between home culture and host culture. He is "a cultural hybrid on the verge of two different patterns of group life" (Schutz, 1970, p. 94). This condition is often described as marginality. The marginal person is "thought of as one whose actions do not reflect well any one culture" (Lum, 1982, p. 386). The marginality of the immigrant may occur because he feels a need for intra-ethnic support, has acquaintances in both cultures, and yet is confused over which cultural patterns to follow. Citizenship in the host culture may be considered because of pragmatic reasons. The relative level of commitment to either culture is uncertain and the immigrant becomes increasingly aware of cultural differences. Becoming aware of differences, as previously stated, ideally is associated with better ways of coping with them.

In adjustment, then, many differences are accommodated, interaction with host culture members increases, and host culture friendships are made. A commitment to remain perman- 
ently in the new culture is also made, although, in spite of the growing positive feelings for the host culture, a sense of marginality pervades. The adjustment condition may involve situational switches, in which an immigrant oscillates between home and host culture relationships to such an extent that he may switch from adjustment to the transitional condition or other conditions, such as identification with the host culture.

\section{Identification with Host Culture}

Identification with host culture is a condition of acculturation in which an immigrant experiences:

1. A strong relationship with the host culture

2. A decreased activity relative to the home culture

The immigrant feels a sense of belonging to, and of integration with, the host culture. The immigrant feels that he has grasped much of the host cultural patterns. Citizenship is willingly sought, and personal relationships with host members, in friendships and in group activities, are common. The immigrant feels that he has achieved many of the goals to succeed which he aspired to before immigration, and can draw on coping strategies learned and synthesized since coming to the new culture. The immigrant is apt to be positive toward the host culture and feels competent functioning within it. 
There is a tolerance for differences and although relationships with the ethnic group and links with the home culture are maintained, they are not of primary importance to the immigrant.

It is suggested that this condition may be only temporary and the immigrant may switch to other conditions depending upon, in part, host culture attitudes and validation (explained previously).

\section{Biculturalism}

Biculturalism is a condition of acculturation in which an immigrant experiences:

1. A strong relationship with the host culture

2. A strong relationship with the home culture

The relationship of the immigrant to the host culture is as strong as that to the home culture. He feels equally "at home" in both cultures depending upon the situation. The immigrant, as previously mentioned, does not forget the old culture but rather acquires new adaptive strategies which become learned behaviors and eventually become "second nature." Nevertheless, he is able to recall former cultural elements if need be, but the situation in which the immigrant finds himself, either inter- or intra-ethnically, mainly defines his function.

The bicultural immigrant, then, does not replace one culture with the other, but is able to accommodate to both 
cultures depending upon the situation (Pusch, 1979). The immigrant feels a sense of loyalty to both cultures, moving in and out of each cultural milieu and situation with ease. Biculturalism is more closely related to the personality and experience of the individual than length of stay in the host culture, as would be consistent with the assumptions of subjectivity and relationship. Intra-ethnic and inter-ethnic relationship are both favorable and friendly, and the immigrant is generally accepted by members of both cultures.

Biculturalism is a favorable condition as far as intercultural communication studies are concerned. One tenet of intercultural communication is that no one culture is better or worse than another, in terms of providing a coherent world-view for its members (Pusch, 1979). Therefore, all cultures and ethnic groups are "valid." In the case of an immigrant, rather than being completely subsumed by another culture, as in assimilation, it is more desirable for him to have a heightened awareness of cultural similarities and differences and to attempt to understand and appreciate them (Prosser, 1978). In this way, ultimately, because of the prolonged relationship with the host culture, an immigrant may selectively adopt host culture values and their concomitant behaviors and attitudes. At the same time he is free to retain influences of his home culture. Thus, a dual identity is developed. 
It is suggested that biculturalism is situational for reasons other than those mentioned above. For example, host culture attitudes may change from positive to negative, perhaps affecting the strong sense of host culture relationship a bicultural immigrant experiences. Examples of this type of situational change might be seen in the discrimination suffered by many German-Americans in World War I, or Japanese-Americans in World War II, who were not permitted to function in the host culture as they had prior to the respective wars (Rose, 1981). The situational changes perhaps force the ethnic person to reconstrue his loyalties to such an extent that strong loyalties to the host culture are diminished. The immigrant may switch to other conditions, such as those of transition or adjustment.

\section{Multiculturalism}

Multiculturalism is a condition of acculturation in which an immigrant experiences:

1. Strong relationships with the home culture

2. Strong relationships with the host culture

3. Strong relationships with other cultures

As discussed in chapter one, multiculturalism describes positive relationships with many cultures.

It is posited that an immigrant may have more of an opportunity of becoming multicultural than any other person because of his experience with other cultures and his in- 
creased awareness of the similarities and differences of other cultures (Adler, 1982).

According to Pusch (1979), the bicultural condition occurs if a person has had experience and functions easily in two cultures, but other cultural differences have little affect on him: whereas, the multicultural condition occurs if a person has had a variety of cultural experiences and has developed the skills necessary to communicate effectively, without anxiety, defensiveness, and distortion in the various cultural situations.

Intercultural communication theorists believe that multiculturalism is a desirable condition. It cannot be avoided that the United States is a nation of diverse cultures. Intercultural communication theorists point out that there is strength in diversity, and people as a whole benefit from the mutual respect and sharing of different ideas, customs, and values (Prosser, 1978).

\section{Assimilation}

Assimilation is a condition of acculturation in which an immigrant experiences:

1. No relationship with home culture

2. Complete relationship with host culture

Assimilation is the antithesis of multiculturalism. As discussed in chapter one, assimilation occurs when the immigrant suffers a complete loss of cultural identity with 
the culture of origin. He blends into the host society so well that the host members are unaware of the immigrant's cultural origins.

In this Framework of Acculturation, assimilation is a condition of acculturation, but it is suggested that it is a most unlikely condition, especially in first generation immigrants. This condition, in intercultural communication terms, is not a desirable one (Prosser, 1978).

When generational assimilation does occur, it may be situational, and not fixed. Herberg (1982) speaks of the revival of third generation people's interest in their roots and of their awakening pride in their ethnicity. Ethnic identification, according to Ting-Toomey (1981), appears to be a cyclical process, rather than a linear assimilational one. In her study of four generations of Chinese-Americans, the fourth generation "searched back for their 'roots'" ( $p$. 400 ), rather than assimilating. From this discussion it is suggested that people need not necessarily remain locked into the assimilation condition but may be able to withdraw from it, as the assumption of process, as used in this study, implies. 


\section{CHAPTER III}

\section{METHODS OF INQUIRY}

\section{THE QUALITATIVE PERSPECTIVE}

Acculturation has been studied from many perspectives. This study emphasizes a qualitative perspective. Qualitative research, in current phenomenological terms, provides for "the application to an individual case of generalizations about observed behavior" (Bemis and Phillips, 1964, p. 268). According to Bogdan and Taylor (1975), in their book about the phenomenological approach to qualitative study, this type of inquiry refers to research procedures in which information is usually in the subject's own written or spoken words or observable behavior. In this study the process of acculturation is described by means of an oral history interview, elicited from eight scottish immigrants residing in the Northwest of the United States.

\section{The Oral History Interview}

According to McMahan (1983), the oral history interview is a particularly suitable research vehicle for use in the discipline of speech communication because this type of interview is a communicative, interactive event. During the oral history interview, meaning is constructed through con- 
versation between interviewer and interviewee. The oral history interview is compatible with the communication based phenomenological assumptions suggested in chapter 1 because this type of interview is based on subjective experience, and is an interactive, relational event. Clark, Hyde and McMahan (1981) propose that the central features of the oral history interview are that this type of interview produces information that cannot be achieved through written sources; it involves dynamic communication between interviewer and interviewee; and it concerns the memory of lived-through (Erlebnis) experience in which the interviewee provides the experience of the past and the interviewer attempts to understand and interpret the presented data.

According to McMahan, the oral history interview involves four relationships:

1. The relationship between the interviewer and the interviewee

2. The relationship between the interviewer and the event to be interpreted

3. The relationship between the interviewee and the event to be interpreted

4. The relationship among the interviewer, interviewee, and the event to be interpreted.

These relationships influence the overall communicative performance of the interview. For example, each interviewee's understanding of the event is based on lived experience (re- 
lationship 3), whereas, the interviewer's understanding of the event is more often based on available written material (relationship 2).

McMahan explains that the oral history interiew "is best defined by its purpose" (p. 239). For this present study, the purpose of the oral history interview is to record oral data in order to describe the process of the acculturation of eight scottish immigrants who reside in the Northwest of the United States, in order to examine the Framework of Acculturation.

\section{THE SUBJECTS}

Eight individual scottish immigrants who live in the Northwest agreed to participate in this study. However, the oral histories only number seven, because subject number five consists of a married couple. This couple asked if they could be considered as one subject as their memories and feeings were very much alike. I found this perception to be compatible with the interview data and honored their request. They, therefore, are included as one subject.

Criteria Used in Selection

of Subjects

The subjects wère selected because they represented an identifiable group of people who have engaged in long term cultural adjustment: in other words, they should be immigrants. The subjects were aiso selected if they conformed 
to all of the following criteria:

1. The subjects should be first generation Scots.

2. In order to give credence to the oral history interview, it was considered necessary to select subjects that were available for extensive interviewing.

3. In order to ensure varied responses, the subjects should be representative of a wide occupational, educational, and age background.

4. In order to describe inter- and intra-ethnic communication, the subjects should represent those whose spouses or intimate friendships are both inter- or intra-ethnic, and those who belong, or not belong, to scottish institutions.

5. In order to consider long term cultural adjustment, it was considered necessary that subjects should have emigrated prior to 1970 .

\section{Selection of Subjects}

The subjects were drawn from several sources:

1. Three subjects were previously known to the interviewer.

2. A request to both the st. Andrew's Society of oregon, and the City of Portland Clan McClay yielded several volunteers. Three of these volunteers were eliminated from consideration because they did not conform to the previously established criteria. For example, one person had not been born in Scotland. 
3. Two of the subjects heard about the study by wordof-mouth, and volunteered their services.

4. One other subject, drawn from Marylhurst College, Oregon, was interviewed, but the interview session was so short because of time constraints that the information gathered was considered to be incomplete and therefore does not appear in this study.

5. One person contacted by the interviewer decided that the discussion of the acculturation experience was too painful and declined to be a part of this study.

The subjects were made aware that the information was being gathered about their experience as immigrants for research purposes. However, they did not have insight into all the objectives and procedures of this present study.

Six immigrants are men and two are women. Their anonymity has been protected and they are not named in this study, however names are available on request. They were all very willing to talk about their experiences.

These subjects are representative of a range of immigrants:

1. Ages range from the mid thirties to the late nineties.

2. Length of stay in the United states varies from twelve years to seventy four years.

3. Formal scottish Institutions feature in the current lives of three subjects, whereas the other subjects are inactive, in that respect. 
4. The marriages of two subjects are intra-ethnic, four are inter-ethnic and one subject is widowed.

5. Formal education range from three subjects with advanced degrees, one with an undergraduate degree, and three with technical master training.

6. Geographical locations of all the subjects, preemigration, were from the west coast of scotland.

7. Present geographical location of all subjects is the Northwest of the United States.

\section{INTERVIEW PROCEDURES}

Time, Length, and Location

\section{of Interviews}

The time of each interview varied. However, in general, the complete session of each interview lasted six hours each. This six hour period was broken up into shorter sessions because attention span seemed to wander after approximately two hours of interviewing. Two hour sessions were the norm for each shorter session. Five of the interviews were conducted at the homes of the subjects. Two interviews were conducted at the home of the interviewer.

It was planned to tape the sessions with a casette recorder, and it was also planned to take notes. However, some sessions were not taped, as will be explained in the limitations of this study.

After the interviews were transposed into the written word, the subjects were asked to review the contents to 
affirm that the information portrayed their experience as accurately as possible. No changes in the information was requested by the subjects.

\section{Possible Distortion of Information}

Consideration was given to the possibility that in recalling past events information might be omitted or forgotten. Communication studies remind us that each of us has some dark areas we either do not wish to disclose or do not even know are there (Luft, 1969). Consideration was also given to the possibility that people might remember in idealistic terms, thus distorting memories of past happenings and feelings. However, the oral history interview is an excellent vehicle for permitting subjects to probe their memories. As mentioned earlier, previous experiences receive additional meanings because of added experiences and changing attitudes and developments. The former experiences, in the light of changing perspectives, cannot be duplicated. Therefore, the memory of the subject is the important thing in an oral history interview.

\section{THE INTERVIEW SCHEDULE}

The interview schedule (found on page 88 ) was devised to facilitate a description of the acculturation experience of the Scottish immigrants of this study. Consideration was given to the immigrant's relational and communication pat- 
terns. Care was taken to provide the Scottish immigrants of this study with freedom to explore their own experiences during the interview sessions. The interview schedule provided the interviewer with a model that allowed for flexibility and adjustment in the interview session and allowed the subjects to describe their unique experiences in great detail. The interview schedule was controlled by the interviewer, and acted as a guide. It was not made available to the subjects. The interview schedule is on pages 88 and 89 .

While each subject was asked all questions of the interview schedule, the sequence in which the questions were asked were varied, depending upon the flow of the interview, and questions were worded differently, depending upon the situation and the subject. The aim was to not disrupt the subject's spontaneity. In this way, unique experiences of acculturation that otherwise might be lost in other research approaches were explored.

The questions for the interview schedule were derived from several sources. Questions regarding demographic information and contact pre-emigration evolved from Metzger's (1977) survey of the acculturation of foreign students in Portland. Questions pertaining to frienship networks, and in particular, inter-ethnic communication, were developed from Young Yun Kim's (1977) study of Korean immigrants in Chicago. Questions relating to education and perception of success were obtained from Weinstock's (1974) study of the 
acculturation of Hungarian immigrants. Other questions were developed from personal experience as a Scottish immigrant, and from ideas which presented themselves during the research of the literature, particularly from the writings of Adler (1975) on culture shock, and transitional experience and from his article (1982) on multiculturalism; and Brislin (1981) on long term adjustment.

The relationship of the individual question of the interview schedule to the Framework of Acculturation is found on page 87. The following explanation is a sample of why questions included in the interview schedule reflect the conditions of the acculturation process. The wording of the questions was changed to suit each individual situation. Examples will be given of the rewording.

For example, the condition of transition includes question number 9, which asks about contact with Americans pre-emigration. It was felt that if the immigrant had had personal contact with Americans in business, school, family, or as tourists, the transition condition at the onset of the acculturation experience would be perceived by the subject as being more positive than if there had been no personal contact.

The adjustment condition contains question number 21, which asks if there have been any changes in self perception during the acculturation experience. While interviewing, this question may be worded differently for different people. For example, it may be changed to, "How did you 
feel about yourself when that happened?" This question, which is suitable for all conditions of the Framework, was chosen to reveal the interviewee's subjective perception of changes in self. For example, in the condition of adjustment, which includes marginality, a perception of shyness changing to a perception of well-being may be interpreted as a strengthening of positive feelings toward the host culture, because shyness may indicate a reluctance on the part of the immigrant to particpate in inter-ethnic communication. A sense of well-being on the other hand, may indicate a willingness for more frequent inter-ethnic communication. In order to verify this interpretation, the interviewer may follow this question with question number 24 , which addresses the amount of inter-ethnic contact at different times.

Identification with the host culture includes question number 19, which is a list of adjectives describing possible reactions to the host culture on arrival, and whether they have continued or changed. It is supposed that if the immigrant still feels the sense of homesickness, or incompatibility, or whatever he may have reported as feeling in the transition period, that he is not in the condition of identification with the host culture. On the other hand, if feeling of competence and contentment are reported, this may be followed with question number 26 which addresses attitudes toward the home culture. If activities related to, and attitudes toward the home culture have decreased, the immigrant may be in the condition of identification. 
The condition of biculturalism contains question number 23, which deals with home culture contact. It is expected that if the immigrant is bicultural, he will have maintained contact with people in the home culture, because he still identifies with the home culture. Question number 40, which asks if the subject feels comfortable in both home and host cultures, may further indicate biculturalism.

The condition of multiculturalism contains question number 29 which inquires about the subject's perception of feeling like a foreigner. The question might be worded, "Do you feel like a stranger (outsider) in this country?" According to Adler (1982), the multicultural person would not feel like a foreigner because he is adaptive, and situational in relationship to cultures. If the subject does not feel like a foreigner, the question may be followed by question number 6 , which asks about self perception of personal qualities, and question number 21 , which asks about changes in self perception. The multicultural person will have undergone shifts in self perception.

The condition of assimilation includes question number 22, which asks about the availability of intra-ethnic networks. The question may be worded differently: for example, "Do you keep in touch with fellow scots?" The assimilated person, who is monocultural and identifies only with the host culture would probably consider his intraethnic network as being the host culture network. If this is the case, question number 28 , which inquires about the 
subject's present perception of self as American or Scot, should be asked. An assimilated person would perceive himself to be an American.

The relationship of the individual questions to the Framework of Acculturation is shown in Tables II and III. 
TABLE II

RELATIONSHIP OF THE FRAMEWORK OF ACCULTURATION TO INTERVIEW SCHEDULE

\begin{tabular}{|c|c|}
\hline $\begin{array}{l}\text { Conditions of the } \\
\text { Acculturation Process }\end{array}$ & Interview Schedule \\
\hline Transition & $\begin{array}{l}9-16 ; 18 ; 19 a-r ; 20-23 ; 29 ; \\
30\end{array}$ \\
\hline Adjustment & $21-25 ; 29 ; 30 ; 32 ; 40$ \\
\hline Identification & $\begin{array}{l}19 ; 22 ; 23 b-d ; 24 b-d ; 25-27 ; \\
30\end{array}$ \\
\hline Biculturalism & $\begin{array}{l}19 p-r ; 21 ; 23 c-d ; 24 c-d ; \\
25-27 ; 40\end{array}$ \\
\hline Multiculturalism & $\begin{array}{l}6 ; 7 ; 9 ; 10 ; 13 ; 18 ; 19 ; \\
22-27 ; 29 ; 30-33 ; 38 \mathrm{~b} ; 40\end{array}$ \\
\hline Assimilation & $\begin{array}{l}17 ; 21 ; 22 ; 23 c-d ; 24 c-d ; \\
26-34 ; 37 ; 39 ; 40\end{array}$ \\
\hline
\end{tabular}

TABLE III

RELATIONSHIP OF OTHER FACTORS OF ACCULTURATION TO INTERVIEW SCHEDULE

Conditions of the Acculturation Process

Interview Schedule

Demographic Information

$1-8$

Process

$17 ; 23 a-d ; 24 a-d$

Communication

9; $10 ; 20 ; 22 ; 24 ; 25 ; 29$; $30 ; 35 ; 36 ; 38 a-d ; 39 a-d ; 40$ 


\section{INTERVIEW SCHEDULE}

1. Name

2. Sex

3. Occupation

4. Marital status

5. Education

6. Self-perception of personal qualities

7. Year of emigration

8. Age at emigration

9. Contact with Americans pre-emigration:
a. business
b. school
c. tourist
d. social, familial network
e. other

10. Intercultural contact pre-emigration:
a. business
b. school
c. tourist
d. social, familial network
e. other

11. Reasons for emigration to the United States

12. Friendship and family network pre-emigration

13. Involvement with national or cultural groups pre-emigration

14. Occupation pre-emigration

15. Perception of the United States pre-emigration

16. Expectations of future success, pre-emigration

17. Length of time in the United States

18. Remembered reaction to arriving in the United States

19. Remembered reactions to the new cultural setting and whether have continued specifically feelings of :
a. confusion
c. being different
b. uncertainty
e. home sickness
d. hostility
g. incompetence
f. incompatibility
i. loneliness
k. fear
h. insecurity
j. anxiety
1. failure
m. lack of self confidence n. exhilaration 
o. excitement

p. happiness

q. contentment

$r$ other

20. Ability to find suitable occupation

21. Changes in self-perception

22. Availability of intra-ethnic networks

23. Contact with home culture (letters, phone etc.):

a. at time of arrival b. after five years

c. at present time d. responsible factors

24. Contact with host culture members:

a. at time of arrival b. after five years

c. at present time d. responsible factors

25. Perception of changes in contact with home or host culture since time of immigration to present.

26. Perceived differences in own attitude to home culture

27. Perceived differences in attitude of home culture people toward the subject

28. Present perception of self as American or Scot

29. Perception of feeling like a foreigner

30. Perception of acceptance by host culture

31. Feelings of competence

32. Feelings of desire to return to home culture

33. Feelings of need for intra-ethnic contact

34. Need for membership in formal intra-ethnic societies

35. Status of citizenship

36. If United States citizen, what changes were perceived in:

a. Loyalty to home or host culture

b. Affiliation with home or host culture institutions

c. Self-esteem

37. Perception of how pre-emigration expectations have been realized

38. Perception of satisfaction of self:

a. in business

b. in interpersonal relations

c. economically

d. in host culture friendships

39. Perception of satisfaction with host culture:

a. understanding or acceptance of host culture behaviors that were originally perceived by the subjects as being different or unpleasant.

b. subject feels happy in host culture

c. subject has a feeling of being at home

d. subject has adopted aspects of the host culture (to be specified by subject)

40. Subject feels comfortable in both host and home cultures. 
CHAPTER IV

DATA

THE ORAL HISTORY INTERVIEWS

Subject Number 1: S.McK.C.

Age: 52 Sex: Female

Marital Status: Married to an Englishman; two children. Education: pre-emigration: completed up to tenth grade. post-emigration: completed AA degree. Self-perception: curious, adventurous, courageous. Year of emigration: 1958

This subject came to the United States with her husband and one child. She had another child after having lived here for one year. She has lived here for over twenty years, during which time she has not been employed. Both she and her husband believe that a woman should look after the children and that work at home is as strenuous, honorable, and necessary as any formal, paid employment. This belief, however, has not limited her to only the home environment: She recently completed a degree program and participates in her husband's avocation of house building. 
Reasons for Emigration

Before coming to this country, this subject said she felt completely secure in the home environment, but part of her "felt restricted, in a trap." To her, life was "dull, drab and uncomfortable with poor pay." She planned to leave because of the stifling atmosphere that she felt pervaded the country after World War II. She also was disenchanted with the class system; it restricted her. But the one factor that "played an enormous part in the decision to come here" was the poor climate in Britain. People who had been in America told her of the good and varied climate which compared favorably to the Scottish one: "Scots cannot escape their climate. We are ringed by the seas. We can work all year for three weeks holiday and it can rain all through it." These were the main considerations for emigration.

\section{The Subjective Experience}

Initially, on arrival in this country, this subject said she was curious. She felt as if she were on her first holiday. The friendliness and courtesy of the people pleasantly surprised her. She was made to feel very welcomed. In fact, she felt she had indeed come to "God's country."

However, these favorable first impressions changed. She soon suffered extreme "feelings of vulnerability," mainly because of the "lack of social services." Concomitant feelings of loneliness and uncertainty arose, and to this day she feels she has never lost them, although at the begin- 
ning of her experience they were much more pronounced than they are now.

These feelings of vulnerability were exacerbated by the perceived poor health care system, which made her feel "distinctly disadvantaged." Her experience with this was extremely unpleasant for her because she had to deliver her own baby because of inadequate attention--an unthinkable proposition in her own country. She has never forgotten this and still feels a distinct sense of distress about the poor quality of the health care services. The medical system was such a problem to her that, had it not been for the favorable weather, she believes she would have returned home. In other words, her feelings of positive relationships to her home culture were heightened because of the unfavorable comparison of the United States health system to the British one. She had never realized until she came here that scots "had it so good."

Loneliness, too, was a problem for a long time. This was because she did not know how to "break into the social structure" nor did she understand American attitudes to socializing. She said, "We come from a tight social structure to one that is practically invisible." She believed that when Americans said, "You must come over and see us sometime" they did not "give it a second thought by following up with an exact invitation." Now, she realizes that this is just a friendly statement, but at that time she felt 
Americans were being hypocrites. She felt socially slighted by the non-specific invitation.

Because of this inability to break into the American social structure, this subject found friends elsewhere. She stated that during this time she felt a need for intraethnic relationships mainly because she wanted to be with people who had the same sense of humor and laughed at the same things that she did. However, this subject found her social network not exclusively with fellow scots, but with other European immgrants, especially German, English and Irish. She eschewed formal clubs or societies because "they don't offer diversity" and as she had never been "a club person in the homeland" she balked at assuming this type of friendship network in the United States.

She believed that her marital relationship helped her to see this time of anxiety and uncertainty through because her husband supported her physically and mentally, and she him. Nevertheless, she believed that the trials they both encountered negatively affected their marriage. Neither were happy with the situation, with each other, with the marriage.

This subject volunteered the information that her strong feelings of vulnerability lasted five years: "That's how long it takes to become comfortable." She claims that she "made it through the worst by trial and fire." 
At the present time, this subject's loyalties appear to be split between home and host culture. Her feelings for her home culture are tinged with ambivalence. For example, she considers Scotland to be peopled by "bigots." These are the "intensely narrow people not inclined to emigrate, snobs - . people caught up in an invidious class system, clinging to outmoded values . . religiously intolerant." However, conversely, she laments the loss of the "strong sense of duty to the family unity," and of discipline which she considers as being paramount to strong character building and found only in scotland. She asks, "How do you tell kids what struggle is like, never being cold or hungry?" In America, "Children are denied the right to struggle... and, therefore, are not geared for survival and trained to cope."

Her ambivalence can be seen in her attitude to returning home. She sadly regrets she cannot, yet, at the same time she speaks of how distasteful it would be anyway. When asked if she wanted to return home she replied, "Sadly, no. Many things have happened." Moreover, she feels the home culture has not progressed, is pervaded by "an atmosphere of gloom and attitudes of despair, mainly because the vigor has emigrated." She claims it is the emigrants "who are the movers and the shakers, who have drained the home culture and undermined its vigor." And so she is resigned to living in the United States. 
Her feelings for America are also ambivalent. Much in America displeases her. For example, as far as social conditions are concerned, she still cannot come to terms with the American attitude that she perceived as "out of sight, out of mind." She believes that Americans do not adequately care for their sick and "are not their brother's keeper" as they would be in Scotland. She is horrified by the American exploitation of labor of ethnic groups, such as Mexicans, saying that it was a form of "culture shock" to her to realize that this country, which valued equality, could treat any human this way.

Her own personal experiences have produced ambivalent attitudes, also. In the host culture she feels "like a foreigner" and supposes that she is "always being pointed out" because of her pronounced accent. She also lacks commitment to the United States, feeling no desire to become a citizen. She believes that "immigrants only need to become citizens in order to get a job."

There is also a lowered standard of the American courtesy that she initially experienced. This initial friendliness has gone because "the American value of graciousness and charm is lost to young people." Selfishness pervades the United States, and young people have become "awfully self-centered" because, she believes, they have shifted their focus from love of country to love of self. In other 
words, her perception is that Americans are not proud of their country any more.

She is also disappointed in her material progress in the United States. Americans value material success and she presumed emigration would bring this. However, these expectations of material success have not fully materialized. In retrospect, though, she is glad about that. She said that her ultimate view of material success in the home culture was to have a cottage and a motor scooter. However, when she came here this soon changed to a more ambitious one. She, and her husband, started a grandiose building scheme which eventually collapsed mainly because of unfavorable economic conditions and legal bunglings. To her, now, material success is equated with arrogance because she discoverd through the building failure her expectations of great material success had made her arrogant. The failure changed this arrogance. She exclaimed, "America gave me the opportunity to be arrogant. But it also gave me the choice to change. Now I am humble again." Her desire for material success has now reverted back to the cottage, this time without motor scooter.

In spite of these negative reactions, she has strong and positive feelings toward the United States. She delights in the people of the United States, and has adopted many of the behaviors of the host culture. For example, she loves to entertain lavishly, and realizes that this is only 
possible for her in this country. On the whole, she feels Americans "are not tense, nor worry, and they live with a sense of security and freedom." They are more inclined to "meet you as an individual in comparison with people in the home country." She feels a certain sense of belonging, especially after she returns from trips abroad: "I feel mellow to be back home." However, she hastens to add that this sense of belonging is specific to only the town in the United states in which she lives, not the whole country, or even the state.

Finally, she describes her position as "being in limbo" in which she is "culturally in the middle". But, she is glad that she had "the moral courage to see it through" to this point in time. Her experience has been "one hell of a trip." 
Subject Number 2: M. MCG.

Age: 42 Sex: Male

Marital Status: Married to an American; five children

Education: Pre-emigration: B.A. University of Glasgow Post-emigration: B.S., M.A., JD.

Self-perception of personal qualities: curious, determined, Catholic, independent, open to change.

Year of emigration: 1958

This subject came to the United States as a very young man, immediately after receiving his B.A. in Spanish and French from the University of Glasgow. Since his immigration, he has continued his education and now has a doctorate in law as well as advanced degrees in languages. He married a third generation Italian-American who migrated to the west Coast from Boston. He has five children ranging in ages from 19 to 2 .

Reasons for Emigration

Before coming to this country, America and Americans were "very attractive" to this subject. He knew people who had been in America. Hearing from their experiences, plus reading and studying about the United States, he felt that the United States was the type of "progressive, vigorous country" in which he would like to live. He believed that America offered him "true democracy." In Scotland, he was a definite minority member as he was a Catholic in a predom- 
inantly Protestant society. He felt that the Protestant Scots were bigoted and his experience was that there was little democracy for him in Scotland.

He believed that, in America, where "the Jews came, were welcomed and allowed to build their own society" he would escape the chains of bigotry. Moreover, to him, the scot in scotland is limited and conservative and he felt he would be unable to reach his potential had he lived there any longer. This conservativeness showed itself in his fellow scots' reaction to his projected emigration: "The more I talked of going to the United States, the more attacked I was by my scottish friends saying I should not abandon the land of my birth." However, his curiosity prevailed and although he loved his country, he eventually emigrated so that he could "find out" for himself.

\section{The Subjective Experience}

This subject believed initially he did not experience "too much home sickness." He was "wide open" to his new experience, and "saw a lot of good, a lot of promise and potential" in America. His expectations of America were realistic. He did not expect to "see the streets paved with gold" and feels that the immigrants who believed that America would bring personal riches are more liable to failure or desire to go home.

His attitude toward the host culture was positive. The 
host culture's attitude to him was positive. First of all, he discovered that, according to his expectations, Americans were not bigoted: "The Protestant-Catholic problem was diffused because Americans believe people should be people." One main problem, however, at that time was finding a suitable job. But he has turned this into a very positive experience because he "was determined to succeed. I did not want to go back home and admit failure." He discovered his languages degree from scotland hardly equipped him for any suitable job but he was not willing to do "menial work." Therefore, he decided to go back to university so that he could obtain his teaching certificate. He completed a second bachelor's degree and became a teacher within three years of his emigration. Shortly thereafter, he completed his masters degree and for many years he was a languages instructor.

His high value of education is shown in the fact that quite recently he completed his doctorate degree in law "just to see if I could do it," but believes that his value to society is as an instructor: "I am a born teacher and I believe that I provide my students with a different and valuable point of view." Overall, he is thankful that his work and education experience have been so positive and beneficial to both him and his new country.

At the beginning of his experience he was lonely but even that he considers a positive experience. Initially, he took solace in fellow scots: "My first friendship network was predominatly scottish." He did not relish the exper- 
ience of joining scottish societies or clubs but rather found his network of friends through the church. Americans in the church introduced him to Scottish friends of theirs and scottish-Catholics also befriended him. He claims that the friendship and support he experienced at that time played an important part in his positive attitude to America.

The most positive thing about this network was that it contributed to his closest social relationship and companionship: his marriage. Through this Scottish-Catholic network he met his future wife, a Bostonian-Catholic, herself a newcomer to the west coast. They married within two years of his immigration.

In time, his friendship network has changed. After having been here for over twenty years it is "indiscriminately American, Hungarian, Scottish, Irish, and South American." When asked why he would choose other foreigners as friends, he replied that perhaps it is because they have had similar experiences and backgrounds and have "more international attitudes." An example of this was that when he was attending law school the one person he was attracted to, and became firm friends with, was Irish. He supposed that this happened because of the similar backgrounds, the similarity of immigration adjustment and "after all, like attracts like; it's easier to make these kinds of friends."

As far as being an American, this subject does not 
belonging to any distinct ethnic group. He describes himself as being "a bona fide American." He is an American citizen and proud of it. Moreover, he is proud of the fact that "people accept me as an American." He believes that living in America has enabled him to "be more objective, to be less swayed by considerations that are Scottish." It has allowed him to "change my life's philosophy: to be willing to consider new values, new philosophies," and "to find my true limitations and potentials."

This fierce pride in being an American does not detract, however, from his pride in his home culture. He identified his attitude to scotland as being "nostalgic, not idealistic, and nationalistic." His pro-Scottish nationalism exists in respect to the struggles the scots have historically had with the English. He exclaimed, "We was robbed!" when he thought about the injustices the Scots have suffered at the hands of the English.

He told me he felt "very close to scottish life and society." He also believes he was fortunate to be born in a country with religious differences because it taught him, as a minority Catholic, to be tolerant of these differences and to accommodate to a society with a philosophy different from his own. Ultimately, the religious differences in the country are transcended by all people "being truly scottish." He related that when he saw Chariots of Fire a film about a scottish-Protestant Olympic runner, he "really empathized with it in that, to me, the story showed that there is a 
feeling among scots that transcends religion. . we are all brothers . . . We all ultimately, have a Scottish identity."

To him, Scotland is a land of "fiercely independent people. - with a colorful culture, rich in folklore, national dress and music." He related that the history of the country is full of rebellion and "Scots tend to support the underdog." His love of the country has not diminished. He told me, "When I hear the pipes, the poetry or the music it stirs my blood." He has never gone home since his immigration because of his education and family involvement, however, he says, "Listening to the music is the next best thing to going home."

In spite of this pride in his scottish identity, the subject felt that his children were "very American" and that they "don't know as much as they should about their Scottish heritage." This, he found all the more surprising when he considered that they "hear more of the scot's family than their mother's family." He says this because, since his immigration to the United States, his three brothers and parents have also immigrated and lived close by, thus forming a strong, cohesive family unit.

Finally, this subject believes that, in the long run, the success of his acculturation lies in the fact that he had a fine education in both the home culture and the host culture. The university education in scotland equipped him with a knowledge and understanding of humanities and an 
insight into himself that enabled him to develop "a broad minded, morally upstanding life style at an early age." His Iife in scotland equipped him with "the amiability, honesty and hard working qualities that make successful immigrants." Ultimately, though, he believes that his United States education experience enabled him to appreciate America, and to rejoice in being an American in "a realistic, objective, and rational way." 
Subject Number 3: W. McB.

Age: late fifties Sex: Male

Marital Status: Single

Education: Pre-emigration: Because of the depression, this subject left high school before completion. He served a full apprenticeship in woodworking machinery manufacturing.

He also participated in British Navy training

courses in marine power plant engineering.

Post-emigration: Various evening school

courses.

Self-perception of personal qualities: athletic, adventurous, full of wanderlust, hard working.

Year of emigration: 1949

This subject initially came to the United States during World war II in 1942 with the British Royal Navy. His ship was outfitted for two months and during this time he had the opportunity to travel from New York to Portland by train. Consequently, he saw much of the country and met many Americans. He was favorably impressed by what he saw. It was oregon, though, that left a lasting impression with him. The fact that so few people lived in such a large geographical area was intriguing to him: "I figured the populace of the state was less than the city of Glasgow." Moreover, he was mesmerized by the beauty and the possibilities of the cascade mountain range. As he was a very active 
mountaineer, he decided that one day he would climb all the peaks in the range.

However, the war persisted in Europe and he returned there. He visited other areas of the world including Russia and North Africa and had many interesting war time experiences. After the war he returned home to scotland, but decided shortly thereafter to emigrate to Oregon.

He has lived in Portland ever since and is presently a partner in an industrial company acting as a manufacturer's representative for pneumatic valves. His work takes him all over Oregon and the Pacific Northwest and he feels very happy with the situation and his overall employment.

\section{Reasons for Emigration}

This subject told me that he always had an "urge to see the world" even from early childhood. Being brought up on the clydeside, which was the world's number one shipbuilding area at that time, introduced him to the great sea going ships. He said that, as a boy, he often spent his spare time watching the ships or visiting the "great marine museum at Kelvingrove." A great wanderlust developed in him: all he wanted to do was join the ships in their voyages.

He did eventually have this opportunity with the onset of World War II. He joined the Royal Navy and spent most of the war years sailing all over the world on the Queen Elizabeth, one of the great ships built on the clydeside. 
When the war finished, two things prompted his emigration: his wanderlust was not assuaged and conditions in postwar scotland were bad. Because his best friend decided to emigrate to New Zealand, he decided that he, too, should emigrate as the aftermath of the war years had left scotland in a severely depressed state. He recalled the Cascade range and the beauty of oregon, which he considered was "a little bit of scotland," and chose this as his place of emigration.

\section{The Subjective Experience}

Because he "knew what the place was like," the subject believes that he had a rational and pragmatic outlook on his immigration experience. As he said, "I was not like Dick Whittington going to London, expecting the streets to be paved with gold." Indeed, he "left it pretty open to go back" if things did not work out. But he never did.

Initially, things, in fact, did not work out. His immediate entry to the United States at New York "past the great lady" was fraught with difficulties and unpleasantries. Because someone, "an idiot who caused great grief", at the American embassy in Glasgow had omitted certain information from his visa, "a great mistake," he was taken at gun point from his ship and thrown into Ellis Island with others whom he considered as "crooks and spies." He "couldn't believe it", but had to stay there overnight. During this time, American "guys with sub-tommy guns" forced him to do 
such things as go to bed. Had they asked him, he would gladly have complied. He saw many people suffering great indignities in this place. To make matters worse, on his release, he discovered that immigration officials had stolen some of his possessions.

Had it not been for his previous pleasant experience in the United States, this subject believes that he could not have tolerated "this very bad experience." But, he kept in mind that there were "Americans who could treat you well." Fortunately, the British Consulate cleared matters up and he was released the next day. This unpleasant experience in Ellis Island has left no lasting effects on how he feels about America and Americans but, he believes, only because he had previous knowledge of the country and its people.

His experience at Ellis Island completed, he found his way to Oregon. But there, things did not improve. The time was "full of worries." There was an economic depression at that time and the job he found "was the pits." The little savings he had accumulated from his Royal Navy days quickly diminished. It was "tough and very discouraging." In fact, he believes that he would have gone straight home had he "bought and played the records of Scottish songs" that he now owns. Although these feelings of discomfort and nostalgia persisted at that time, he maintained little contact with friends and relations back home. He did not write home 
much, and although his sister still lives there he claims he communicated rarely.

In spite of the unfortunate experiences, he stayed in Oregon and saw these unpleasant times through mainly because he "loved the mountains" and because of his friends. The fact that he liked oregon because it was "green like home - . it rained, but not too much and had the oceans and the mountains" was significant to his staying. As far as friends were concerned, his hobbies brought him friendships.

In Scotland, he had been an active mountaineer and at this time he put his hobby to full use. By joining the mountaineering $c l u b$ he made friends because "mountaineering types have good rapport." He also became active in golfing circles and it was through this golfing friendship network that, one year and a half after coming to oregon, he acquired a good job. By "a stroke of fate" another golfing scot told him of an opening. This new job "turned things around," gave him a substantial increase and was "a step in the right direction." He has never looked back.

The friendship network that this subject formed during and since that time is of an eclectic nature: "My circle of friends is mixed and varied." Initially, his friends were those with whom he lived in a boarding house. Two of these were ex-United States Navy men from New York and Boston. They "all got along famously because of the Navy bond." He remembers, though, that they all felt like "outcasts" when 
they went out socially--"like the Three Musketeers." For example, at one university party they went to, everybody ignored them. His general social experience is that "there is a lot of that" but he is not surprised because "that's what people are like if you're a stranger."

He does not feel like a stranger any more. He believes that because of his hobbies of mountain climbing and photography that he is "not quite as lonesome as some other people might be." Because of this, he has made many American friends. As well as the mountaineering club, he joined the oregon Camera $\mathrm{Club}$ and became an active participant.

He considers himself to be very athletic and consequently he joined sports clubs, too. His interest in European sports, especially soccer and golf, enables his friendship network to include people from Germany, Denmark, and Ireland as well as Scotland.

Scottish friendships were developed through the Scottish Clan McClay and st Andrew's society. In fact, his present occupation, to which he contributes his sense of happiness and contentment, is in partnership with a fellow Scot. With all these connections and hobbies he was able to keep active and loneliness was no problem to him: "I didn't have time to twiddle my thumbs."

The Scottish Clan and societies are not important to him now. His work and other interests keep him traveling 
and satisfies him. He feels no need for social participation with clan members or to participate in clan events. This disinterest in fellow scots is no reflection on his own feelings of scottishness, however. He said that he has "always been proud of being Scottish." He listens avidly to scottish records, subscribes to scottish magazines, and still "feels fond of the city of Glasgow."

He did return to scotland recently for a visit. The overall impression he had was that his "pace of life had changed" and that he had forgotten how "nice and generous the scots were." However, he was glad to return to Oregon which he considers his true home and in which he is proud to say that he has achieved his youthful goal of climbing every major peak in the Cascade range. 
Subject Number 4: T. S.

Age: late fifties Sex: Male

Marital Status: Married to a Scot; no children

Education: Pre-emigration: He left high school at age fourteen to start an apprenticeship in foundry work. By the time his apprenticeship was completed at age twenty one, this subject had learned mathematics, English, science, and metallurgy in evening school, as well as the daily apprenticeship foundry work. He "could do everything" in foundry work.

Self-perception of personal qualities: reserved, shy, honest, thrifty but not mean, independent. Year of emigration: 1947

This subject first emigrated to Canada in 1947 shortly after his marriage. However, his experience there was "a real bummer." The work was not what had been promised, his wife was very homesick, and generally, conditions were "tough." He and his wife "hated it." A co-worker, who had a business in Portland, oregon, offered him work, but it took quite a while to obtain a visa for entry into the United States because of the low Scottish quota that the United States government imposed at that time. He was quite disturbed by this because a previous visit to Portland had left a positive impression on him and he felt he had "something to offer America" and yet he "couldn't get down from 
Canada." Through an immigration lawyer he discovered that Canada had a high immigrant quota to the United States and he finally managed to obtain a United States visa after he and his wife claimed Canadian citizenship.

Coming to the United States was "the turning point" in his experience, "The best move we ever made." Now, this subject is a director in the same company he tried so hard to come to in 1952 .

\section{Reason for Emigration}

This subject decided to emigrate to North America because the aftermath of World War II had left Scotland in an extremely depressed economic state: "You couldn't get anything." He and his wife decided, "Let's get out of here" when they heard of the favorable working conditions and the many opportunities in Canada. As previously mentioned, the Canadian immigration did not work out for him. Conditions there were worse than in Scotland, "We didn't have a penny." He related how poor he felt, for example, how his wife had to use a washing board to do her washing; how they did not even have enough money to go to a picture show; how they were forced to buy second hand furniture. Moreover, his work was quite unsatisfactory to him. This was not what he had anticipated. Therefore, the opportunities that the United States offered him made him decide to emigrate again, this time to Oregon. 
The Subjective Experience

When this subject finally arrived in oregon from Vancouver, British Columbia, he was favorably impressed by the work he came to: "A good job is important to a man." Also, the friendliness of the people was impressive. Everything was "so nice." Compared to Canada, where he had felt like "a stranger in a strange land," he found Americans to be friendly and, in fact, his initial friendship network was with Americans. He believes that this was "mainly because of the job." His first Christmas was spent with Americans who "took us in as if we were part of the family..." However, he has found through the years that friendship with Americans has "not the depth of previous friendships" and that Americans "cast on and cast off a lot easier."

His initial social network with Americans soon expanded to include fellow scots, whom he met, not through work, but athletic activities. He came in contact with a soccer team which contained several Scottish players. They introduced him into their own social network. Soon, he and his wife joined a Scottish country dance club. He had not originally planned to become a clan member: "We were against the Clans for a while" but he met "so many nice people" that he eventually joined the Scottish Clan Mcclay.

In retrospect, he said, "I don't know what we would have been without it." It was "a definite need" for him, helping him not only to understand the ways of the United 
states, but a "crutch" in which he as "a stranger" who "needed a place to be welcomed... needed my own kind, somebody I could relate to" found lasting friendships.

Nowadays, his friendship network comprises people from the United States and England: "We have lots of English friends - . we like English people because they are progressive." The most intimate friendship network, however, is scottish. "I have more Scottish friends because of my association with the Clan."

This association with the various scottish societies in oregon is very strong, and has not diminished with time. As a director of the St. Andrew's Society and as head clansman of the clan McClay, he is very active in, and proud of, Scottish societies in America. He reminded me that the original concept of the clan system in America was as a benevolent society for Scottish people "set up at a time when there were no insurance, unemployment, and medical care in the United States." The clan system contributed to, and supported members to obtain such things as gainful employment or widows' and orphans' pensions. It is the oldest benevolent system in North America, having its start in Boston in the early 1600's. Originally, it was founded by scottish soldiers taken prisoner by the English and deported to the Colonies, as indentured servants. Once in America, they had to work for their freedom. The fund was to protect these people and their families so that no scot was fall desti- 
tute. Today, it is worth millions with many successful Scots contributing to it. Andrew Carnegie, the Scottish steel industrialist, for example, was a large contributor to the fund. It still exists "for the benefit of indigent scottish people." However, this subject believed that "there is no scottish person here in need anymore." Therefore, funds are spent on scholarships, in financing hospital beds, and in establishing inexpensive condominium living for elderly Scottish emigres.

Nowadays, the clan system serves social needs and fosters scottish identity. The clan and societies enable this subject to "take part in Scottish things." They have given him "a kind of security and allowed him to "appreciate his culture and familiy more."

The back bone of the clans and societies today are first generation scots who meet and discuss many things including "things happening at home." This group "keeps it going." Although many second and third generation scots are members, they "dodge in and out" because they find that "it was not what they thought." They also find that the first generation scots are very cliquish, prefering to keep to themselves. Unfortunately, in the last decade with diminishing scottish immigration, the membership is also diminishing. This subject believed that the clan system serves to keep Scottish culture alive. In America, "The average scot knows more Scottish songs than in scotland where the 
entertainment is the same as in America. . he has more of a Scottish identity and pride in nationalistic things."

As far as his connections to scotland are concerned, he maintains contact with his friends and family by mail. Also, "the telephone is handy to keep in touch." He has visited scotland several times and is able to draw comparisons between scotland as it is now and the United States. There, he finds the people "friendly . . welcoming . . willing to talk to people for ages . . and inquisitive." Their generosity ranges from "offering complete strangers dinner" to "cream caking us to death." To Scots, "Money is the least important consideration" in comparison to the Americans, "Here the dollar is ultra important." One interesting point is that he notices his paralanguage has greatly increased in volume since coming to the United States. When he visits scotland he "talkes too loudly" and has to lower his pitch. He also has noticed that his pace of life has increased since living in the United States. He is aware that he is "on a treadmill," always rushing to do things. People take life a lot easier in Scotland. Nevertheless, he finds his visits "good for only a month. I'm glad to come back."

As far as his relationship with the united states is concerned, he enjoys his "style of life" in America and would never want to go back to Scotland to live. In spite of his fierce loyalty to scotland and scottish culture, he 
is extremely proud to be an American: "I am happy I can wave two flags."

American citizenship is important to him. He pragmatically believes that "if we live here, and this is our home, we should become citizens." He took the oath of citizenship with ambivalent feelings, believing that "that's our country" but being relieved that Scottish law allows for dual citizenship. To begin with, he was very worried about the reaction of his family in scotland to his American citizenship. It was a great relief when his father reassured him, "You did the right thing."

His perception is that he understands Americans well, although he claims that he would not talk about "religion and politics with them" yet he would with his "own kind." In spite of this, he finds that, in general, Americans are more tolerant and not as bigoted as people in scotland. America offers "a lot more freedom" to him. He is aware that the system, needs, and conditions are different here. For example, comparing the lot of retired people, he believes that the United States elderly "have it a lot better than the Scots because private pension funds are fair." As a final consideration, although at festive times he misses Scotland, he is content to be in America: "This is our home, where our friends are, where we live." 
Interview Number 5: Mr. and Mrs. R. and R. G.

Age: Mid-forties

Sex: Male and Female

Marital Status: Married to each other; four children

Education: Pre-emigration: She: finished high school

He: left school to become an apprentice painter. Before he left Scotland he had become "a master craftsman."

Self-perception of Personal Qualities: not pushy, friendly, hard working, reliable, determined to be successful.

Year of Emigration: 1957 to Canada: 1960 to U.S.

This married couple emigrated to the United States after having lived in Canada. They lived there for three years and then went back home to scotland, partly because their first baby was due and they wanted him to be born in Scotland.

During their return trip to Scotland, they re-applied for visas, this time to the United States. When they were granted, this couple came directly to Portland from Scotland and have lived in oregon ever since.

They have formed a strong family network since their immigration to this country. Their other three children have been born in oregon and members of their family from Scotland have since emigrated to Portland. They both work, he has recently branched out in his own painting business, 
and she is a secretary.

Reasons for Emigration

To begin with, this couple emigrated to Canada, ostensibly because "everyone was emigrating." Moreover, they believed that North America "offered a better way of life" and that they "would be better off here." Not only promises of increased opportunity prompted their emigration, but the bad weather conditions made life discouraging in scotland: "It was always raining." Promises of "the land of sunshine, of plenty, of big houses.. - of glamour", coupled with the wanderlust, induced them to leave scotland on April Fool's Day, 1957. "We had the wanderlust... we just got it in our blood to come here."

They hastened to add that, although they dreamed of increased opportunities they already "had everything we needed," from two cars to a fine house. They both "earned a lot of money," she as a crane driver, he as a master painter. But, in spite of this, they left for Canada.

Unfortunately, Canada was not what they expected. Vancouver, British Columbia was overcrowded and working conditions were very bad. Housing was even worse. They house they got "was a dump." They "couldn't believe it." The glamor and increased opportunities they had anticipated did not exist for them. So, when their first child was due to be born they went back to scotland. 
It was very coincidental to their lives, that on the initial passage by plane to Canada, the wife had met and made friends with an American woman from Portland, Oregon. She offered them a warm invitation to visit her. While living in Canada, they followed this through and made a trip to Portland. Oregon left a favorable impression on them. The scenery was beautiful, the houses were large and comfortable, the people seemed friendly, work was plentiful and well paid. Because of these considerations, they decided to re-emigrate after their child's birth, this time to oregon.

\section{The Subjective Experience}

Initially, this couple recalled that their impressions of the United States were quite favorable. They lived in a friendly neighborhood where "everybody was young and had children", always "giving tea or coffee." The wife regretfully added, "It has never been the same since."

In spite of this favorable attitude they remembered that some American behaviors annoyed them. For example, as the public transportation system was so poor compared to the Scottish one, the wife had to walk five miles to the stores. What was doubly annoying, though, was that people "who had never seen anyone walking along the roads" stared. Soon, they had two cars, "Just like everybody else."

Although they had their initial American friendship network, they both missed fellow scots. Shortly after their arrival therefore, they joined the scottish clan Mcclay 
"because it was the right thing to do." They claimed that "everyone that was here did it" and they were glad they joined because they "feel more at home with our own kind. . - It's nice to be with someone from home." They made lasting friendships with these Scots. Soon, members of both sides of the family emigrated from scotland, which caused the subjects to "drift away" from American friendships. They both agree that they "could have had more American friends" but they were "always with scots.. . we talk too much to each other." Losing their American friends "was wrong, but in no way prejudiced," they hastened to add.

Their initial enthusiasm for Americans has changed. Conversely, they notice a change in Americans toward them. The husband noticed, for example, in the last five years that Americans who used to work closely with him on the job, leave him "alone. . . to work all by myself." The wife recalls that this was the first year since coming to America that she has been called a foreigner, to her face. One hostile American, at a social function shouted to her, "We ain't god damn foreigners. We are Americans and are god damn proud of it." This hurt her deeply. They both believe that the current poor economic conditions, coupled with the recent influx of refugees, has caused many Americans to harmfully stereotype non-Americans as being a threat to their security. Even the scottish accents that "they used to love" make Americans now think, "Oh, another foreigner." The 
subjects hastened to add, "We aren't refugees--we paid for our passage here."

Over the years, the husband, too, has become disillusioned with his work situation. He believes that he has "lots of worries" in America, but his main worry is his work. In America a man is "paid for time, not craft... time is money. Quality workmanship does not make any difference. A man is not encouraged to do the job right because it's too slow this way." This subject is a master craftsman, highly trained in Scotland, where the philosophy is "I don't care how long it takes you to do it: just do it right." Consequently, he does high quality work and is trained in all the facets of the trade. Because of this, he can do any work. In fact, he has been an instructor in his trade at the community college. This scottish philosophy is in direct opposition to the American one in which "workmanship does not make any difference, as long as the job is done as quickly as possible." Training is highly specialized--one man can do only one job. It is this way, because "thorough training takes too much time. Americans are good at specific jobs, but not good overall."

His worries arise because, although he has never been fired from a job, "Americans want to keep you, but want the work done faster and faster." To him, these conditions "are murder" because "it takes time to do things right." Also, he perceives that, in this recent economic crisis, his fel- 
Low American workers resent he is so flexibie in his skills. Because of his master craftsman training he gets more work while others are laid off. "Now they aren't working and you are... I can see the point why they're jealous."

Nowadays, he and his wife are also disillusioned with the clan system, so much so that they do not attend meetings any more. "It's not working as it is supposed to be." If, as they claim, the overall motto is "A hand to those in need," this has not been honored in their experience. Needy Scots are passed over because of politicing within the societies. Scholarships are given to unneedy Americans and not needy scottish immigrants. And they both despair that the original noble intentions have changed so much. They exclaimed, "Jewish people and Chinese people stick among their own kind like glue, but the Scots don't any more." They only retain membership because of the good commercial insurance policies which are offered to clan members. Sadly, they believe that the clan system in the United States will not survive for long.

Both these subjects had strong positive feelings about Scotland which they feel have increased over time. They have taken many trips back and their impressions are that people are a lot happier there than they are here. "You just have to look at their faces to see how happy they are." This happiness, they attribute to many things. "They are satisfied with how they live." People in Scotland "don't 
worry about making a buck. . they live a simple, plain life. . they have little, but are happy . . they appreciate what they get. . . they know they can't afford many things and look after what they have." To this couple, the "people are great, relaxed, not phoney, and trusting." For example, while this couple was touring scotland with six other people they could not get hotel accommodations in one specific town. A complete stranger took pity on them, let them all stay in her private home over night, fed them breakfast, would not take any money and, as she had to leave early for work, told them, "Don't rush. When you're finished just lock the door behind you." They told me, "You don't get that here." The only thing they found bad about Scotland was the lack of money. "The rest is great." Even the occasional impolitenesses and poor service they received in scotland, they excused by the fact that the scots giving the bad service thought that they were Americans, that Americans are all impolite, and accordingly they behaved impolitely back.

In spite of their favorable impressions of scotland and the people, they regretfully believe they would not go back to live there. Although, when they visit, they "fall right in" to scottish ways. There are times, though, when they wish they could go back permanently. Their feelings are rather ambivalent on this subject. Both say they are "constantly unsettled and homesick" in America, especially 
the husband. Yet, they say they "do not regret coming here." Ideally, they "would like to take this life back to scotland" because they "love the country there" but believe that it is "a wonderful country here as long as you are working and pay your own way."

They have definite attitudes and perceptions about America. They believe "the way of life changes people." Family life is not what they wish it to be. Children, for example, are spoiled. "There is no discipline here--it does not exist." Adults, too, are spoiled. "We buy new T.V.s instead of repairing them. We do not appreciate things . . - neither are we satisfied with what we have. Immigrants come here, happily start with a one bathroom house and pretty soon want to or three bathroom homes... why do I need another toilet?" People learn to be more aggressive in America but also to be more ambitious. The husband believes, "If, in scotland, I had the ambition I learned here, who knows what I'd be doing."

Being in America has created another worry for them: health care. "Medicare isn't worth a nickel." The husband says this because when he regularly visits the sick, as one of his Masonic duties, he becomes angry with the system that makes ill people "cry on my shoulder because of the financial burdens of being sick." He feels very insecure with his own health care insurance coverage, and wishes the 
system would change to the more care-free socialized Scottish system.

Neither has become an American citizen, although both went to evening classes to study for the tests. They say that nobody they knew who took that same class did, in fact, apply for citizenship. Maybe, they surmize, like them "they can't be bothered, or are too busy."

Their overall feelings of unsettledness about their experience is summed up by the husband who said, "I don't know if we've changed, they've changed, or we've all changed. Somebody's changed." 
Interview Number 6: J. W.

Age: 97 Sex: Male

Marital status: Widower (twice): one child.

Education: pre-emigration: Theological Seminary College:

Degree in Theology. Post-emigration: further theological study in America. While on

sabbatical in Scotland this subject continued more theological study in Edinburgh.

Self perception of personal qualities: a modest nature, good adaptor, not quarrelsome, never upset or disturbed. Year of Emigration: 1909

This subject emigrated to Iowa from Scotland after completing training in the Methodist ministry. He was twenty four years old and single. Previous to his theological studies he had lived on his father's dairy farm in the south of Scotland, in Annan, where he and his seven siblings learned all the varied skills of farming including sheep shearing.

Some members of his familiy had already emigrated to America and were very influential in his decision to leave scotland. His mother's sister had married a farmer and both had emigrated to Iowa in 1880. On her death in 1892, his mother's second sister emigrated to care for her dead sister's six children. Soon after, she married her brother-inlaw and they also had six children. They were deeply religious people; consequently, when they heard that J.W. had 
newly graduated as a minister, they gave a strong invitation to him to emigrate to Iowa to become the preacher for the area. Although he had never seen his uncle or his twelve cousins he decided to accept the offer. His own family was highly supportive of his move. They offered "no opposition, but lots of help."

He remembers his journey vividly. He traveled by ship to Boston. From there he traveled through Montreal to Chicago by train and finally landed in the small farming community in Iowa that was to be his home for many years.

He stayed there for three years as the country preacher during which time he accumulated a horse, and eventually, a buggy; a home; and furnishings. Then, after he considered his home was ready he returned to scotland to marry a woman he had met there previously. "In those days," he said, "unless you had a home ready to support a wife, you did not get married." They both returned to America, to the home he had prepared for her and there they lived happily. They had a daughter, born in 1927, but shortly thereafter his wife died. Five years later he married an American woman with whom he lived for forty years until her death in 1976.

He had an extremely "satisfying" and selfless experience as a minister. All in all, he had only seven parishes in Iowa in fifty years. He lived there during World war I and traveled all over the Mid-West "making speeches for liberty bonds." Later on, during the Depression, he was 
appointed to a church of 800 members. The church building had never been finished and the parish was in considerable debt. In order to reduce this debt he developed a form of farming, using hybrid seed corn which, at that time, had not been introduced to the Mid-West. This type of seed was better adapted to the soil but the farmers were "highly superstitious" and were not willing to try any new ideas. Nevertheless, he successfully persuaded them to try, asking them to give a percentage of the proceeds back to the church. He also taught farmers about "what good seeds will do for pig farming" and to this day, generations of healthy, prolific pigs are reared in that area because of his influence. Within five years, the church debt was paid of and hybrid seed corn has become a staple crop of the whole area. "Life" magazine wrote an article on his good works in the Depression, but in his modesty, he disallowed its publication because he "thought it wrong to publish the work of the church."

Because of his business acumen, many companies tempted him to leave the ministry, but he had dedicated his career to the Lord and refused all offers. He said, "Just let me preach."

In spite of his success in raising significant sums of money for the church, as a minister, he made very little money for himself. At one time, as pastor of two churches he earned only $\$ 650$ a year. However, soon he put his child- 
hood farming skills to good financial use. His income was augmented greatly because he sheared sheep as a sideline. He was so fast and adept that in some days he sheared forty sheep. Often he "sheared all the sheep in the community." This, more than anything else, helped him support his family.

His fame as a sheep shearer had spread soon after his arrival in Iowa in the following way. One day a lady asked him to give her a ride to her son's farm, which he gladly did. When he arrived, the lady's son and friends all laughed derisively saying, "Here comes the preacher." Little knowing that his childhood had been spent on a farm in scotland, they challenged him to try to shear a sheep, thinking that they were in for some comedy entertainment." However, that laughter soon changed to respectful praise when he completely sheared the sheep in less than seven minutes. An invitation to dinner was next on the agenda and firm and respectful friendships were established.

He officially retired from the ministry in 1957. However, the value of his work was so considerable that he was asked to continue for another four years. It was after this, in 1961, that he eventually retired to Oregon where he has 1 ived ever since. He now lives with his daughter and her family, and spends his days in reading, studying the bible, and meditating. 


\section{Reasons for Emigration}

He was quite dissatisfied with life in Great Britain. Although his childhood had been an extremely happy one, the crass snobbery of the society, which even extended into the ministry, alarmed and displeased him. He firmly believed in egalitarian ideas and was offended by a social system such as this: "I was pretty well disgusted with the upper class - . there was too much class distinction."

But if this society displeased him, another one attracted him. He remembers that while he was in theological school, recruiters from Canada came to speak to young prospects. The descriptions they gave of the way of life, of the land and of the people of North America intrigued him. Therefore, when his uncle and aunt in Iowa proposed that he go there, he immediately made plans for the trip.

\section{The Subjective Experience}

Becoming a minister changed this subject's whole life because "it gave me the opportunity to come to America." In spite of the primitive conditions he initially encountered, he said, "I loved America from the first time I saw it." He came to a state where there were no paved roads and where most of his transportation was by foot along dirt or mud tracks. He remembers one of the most outstanding experiences at that time was when he bought his first horse for $\$ 50.00$ at a horse auction. This enabled him, from that time 
on, to visit more of his scattered parishioners more often. A while later, he added a buggy, and his joy was complete.

He came to a large kinship network. His cousins welcomed him "as one of their own." The fact that "I had too many relatives here who came ahead of me before I was born" made his initial connection to the United States pleasant. He recalled that he "never felt alone" and adapted "so quickly" to his new situation "that it was unbelievable."

When he arrived here he thought it would be just like home but found it quite different. "Even writing by mail did not give me any notion of the differences." The most surprising difference to him was the English language. The language, which he assumed would be the same was, in fact, "quite different." He remembers often misusing vocabulary and saying the wrong thing. However, he "was not afraid to ask for help" and soon learned the correct way. He was much impressed at that time by the vigor of the people and he always felt "in the right place, even though my folks were in scotland." He was amazed, and still is, by the "pretty prosperous ongoing way of life" and marvelled at how quickly things got done.

He claims that he never suffered feelings of loneliness: "People made me so welcome and loved me so much that I never felt lonely." Initially, his friendship network comprised his cousins and their families and his parishioners, both American and foreign. Many of the parishioners came 
from Sweden and Norway, and particularly Denmark, "Lots of Danes, they're very fine people." His parishioners were varied in their experiences, too. Some of them were pioneers. He "hit the tail end of the pioneer days" and some of them "were alive from the civil war." Consequently, he believes there was "a strong cameraderie. . . solidarity . - many things in common."

To augment this network of support came his sister. She joined him a year after his immigration to function as his house keeper until he married two years later. Even his parents followed, although at a much later date. When they were seventy years old, because of his enthusiasm for North America, they emigrated to Canada and homesteaded a large farm area there. He exclaimed that he was always surrounded by supportive people.

This did not mean that everything was perfect. A couple of experiences were distasteful to him, especially when one person told him to go back where he came from. But he overcame these types of problems by using his formula for dealing with interpersonal problems, namely, he did not quarrel. "They could complain all they wanted but I never got upset or disturbed." He added, "I am happy to say I have been very kindly and helpfully received.. . I have nothing else but friends."

In 1920 he decided to become a citizen. He was turned down the first time he applied because he had made a trip 
out of the country which interfered with the residency requirements for aliens. But, undaunted, he reapplied after the appropriate time had elapsed and was granted citizenship. He believes that "one of the most wonderful things is to have United States citizenship.. . one needs to be part of the country." In fact, his attitude is so strong that he said immigrants who do not want to become citizens "would be better to go back home again."

All in all, this subject feels he has had a very positive immigration experience. To him, America is a country where he could escape the cloying class system and the snobbery of Scotland; where "kings and queens do not exist"; where "good things happen" and where "opportunity, even yet, is waiting to be taken up and used." It is a land "where all fancy notions go with the wind" and where simplicity and explicitness are the strength of the people. He sums up his experience in America with the following story. He speaks of the time when he retired from the ministry. After delivering his speech, as he walked down the aisle, someone grabbed his arm and inquired, "Mr. W., would you do it again if you had to?" He proudly replied, "Yes, I sure would do it all again." 
Interview Number 7: E. G.

Age: late thirties

Sex: male

Marital Status: married to a Hawaiian; one child;

divorced from an American; one child.

Education - pre-emigration: this subject graduated from the Glasgow School of Art, Cumma Sum Laude. He specialized in sculpting, photography and cinema making.

post-emigration: his scholarship and creative talents enabled him to secure a Fulbright Scholarship to the University of Chicago, where he completed a Masters of Fine Arts.

Self perception of personal qualities: lots of integrity; faith in mankind; insatiable curiosity; an appreciation of the quality of life in which quality is defined as "a recognition of mankind, an acceptance of what I find . . a hygienic environment with clean living, neither aesthetic or fashionable, but with healthy people and good food;" a belief that he has a great deal to offer, however, "I am not giving America my energy; I'm giving the world my energy."

Year of Emigration: 1969

Initially, this subject came to chicago as a participant in the Fulbright Scholarship program. He remained in 
that city for the two years he took to complete his degree. His overall goal in coming to America was "to go and try anything." However, his immediate goal was to obtain a degree. This tied him into a two year's program but his general expectations for his "self imposed exile" were not measured in a time sense: length of time was mutable to him and he was open to new experiences and any future development that his life might take.

In Chicago he had "a new experience in art." Before going there he had wanted to "break with traditional art styles" and he, indeed, found that chicago changed his style. There, he dealt with "words, film images, and conceptual art" rather than traditional considerations. He felt free to explore new concepts, new relationships, new media, new angles. He questioned structural compositions, discovering new designs of gravity, of color, and devising new balances. Of particular interest to him was the law of Entropy. His desire as an artist was to apply this law to art. The law, which deals with change and balance, was translated into art by his building of a huge plexiglass structure into which different colored marbles were poured in unmixed units of color. The different colors created the balance. Some combinations of color did balance, some did not. The importance was to find what did, in fact, make the balance. The prototype plexiglass structure, built for his 
degree program, is still in use today but has been added to and experimented with further.

While in Chicago other personal developments took place; he married an American woman. After he received his degree, both he and his wife travelled extensively, as far as Colorado, Texas, and the Northwest States. During this time he gave lectures on sculpture and art, in various universities and colleges throughout these states. One of his assignments was as a visiting lecturer in fine arts at the University of Oregon at Eugene. This proved to be so successful that he was offered a permanent position on the faculty, which he accepted. To him, Oregon had the type of environment that was healthy. It also signified "a land of various opportunity." Compared to Chicago, which was "quite horrible" with its pollutants, and dead fish floating in the lake, "Oregon seemed like a paradise."

Unfortunately, he found it somewhat disappointing. "It did not offer any big change after all." The country side might have been desirous, but the cultural stimulant was missing. In retrospect and comparison, the art work and possibilities in Chicago "were phenomenal." After a short time in oregon, he decided to return to scotland "to live off the land." In other words, he wished to become a selfsufficient farmer, while at the same time devoting himself to his art. After two years of living like this in scotland, in a remote farming area, he decided to return to 
oregon. He believes that he could have stayed there, but his wife missed the United States and was persuasive in her appeals for their return.

As he had a desire to experiment and work with wood, the thought of returning to oregon was quite seductive: wood fascinated him and he wanted "to see how things are built." Oregon offered a wide variety of woods and plenty of opportunities for experimentation. And so he returned.

Since his return, he has devoted himself to furniture building and has developed a reputation as a master wood artist and craftsman. He also teaches his craft to others. He divorced his first wife and now lives with his new partner, of Japanese-Hawaiian culture and their baby daughter.

\section{Reasons for Emigration}

This subject believes that his overall reason for his emigration to the United States was self growth. He claims his philosophy of life is holistic, "in which I see things as parts of the whole instead of individual pieces." To stay in scotland would have been tantamount to denying access to the whole, to remaining fragmented. He said, "I wanted more than I had in Scotland and looked to America." Having just finished a glowing career as an art student and graduating with the highest distinctions from his college, all that faced him was a job offer from the same college. He felt that would be a step back, artistically and growthfully, "I need more, I've got to go out and find out how to 
do things." He had "outgrown ruby academia" and realized that there were "limitations within the structure of Scotland." His perception of why Scots, in general, emigrate echoed his own personal reasons: "scotland could not contain the emigrants. Their minds were broader than the traditions, and therefore they had to go abroad." In the same vein, he believes that people who are "the top of the class have to go to other countries."

Being himself in this position as the most outstanding student in his graduating class he "moved" (as he prefers to call "emigration") because he "needed more information than what they could give me in Scotland." He chose the United States over Europe because he knew this "information" was not available in the form he sought. He had travelled extensively, especially to France and Spain, and found the same traditional influences that were alive in Scotland. On the other hand, the art scene in America of the late 60's fascinated him. At that time "the United States was powerful in art," especially in a field of his interest, mediaized art. He, therefore, decided to apply for a Fulbright scholarship which he readily received. He came to America and stayed for several years.

As previously stated, after a few years he went back to scotland to settle, but it did not work out. He returned to America. Apart from his personal family considerations, his reasons for returning to the United States included the 
bad weather in scotland, the "freedom in oregon with its aesthetic sensibilities" and ultimately the thought that "it's easier to live in oregon.. . I can achieve more things over here." Here, he can work in the medium he wishes, maintain his artistic and aesthetic integrity while, at the same time, make a good living.

\section{Subjective Experience}

This subject recalls that his initial contact with America, in Chicago, was a time of high expectations mixed with confusions. First of all, he half expected the United States to be like "John wayne country, with wide open spaces, clear blue skies, and clean pure air." However, that was not to be in Chicago. He was horrified by the rampant pollution he encountered, by the dead fish around the lake, the hot dusty environment, the very large ugly cars, and "everybody going somewhere but I could not figure out where." He also was "totally abhorred [sic] by suburbia. "Suburbia, suburbia . . absurdia."

Although on his immediate arrival he lived with relatives in a chicago suburb, he "couldn't handle being in a house that looked like every other house.. . and being shown off as a conversation piece." Therefore, after only a week and a half of this "callous insensibility" he moved out never to return. This experience left such a bad taste in his mouth that he severed all further contact with his only relatives in America. 
His impressions "at that time were mind boggling. I was abhorred with what I was doing." First of all, his self concept in his artistic mileau suffered. "I changed from being the biggest fish in the sea to the smallest." He suffered physiological changes, too. "My nose bled for ages. I was very quiet. I walked and walked through the streets and around the lake.. . It took me six weeks to even find a mail box."

This period of questioning and abhorrance eventually "worked out after a time span of nine months." During this span he creatively chanelled his activities into his art work although, he believes "it took me quite a while to become productive." For instance, as an expression of his awareness of his feelings, he took a series of photographs of the city showing the pollution, the lake and the dead fish. He also created plexiglass cubes showing the horrors of pollution. "I think showing the pollution was an expression of my awareness, a retiring into myself." In other words, this period of obvious culture shock became important to his creative development and personal growth. The frustrations and horrors that this subject encountered were positively integrated into his artistic experience. In an attempt to cope with his sojourn experience he translated the unknowns and the abhorred into something he understood --his art. 
A further evidence of this creative channeling of his frustrations can be seen in how he dealt with his initial disappointment that Chicago was not what he had pictured America to be like. On finding that it was not like the "romantic cowboy and Indian depiction of America " that Hollywood exports, that there were "no wide open spaces. • - I took myself West to find out the true West." He was granted an independent study to Montana. There, he "lived with six horses for six months. . I learned how to be a cowboy" including lassooing and horseback riding. At the same time, he gave his experience an artistic expression in media form. This proved to be an artistically and psychologically positive experience and when he returned to Chicago, he was ready to continue his art degree work.

At no time during this initial "moving" experience did this subject feel a need or desire to be with fellow scots. In fact, his friendship network comprised mainly Americans whose interests were the same as his. To him, "It is interesting to meet new people." He "mixed with Americans" in his classes and all shared a common "new experience of art." He recalls that he had lots of fun . . made movies

- . and never felt like a foreigner" although he decried people's "inability to hear what I was saying" as far as his accent was concerned. This prompted him to "quickly pick up the vernacular for use in certain situations and to use very careful English for others . . I learned to juggle the 
language." He eventually married an American woman and graduated from the University of Chicago.

From Chicago he moved to Oregon. His position in Eugene as professor in fine arts was very successful. Nowadays he continues his teaching in Portland in a private capacity, devoting most of his time to his creative wood works. Teaching, to him, is "having to teach what you believe in. It must pull people out of the ordinary, and channel them to new ideas and philosophies. Students are too much cushioned by school. As a teacher, I have a responsibility to show them as many avenues as possible."

This sense of responsibility expands beyond his students, oregon, and even beyond the United States. He maintains that he has to "look to the world. . how all people contribute to it, and I to them." His art experience in Entropy and balance has perhaps contributed to this life philosophy. He does not "do things for myself" but rather feels he "should satisfy my own balance in the crowd of humanity." He feels comfortable with the crowd he speaks of, "I feel comfortable with all people, regardless of their nationality or profession." To him, people are not predominantly Scottish or American, but are individuals.

As far as his relationship to scotland and scots is concerned, he maintains "zippo" contact with scots because he has his "own rhythms and interests." However, he continues his interest in Scottish cultural aspects including the 
music and attending the local Highland Games. Moreover, he has a positive attitude towards the essence of scottishness. He believes that scottish people, as a whole, are "introspective, quiet until well oiled, respectful of nature and its power. . capable of immense true love... very fair - . don't ask too much out of life." He added that he "would be proud to know scottish people because of their integrity and perception . . I'd count on them."

Nevertheless, his contact with family and friends in scotland is "once every six months, by mail" although he "thinks about them deliberately, fondly and still [has] strong emotional ties to them." However, he feels his "life is too full for sadness or regrets."

Although he has strong positive feelings about the United States, American citizenship "does not mean anything, short of a political reason. It has no advantage." He is "happy to be a Scot living in America." In Oregon, he is "immensely satisfied" with his life which has "shown real progress." Although he believes that "I should be making more money - . but my means get met" there is a sense of happiness in that "I am doing what I want to do." This satisfaction encompasses "my good circle of solid friends . . my good life."

Oregon has enabled him to live the good life he seeks but he also wishes to enrich his artistic and life experience beyond the united states. He does not like to be 
locked into a "finite life style." Instead, he prefers "an infinite life," which, for the moment is more accessible in oregon and more suitable to his needs. However, although Oregon has given him the freedom to pursue this life style, he believes that he has much to offer other societies and nations, and they him. In turn, he can satiate some of his driving curiosity and learn more from them. He maintains, "I am a global traveller. I belong to the world." 


\section{CHAPTER V}

\section{ANALYSIS}

In this chapter the preceding interviews are analyzed. First, the subjective experiences of the subjects are discussed according to the six conditions in the Framework of Acculturation. This includes the conditions of transition, adjustment, identification, biculturalism, multiculturalism, assimilation. Second, an analysis of the effect of intraand inter-ethnic communication on the acculturation process is presented. Finally, several limitations of the study are noted.

\section{ANALYSIS OF THE SUBJECTIVE EXPERIENCE ACCORDING TO THE FRAMEWORK OF ACCULTURATION}

The data in the previous chapter were gathered by means of the individual oral history conversation. The interview strategy was to induce the subjects to focus on stories and perceptions connected with their experiences in the United States, including the extent of their intra- and inter-ethnic communication. The subjects were encouraged to develop their remembrances with as much detail as possible. 
A typical sequence of questions, interspersed with the answers, may have included the essence of, for example, question number 19. On the interview schedule it reads: Remembered reactions to the new cultural setting and whether they have continued. However, in order to probe the memory, this question may have been worded, "Do you remember how you felt when you arrived in the United States? Why do you think you felt that way? Do you still feel that way? Why or why not?"

Each interview was transcribed and edited into the narrative as presented in chapter 4. As the purpose of the conversations was to clarify the phenomenological based Framework of Acculturation, information deemed not pertaining directly was omitted in chapter 4.

\section{Transition}

Transition is a condition of acculturation in which an immigrant experiences:

1. Change and uncertainty in the host culture

2. Feelings of alienation toward the host culture

3. Feelings that intra-ethnic relationships are important

4. Increased positive relationship for the home culture If, according to the explanation in the Framework, transition is a condition in which culture shock, uncertainty and alienation occur, all the subjects of this study 
experienced transition. Subject number 6 , who immigrated in 1909, did not explicitly report feelings of alienation, however it is perhaps significant that he immediately sent for his sister to be his housekeeper and devoted much of his time to making a house ready for his scottish bride-to-be. Perhaps this activity was his way of coping with the transitional condition, and of construing his situation so that he would be near familiar faces. However, his recollections did not include any memories of alienation. With this exception, all subjects agreed that their transitional condition had been fraught with difficulties. Subject number 3, for example, was incarcerated in Ellis Island. All suffered feelings of loneliness, vulnerability, and a need for human relationships, whether inter- or intra-ethnic.

All had to reconstruct their interpersonal field, especially the four unmarried subjects. Subjects 1 through 5 sought intra-ethnic relationships. Subjects number 3, 4, and 5 joined the Scottish Clans. Subjects 1 through 6 found informal networks with fellow scots or fellow immigrants. subject number 1 on immediate arrival had strong positive feelings for the host culture but when she found it difficult to make American friends her attitude switched to alienation from the host culture. She, instead befriended, fellow immigrants.

The stresses of this condition included economic adjustment which, for some, increased feelings of aliena- 
tion. For example, subjects number 3 through 6 reported that the economic benefits were not increased as they had anticipated pre-emigration, but fell to a reduced level. Adjustment to changed living conditions contributed to stress. For example, all subjects, with the exception of number 1 , reported discomfort with housing and accomodations. Subjects number 5 berated the different and inconvenient transportation system. Both subjects 1 and 5 were greatly displeased with the medical system, and continue to be so.

The transitional condition found subjects 2 and 7 alienated, but they construed this experience positively through creative activities.

Another problem of the transition condition for four subjects was found in the language. Even though Scots and Americans are linguistically similar, some vocabulary is different or has different meanings, the dialect, accent and nonverbal behaviors carry different or interfering messages. The Scottish speech may be strange to the listener's ears, and often, host culture members listen to the paralanguage instead of the intended message, or misconstrue nonverbal behaviors. It is important to note from this that, in spite of being able to speak and understand the host culture language the stresses of cultural adjustment occurred for subjects in this study. 
overall, the remembered perception of transitional acculturation was of loneliness, discouragement, and feelings of nostalgia for the home culture for most of the subjects of this thesis.

In spite of the fact that all of the subjects claimed disenchantment with the home culture and that they left scotland because of dissatisfaction with the home culture and its people, they experienced stress and feelings of alienation in the host culture. For example, subjects 1, 3, 6, and 7 said that, in retrospect, they could not tolerate the bigotry or narrow mindedness of the people of the home culture. Subjects $1,3,4$, and 5 mentioned intolerable conditions stemming from World War II. Subjects 1 and 5 also included bad weather condition. All looked forward to living in a new country. And yet all experienced feelings of alienation from the host culture.

Positive self-perception did not help to alleviate feelings of disenchantment either. Feelings of alienation to the host culture arose in spite of the fact that the subjects eagerly anticipated their new experience with feelings of expectancy and curiousity and also in spite of the fact that they perceived themselves as possessing adaptive qualities, ranging from flexibility to courageousness: three subjects mentioned curiousity; three said they were adventurous others said they were "open to change," "good adaptors," and "friendly." 
The sense of alienation was so strong that several subjects reported that they would have returned home had they had the chance. However, pride and a need to prove something to themselves, were stronger than homesickness and perhaps kept them from returning to the home culture. Perhaps the intra-ethnic support and example of established fellow immigrants also influenced some of them to stay.

All subjects, therefore, experienced this condition of transition and its concomitant feeling of alienation. Some stated clearly that this condition lasted a definite time: subject 1 said five years; number 2, two years; number 3, a year and a half; number 4, three years in Canada; number 5 , two years in Canada; number 7, nine months. From this we see there was no uniformity of time in this condition for the immigrants of this study.

Although these subjects experienced alienation, bad times, poor economic conditions and loneliness, with the definite exception of number 5, and perhaps number 1 , they have perceived their overall acculturation experience as being successful. Therefore, initial alienation from the host society in the form of culture shock, loneliness, or unpleasant experiences is not a predictor of future unsuccessful acculturation: successful acculturation does occur in spite of initial culture shock, loneliness, or unpleasant experiences. 
Subjects number 5 had lately experienced host culture hostility which they specifically stated is caused by the recent high unemployment and economic problems in the host culture. They have switched back to this condition of transition and feelings of alienation, although they expressed that they, at one time, had strong positive feelings toward the host culture. Their sense of alienation bordered on marginality and will be discussed in the next section.

\section{Adjustment to the Host Culture}

Adjustment is a condition of acculturation in which an immigrant experiences :

1. Feelings of cultural ambivalence

2. The progress of inter-ethnic relationships

3. Meaningful intra-ethnic relationships

Adjustment to the host culture is a condition in which marginality may occur. According to the subjects of this study, two have had definite experiences of marginality, and continue to be marginal. Subjects number 1 and 5 have shifted to other conditions but have shifted back to this condition.

First, consider subject number 1 . She displayed an amibivalence of relationship to both home and host culture. In spite of her acculturation experience of twenty four years, the United States did not satisfy her. On the other hand, she knew the United Kingdom, with its "bigots" and "bad weather" would not satisfy her either. Although she 
was ambivalent to the United States she had channeled her energies into obtaining a college degree, had travelled extensively throughout the world, and was an avid reader. She was aware of cultural differences, but could not accept American social conditions and governmental attitudes. Her marginality was permeable and sometimes shifted into the Identification phase of the Acculturation Framework, because, in spite of her strong criticisms, she had certain strong positive feelings for the United States. However, she still felt out of place, like a foreigner, and clung to her British citizenship. In this subject's case, nevertheless, marginality was not dysfunctional. She led an active and productive life in the United States and yet possessed such self-awareness to say that she was "culturally in the middle" between the home and the host cultures. This subject supports the phenomenological process perspective that acculturation is not a lock-step development.

subjects number 5 also experienced marginality, but they experienced a strong sense of alienation from the home culture. They arrived in the United States twenty one years ago, and from their description it appeared evident that they had undergone transition, shifted into adjustment, into identification with its feelings of integration into the host society, and had shifted back, in the last five years, into the adjustment period. Presently, they experienced a sense of withdrawal, a loss of self esteem, and negative 
reactions to the United States and its people. This sense was so strong that perhaps they might have already shifted to the transitional condition, as previously mentioned. They showed a marked strong relationship to the home culture and yet their feelings for that culture were tinged with ambivalence. They realized they would never go back there to live, and disliked the narrow-minded people. They were pragmatically aware that they have to remain in the host culture. Subjects number 5 supported the view that acculturation is not a linear progression because they have shifted back to earlier conditions of acculturation.

Neither subject number 1 , nor subjects 5 have become citizens, in spite of their many years in the country. However, subjects 2,4 , and 6 have embraced United States citizenship. Because they reported strong positive feelings for the United States perhaps it could be said that the commitment of citizenship tends to create strong positive feelings towards the host culture. On the other hand, of course, strong positive feelings towards the host culture tend to make one willing to become a citizen. It would be interesting to know which preceded which. Unfortunately, the experience of subject number 7 , the other non-citizen, is no clue to the answer. He has very strong positive feelings for the United States and yet sees no reason to become a citizen. He claims he is is globally minded and feels a commitment to the world. No other non-citizen felt this way. I suggest 
that the strong positive feelings precede citizenship and that the factor of citizenship creates a commitment to maintaining a positive relationship with the host culture. Citizenship could be said to be a bonding factor.

\section{Identification with the Host Culture}

Identification with the host culture is a condition of acculturation in which an immigrant experiences:

1. A strong relationship with the host culture

2. A decreased activity relative to the home culture

Three of the subjects were presently experiencing this condition of identification with the host culture. Subjects number 3,4 , and 6 felt that their relationships with the host culture were strong. Each had different attitudes toward the home culture. However, none of these different attitudes were as strong as to the host culture. All felt a sense of belonging to and integration with the host culture and perceived that they understood much of the underlying structure of the host culture. They were proud of their American citizenship and severely chided immigrants who were not citizens.

Friendships with host culture members varied in degrees of intimacy. They felt a great sense of satisfaction with their experience in the host culture and agreed that, although they had some ties to the home culture that could never be broken, they were happy to be Americans. All reported, for example, that no matter how glad they were to 
visit scotland, they were even happier to return to the United States from trips to scotland. They felt an extremely strong sense of satisfaction with America because of the opportunities they had experienced in the United States.

This satisfaction with the host culture does not detract from their strong Scottish identity, however. Subject number 4 is tremendously active in scottish clans and societies in the United States, and has a friendship network comprising mainly scots. His attitudes toward home and host culture contained elements of biculturalism because he switched situationally between home and host cultures. However, he felt a strong relationship to America and said that he would not go back to Scotland to live.

subject number 3 chose his relationships inter-ethnically, rather than intra-ethnically and also had very positive feelings for the United States. Subject number 6, who had been in this country since 1909, felt a certain sense of loyalty to the home culture, however, his loyalties to the United States took precedence.

The subjects mentioned in this section were extremely comfortable in their adopted land. It is clear from these subjects that the condition of adjustment did not neccesitate a rejection of the home culture.

\section{Biculturalism}

Biculturalism is a condition of acculturation in which an immigrant experiences: 
1. A strong relationship with the host culture

2. A strong relationship with the home culture

No subjects in this study appeared to be completely bicultural. As mentioned previously, subject number 4 had elements of biculturalism because his friendship networks were very Scottish in their character, and yet he was a fulIy functioning member of the American society. However, he claimed a very strong allegiance to the United states and was relieved to return back to the states, where he felt much more "at home." This subject shifted back and forth between conditions of biculturalism and identification with the host culture. However, the latter condition prevailed. This subject's situational behavior would support the process view that conditions of acculturation are not static or fixed, but are permeable and situational.

\section{Multiculturalism}

Multiculturalism is a condition of acculturation in which an immigrant experiences:

1. A strong relationship with the home culture

2. A strong relationship with the host culture

3. Strong relationships with other cultures

Subjects number 2 and number 7 were multicultural in their attitudes. These subjects were not bicultural because their cultural awareness stretched beyond the Unites States and scotland. Each revealed more than a strong relationship to two cultural realities. 
In other words, both subjects number 2 and 7 had the properties of the multicultural person. Number 7 explicitly said his world view was global and that his mission in life was to benefit all mankind. In this same vein, subject number 2 believed his teaching provides "a different and valuable point of view" and did not feel as if he belonged to any distinct ethnic group. He claimed he fits in with any cultural group. Of course, this ability was greatly aided by his fluency in several languages, his considerable knowledge of the folk music of these countries, and his continued scholarship in studying about them.

Both enjoyed cultural differences. One was married to an Italian-American, and the other, currently to a Hawaiian, and formerly to a Jewish-American. Both maintained a pride in their home culture and recognized that they were influenced by it. However, they were objective about their home culture. Both enjoyed living in the United States but would not mind living in other parts of the world to achieve new dimensions. One was a citizen of the United States; a "bona fide American," the other was not; a "citizen of the world." Both were creative, one as an artist and teacher, the other as a musician and teacher. Both have stated that leaving scotland, although traumatic in the beginning, was growthful and progressive for their life experience.

Both have continued improving their life experience by participating in higher education in the United States, one 
receiving his M.F.A.; the other, his B.A., M.A. and J.D. Perhaps this last factor of the pursuit of higher education, plus these subjects' self-perception of qualities such as "curious," their creative abilities, and their positive reaction to their acculturation experience have enabled them to achieve the personal growth that is necessary to become a multicultural person. As subject number 2 said, living in America has enabled him "to change my life's philosophy: to be willing to consider new values, new philosophies."

Because of the multicultural nature of these subjects, they were able to shift back and forth into other conditions of the acculturation process, such as identification with the host culture and biculturalism.

\section{Assimilation}

Assimilation is a condition of acculturation in which an immigrant experiences:

1. No relationship with home culture

2. Complete relationship with host culture

No subjects in this study exhibited the condition of assimilation, as defined in this study.

THE EFFECT OF COMMUNICATION ON ACCULTURATION

One purpose of this present study is to describe the influence of intra- and inter-ethnic communication on the process of the acculturation of the particular group of Scot- 
tish immigrants because, if acculturation is viewed from a phenomenological relational perspective, communication is a vehicle through which acculturation operates.

It was found that intra-ethnic communication was initially influential to all subjects, except number 7 . This subject's main network of support was derived from people in his area of interest, namely, art. What mattered to him was not nationality but a specialized field of interest. Nonparticipation in intra-ethnic communication, however, did not mean a decrease in his intrinsic high value of his own scottishness. From the remaining interviews, intra-ethnic communication, relationships and support, were indeed important to the Scottish immigrants and, in several cases, such as subjects 2,4 and 5 , did not diminish.

This intra-ethnic communication varied in style from formal to informal. As far as formal networks were concerned, for subjects 3,4 and 5 it meant joining the clans and scottish societies available in the area. Although these subjects had also some informal American support at the beginning of their experience, they reported that they had more of a desire to communicate with fellow scots. The Clans fulfilled this need.

The Clans and societies are unique institutions. Meeting are highly ritualized; membership is restricted to proof of Scottish ethnicity. The clan ritual ranges from secret pass-words and hand shakes to symbolic dress, ceremonial sym- 
bols, rituals, and a distinct heirarchical structure. In subject number 4's data the original benevolent functions of the Clans are described. Recently, however, the Scottish societies and clans have changed in their overall structure: changing immigration patterns and immigration needs in contemporary life have created a changing organization. Unfortunately, too, many of the Scottish societies and aid groups of the Northwest are declining, not because of lack of enthusiasm, but because scottish immigration has been significantly reduced in the last decade.

Societies, such as the St. Andrew's Society and the Clan societies, have changed from the originally intended insurance and aid societies for fellow Scots. Now the emphasis is more socially defined, although scholarships and financial aid are still given, if the need arises.

Another change is the type of membership, from immediate immigrants to a generational group. According to subject number 4 , some members of these societies are second or third generation scots. This has caused cliques, such as the American-Scots or the Scots born in Scotland.

This discussion of the changing nature of the formal institutions supports the phenomenological process perspective that ethnic institutions are flexibly construed and reconstrued to meet the changing experiences of the society and the changing needs of the immigrants. 
Nevertheless, according to the people in this study who were, or still are, connected with the societies, Scottish societies were influential in the acculturation process of the still predominantly immigrant membership because the societies acted as a buffer and a guide to the host culture while enabling the immigrants to maintain an identity with the home culture.

Within the formal societies, informal friendship relationships were found. It was in this social group that subjects number $2,3,4$ and 5 established friendships with fellow scots. It appeared that the sociability and friendship found in these groups softened the pain of being uprooted from the home culture and of the confusing changes taking place in the immigrants' new lives.

For some immigrants, the formal societies therefore, were indispensible for their process of adjustment to the United states. Several immigrants in the study provided help and encouragement for newer immigrants. Subject number 4 is an outstanding example of this. He found strong informal relationships in the clan and is now active in helping new members. Subjects number 5 , although mainly inactive as Clan members now, still aid new immigrants.

It is perhaps significant that subjects 3,4 and 5 , who drew their intimate friendship relationships with other scottish immigrants, had no family already established in Oregon: to them the clan became a surrogate family. Number 
3 has dropped all association with the Clans for personal reasons. Although he maintains a few Scottish relationships, his intimate network has always included people who share the same hobbies and interests. Now, for him, common interest takes precedent over ethnicity.

A diminishing interest in Scottish ethnicity was not evident in subjects 4 and 5 . These subjects had maintained the closest ties with the formal clan system and had also the closest informal relationships with Scottish people. These are the only subjects married to fellow scots. Subjects number 5 had four children and family members who emigrated to join them. Since then, their ties to the formal institutions had weakened, although not completely vanished. Perhaps the family support they received diminished the need for the support that the Clan provided.

The other subjects, with marital status ranging from unmarried to marriage with a partner from England, America, and Hawai had no such close intra-ethnic relationships to fellow scots to such a high degree of commitment. Perhaps these subjects have changed their perception of the importance of intra-ethnic relationships in their lives and have responded to their acculturation experience by modifying their relationships to include important inter-ethnic relationships.

Intra-ethnic relationships were also modified by some immigrants who extended invitations to their own families 
still in scotland. Subjects number 2,5 and 6 felt so positive about their acculturation experience that many members of their families followed them to North America and thus created more immediate intra-ethnic relationships. Although subjects number 5 have become recently disillusioned and unhappy by their experience, members of their family arrived long before this occurred. Their unhappiness, therefore, probably does not stem from lack of support or from lack of intra-ethnic relationships. With one exception, then, to the scottish immigrants of this study, intra-ethnic communication was a positive component in their acculturation process, whether formal or informal. As subject number 4 said, "I don't know where we would have been without it."

One consistency in these intra-ethnic findings is that most all subjects have maintained, in varying degrees, their Scottish network of friends, with the exception of subject number 7, who never had any, in the first place. Those who are strong Clan members, however, have the largest and most continuous relationships intra-ethnically excluding family members.

The process of adjustment to the host culture was modified also by inter-ethnic relationships for the subjects of this study. Most people had branched out inter-ethnically to include relationships with Americans and particularly with immigrants of other ethnic groups. This latter finding is significant: all subjects, with the exception of 4 and 
5, have formed strong interpersonal relationships with immigrants from ethnic groups different from their own. Perhaps commonality of the immigration experience is a strong relational or bonding factor for immigrants and the "arm to lean on" that Handlin (1974, p.152) speaks of, may well come from inter-ethnic fellow immigrant sources, as well as intra-ethnic ones.

If this is the case, it would tend to bear out part of Sarna's (1978) ascription theory previously mentioned (page 18) but, at the same time, broaden it to include immigrants from other ethnic backgrounds. Sarna tells us that an immigrant is categorized and ascribed membership by the host culture, in broadly defined terms, as belonging to a particular ethnic group. However, according to this study of Scottish immigrants, the terms would be so broadly defined that the membership ascribed would not be to the immigrant's own ethnic group, but to the very generalized group of "immigrant." Sarna continues the ascription theory, claiming that host culture ascription awakens ethnic awareness in the immigrant and drives him into his own ethnic enclave. However, from this study of scottish immigrants the host culture ascription is so very broadly defined that immigrants are driven into establishing relationships with those undergoing the same experience, whether or not from their own ethnic background. This might explain why often at informal functions such as ballroom dances sponsored by German/Swiss 
clubs, one can find a mixture of British, Mexican, Latvian, Yugoslavian, Scandinavian and Russian emigres, as well as Germans. Likewise, at Scottish informal functions and parties one meets immigrants from countries including Ireland, Latin America, Spain, Italy, Germany and so on. Not only do they share a common cultural activity not readily available in the culture of the United States, such as ballroom dancing, but they share the commonality of the immigration experience.

To be sure, the Scottish immigrants in this study had established intimate relationships extending beyond the boundaries of any one particular group. Subjects number 1 , $2,3,6$, and 7 numbered relationships with immigrants from different cultures. All of the subjects, with the exception of subject number 7 , had maintained intimate relationships with fellow scots. This is not to say that these subjects were bicultural or multicultural. Rather, in phenomenological terms, it shows that they increased opportunities for forming relationships according to the situation and to needs.

This matter of friendship networks with immigrants from different cultures showed flexibility on the part of the immigrants of this study. Rather than being forced into one particular group, they accommodated to the situation by broadening their opportunities for interpersonal relationships. If viewed phenomenologically, in situational terms, 
it shows that the immigrants accommodated to the new situation by not being locked into intra-ethnic relationships. Rather, they were flexible and creative enough to avail themselves of new experiences and opportunities. The fact that the subjects gravitated to fellow immigrants would also illustrate Kelly's (1963) Commonality Corollary, mentioned previously. Kelly contends that people like to be with people because they construe their experiences in the same way.

For the immigrants of this study who have formed friendship networks with immigrants from different cultures, it was not as much the experience of common ethnicity as the common experience of immigration. Moreover, this contention of Kelly's, extrapolated further, would explain the relational network of subjects number 3 and 7 . They liked to be with people construing the experience of art, photography, or sports rather than either ethnicity or immigration.

Another factor relating to intra-ethnic communication bears mentioning. In chapter 2 , it was noted that shibutani and Kwan (1965) state that intra-ethnic communication is a hindrance to acculturation because it strengthens ethnicity and also reduces participation in host culture communication. If we consider ethnic identity and the claim that it is strenghtened by intra-ethnic communication, in this study of Scottish immigrants we see that they have maintained a strong ethnic identity whether or not they participated in intra-ethnic communication. Even subject number 7, who 
avoided intra-ethnic communication and participated in inter-ethnic relationships had a strong scottish identity.

others who had both intra- and inter-ethnic relationships had strong ethnic identities as well. Subject number 3, whose friendship networks were inter-ethnic, also perceived himself to possess a strong ethnic identity. Subject number 2, who was married to an American, had many interethnic relationships and described himself as "a bona fide American," highly valued his scottish ethnicity. In the same vein, subject number 6 who had strong inter-ethnic relationships reported a continued strong identity with his scottish ethnicity, even though he had lived in the United States for more than seventy-three years. In other words, it is apparent that, for the subjects of this study, a strong ethnic identity occurs with or without intra-ethnic communication. Perhaps one could say that the act of emigration itself strengthened these subjects' ethnicity rather than the intra-ethnic relationships formed after emigration.

A strong ethnic identity did not detract from these subjects' perception of the success of their acculturation experience. Six of the subjects were satisfied with their acculturation experience, five of them extremely so. Even subjects 1 and 5 , who reported a certain dissatisfaction with their acculturation experience, said they probably would not return to scotland to live.

As stated before, Shibutani and Kwan posit that intra- 
ethnic communication is a hindrance to acculturation because it reduces participation in host society communication. However, according to the subjects of this study, intra-ethnic communication is not a hindrance. Subjects numbers 1 through 6, whether formally or informally, participated significantly in inter-ethnic communication, particularly in work related activities.

The majority of the subjects had assumed diverse leadership roles in the host culture. For example, number 2 was a lawyer as well as being chairman of his foreign languages department: numbers 3 and 4 were directors of large American companies: number 5 (male) was an instructor in college and now managed his own business, employing Americans: number 6 was a leader in church and farming activities and a spokesman for the government in WWI: number 7, formerly a university professor and now a private instructor, ran his own school and company.

If viewed phenomenologically, in terms of intentionality, it can be seen that most of the subjects of this study have construed their own subjective interpretations of their acculturation experience with fluidity, shifting back and forth from inter-ethnic communication situations to intraethnic communication situations without one situation being dysfunctional to the other, some subjects with more flexibility than others. For example, subjects number 1, 2, 3, and 7 seemed to possess a great ability to cope with dissimilar life patterns. They appeared to be adaptable to changing 
situations. Whereas, subjects numbers 1 , and especially 5 , have been more inflexible in their acculturation experience and more tied into reconstruing events according to past experiences in scotland. For example, subjects number 5 wished the way of life in America could be like the way of life in scotland. They displayed ethnocentric tendencies by saying "America has no values," and blamed the host culture for their misfortunes. As previously suggested, in chapter 1 (p. 23), blaming behavior is dysfunctional to any relationship in process, and would be expected to cause continued problems for these subjects in their relationship to the host culture.

In spite of this, most of the other subjects of this study believed that they could communicate successfully in intra-ethnic or inter-ethnic situations. Thus, they were able to understand situations "directly in terms of their possibility for [their] acting in the world" (Deetz, 1973, p.43) and shifted back and forth from their intra-ethnic relationships, to host culture relationships, to other ethnic relationships in context or situation specific behaviors.

In conclusion, it is apparent from this study of scottish immigrants that the influence of prolonged inter-ethnic contact has not eliminated diversity or contributed to individual assimilation and homogenization of the subjects in this study. One has only to consider subject number 6 , who came to the United States in 1909, to see that his ethnicity 
has not been eliminated or even discouraged while, at the same time, acculturation has been positive and successful to both himself and his community.

It is also apparent that the acculturation experience has been of mutual benefit to the host culture as well as to the immigrant. It is clear from the oral history interviews that the immigrants have participated positively in the host society with beneficial and enriching results to it. Many achieved leadership roles, imparting their skills and knowledge to the host culture community, bringing up generations of future Americans (from the eight subjects, there were an accumulated fourteen children, three grandchildren, and one great grandchild) and, in general, enriching the diversity and cosmopolitan nature of the United States.

\section{LIMITATIONS OF THIS STUDY}

Several limitations of the present study should be noted, and the analysis should be interpreted with these in mind. First, the method of interview schedule selection was dependent on the interviewer's own research, experience, observation, and decision about which items would be pertinent in each condition. Also, an attempt was made to keep the items on the interview schedule as few and as open ended as possible, which resulted in abstract written questions. Thus the interview schedule is limited. The more abstract questions should be simplified and expanded in order for the 
study to be replicable. Questions dealing with the specific inter-ethnic communication of immigrants with immigrants from other ethnic groups should also be included.

second, caution is urged in using certain conditions in the Framework of Acculturation. The data shows that it is possible to describe the long term cultural adjustment of immigrants using certain conditions of the Framework of Acculturation as a guide. The conditions of transition, adjustment to the host culture, and identification with the host culture were particularly useful. However, the condition of biculturalism, as described in this present study, may not be useful. Perhaps too much attention was placed on situationality and accommodation equally to both home and host cultures. As suggested in the desciption of biculturalism, this condition is closely related to personality and experience. A clearer description of personality needs to be offered. Maybe biculturalism as a phenomenon of immigrants in a host culture is more clearly defined in the condition of identification, in which the immigrant participates in intra-ethnic communication but it is not of primary importance. It may be unrealistic to expect immigrants to maintain a strong sense of relationship to two cultures and to move in and out of each cultural milieu with ease. It appears that some sacrifice of the home culture is involved, although a clear distinction should be made between marginality and biculturalism. 
The description of multiculturalism should also be more clearly defined. The description in this present study may be indicative of uncertain cultural loyalties instead of a person whose cultural reality is relative.

While there is some reason to believe that the Framework might be generalizable to other situations and other ethnic immigrants, it should be validated by using larger samples. Obviously, the number of subjects in this present study is small, but it should be kept in mind that this study is an oral history assessment. It would be interesting, also, to study each condition separately.

Third, it should also be considered that the subjects in this present study responded to the interview schedule in the context of a specific communication situation. In order to understand and evaluate the oral history interview, the dynamics of the communication interaction need to be considered.

Lastly, originally it was planned to tape all the interviews. However, in the process of interviewing, some oral history conversations were taped, but some subjects were reluctant to have their interviews taped. Two of the people who had initially agreed to the taping kept asking during the interview for the tape recorder to be turned off, on occasions when they intimately detailed their feelings. Therefore, of the seven interviews of this study, there are three tapes, two which do not contain all of the interview. 
I would suggest for further oral history interviewing that the interviewer should be immediately sensitive to the fact that, although subjects say they do not mind being taped, taping may be a deterrent to a free flow of information. It became readily apparent to me while interviewing how the subject was perceiving the tape. Often, after the recorder was turned off there was a more relaxed atmosphere with the subject becoming more disclosing than before.

The subjects did not object to notes being taken and, in fact, when something being said was written down the subject frequently offered a more detailed account. Perhaps note taking is perceived as a positive reinforcement by the subject. It certainly requires more effort on the part of the interviewer but the interviewer should be prepared to gather information by the use of tape, notes, and recall. 


\section{IMPLICATIONS AND APPLICATIONS}

Some of the possible implications and applications of this study of acculturation are explored in this chapter.

\section{IMPLICATIONS FOR FUTURE RESEARCH}

One purpose of this thesis is to provide suggestions for further study and research. The following section of this chapter proposes questions that arose from this study which lend themselves to further research in communication studies on immigrants, ethnicity, and acculturation.

\section{Questions for Future Research}

Is a strong ethnic identity a hindrance to interethnic communication in the acculturation process?

Is is apparent from this study that the immigrants involved in it did not lose their scottishness, and yet they acquired American ways and participated freely in the host society. It would be interesting to study the offspring of first generation immigrants to see what intrinsic home culture nationality they still retain.

Does a shared or common language between host culture members and immigrants actually increase the stress of culture shock? 
This study reveals that language similarity can hide cultural differences. Knowing the host culture language did not shield the subjects of this study from painful transitional experiences. To what extent does lack of knowledge of the language of the host culture shield against painful encounters with members of the host culture during the condition of transition? In the same vein, to what extent does the cultural mediator who represents the home culture to the host culture and guides the new non-English speaking immigrants into the host culture shield the new immigrants from unpleasant verbal experiences? To what extent is the immigrant who speaks the language fluently more exposed to difficulties, to harmful criticism, and to negative feedback? To what extent does this language ability influence his own negative attitudes to the host culture?

To what extent does music of the home culture act as a vehicle for maintaining intra-ethnic communication?

Several of the subjects of the study mentioned that music and songs of scotland were important to their own sense of cultural identity and well being. It would be interesting to describe the relationship of music, dance, and song to the acculturation process of immigrants. Further, it would be interesting to pursue the question: to what extent does immigrant music as a communicative tool influence the music and customs of the host society? 
To what extent does the home culture social class system influence acculturation?

Social class lines are still significant to the immigrants of this study. The class system in scotland is distasteful to nearly all the immigrants in this study. Several mentioned the bigotry of the home culture and they did not want to return to such a restrictive class system.

Do immigrants from other cultural backgrounds chose intimate realtionships with immigrants from cultures different from their own? If so, what are the factors that create this type of relationship?

Nearly all of the immigrants in this study had an intimate relationship network comprising immigrants from other ethnic backgrounds.

Is it possible that immigrants with a family network have a lesser need for a formal network system?

Some subjects of this study who embraced the formalized institutionalized ethnic networks had no family established in the United states. This study tends to support the notion that these formal societies serve as surrogate families to immigrants because most of those subjects who had no family immediately joined some type of ethnic formal society.

What is the role of marriage in acculturation? Does intra-ethnic marriage aid acculturation because it provides 
mutual support and understanding, or does it hinder acculturation because it may shield the immigrant from participating in host culture activities? As the two multicultural subjects of this thesis were both married inter-ethnically, it would be interesting to investigate to what extent interethnic marriage is instrumental in multiculturalism, or if a multicultural frame of mind promotes openess to an interethnic marriage.

What conditions promote immigrants to induce family members from the home culture to emigrate?

Five of the subjects of this study had sponsored family members to join them. Does this increase of intra-ethnic networks aid the acculturation process?

The following statements of a general nature are suggested hypotheses to investigate:

1. Disenchantment with the home culture does not alleviate the stress of culture shock in the host culture.

2. Positive self-perceptions of adapability and flexibility do not decrease the stress of culture shock.

3. Initial alienation from the host culture in the form of culture shock, loneliness, or unpleasant experiences is not a predictor of future unsuccessful acculturation.

4. The duration of acculturation is no guarantee for uniformity of experience. The rate of acculturation is different for different people. 
5. Difficulties in the health care system are a salient factor in acculturation stress.

6. The Framework of Acculturation was found to be useful in describing the experiences of scots immigrants. For this model to have general descriptive usefuleness it should be applied to other long term cultural adjustment situations: for example, Americans in Israel or Scotland; other ethnic groups in the United States; Ugandans in Kenya; English in Ireland.

\section{AP PLICATIONS}

This section on applications contains suggestions for future intercultural communication oriented training. A discussion of the necessary type of training is presented, in which relevant phenomenological assumptions will be considered as they pertain to communication training. The potential participants in the training program are proposed. Consideration is given to the type of agencies that could participate in the training.

\section{Type of Training Session}

Sessions for the immigrant should include both culturegeneral and culture-specific training. Culture-general training, in the form of intercultural communication training, emphasizes an overall expansion of cultural awareness, and an increased tolerance and acceptance of different values, attitudes and behaviors. 


\section{Values Training}

The immigrant needs to understand himself before he can understand others. As stated in chapter one, a prerequisite to understanding one's self is to be aware of one's value system. Perhaps values training for immigrants in itself, could alleviate the stress of immigration and increase positive understanding of the host culture. People involved in values training should consider the following.

Each person has a set of values. These are moral and ethical judgments which affect our attitudes, beliefs, and behaviors. In training sessions it is important to guide people to comprehend their own value system because once people have an insight into some of the characteristics of their own cultural values, they may be able to make meaningful and knowledgable comparisons to other cultural systems.

One of the subjects of this study had experienced insight into her values. She lucidly explained that her value system had not changed since coming to the United States, but had "flowered and expanded," particularly since the time she had realized higher education was available to her in the United States. One of her own values is education. A United states cultural value is also education, but it is manifested in a different way. This subject chose to contrast the United States and Scottish education system to show the difference.

Before this subject emigrated to America she had 
little respect for the quality of American education and believed European education, and Scottish education particularly, to be vastly superior. However, in retrospect, to her Scottish education was "ritualized education" in which the society treats a little knowledge with "enormous reverence" as she did when she lived there. She decried the boastfulness of the degreed person and said that when she lived there, higher education was an option she did not even consider as she had not the appropriate certificate for entrance to university. She believed that this certificate was necessary for entrance to university here, too.

However, recently in America she completed a college degree program in her late forties. She said that going to college at her age would be a most unusual occurrance in scotland. She was not aware until recently that there were opportunities in the United States for older people to continue their formal education.

It is suggested that if this subject had been made aware, through initial values training sessions, that Americans valued education for all, and that, therefore, the system was accessible to her, she would not have had to wait until such a late time in her life to complete her education. Her acculturation may have been more positive. Another subject categorically declared that Americans had no values. It is hoped that values training would help him understand otherwise. 
Sessions in values training should focus on cultural self-awareness, as that term is used in intercultural communication while simultaneously guide toward an understanding and coping with American cultural values. In this study there were several areas of the United States system that gave great concern to the immigrants. Of greatest concern was a fear of growing old in this society that values youth. Values training sessions could address this particular fear and point out ways to cope with the problems of growing old in the United states. For example, immigrants could be taught to maintain, and actively work at, hobbies they had pre-emigration and not drop them because of the problems of adjustment. Several of the scots of this study believed that the continuation of their hobbies, such as photography, woodwork, and sports activities had helped alleviate long term adjustment problems. Opportunities for acquiring new skills that can be used after retirement should be made available, too.

Fear of growing old was associated with a fear of the high cost of United States health care. Most immigrants in this study valued the concept of socialized medicine. The United states system, in turn, values minimum governmental intervention, that is, a free enterprise system. To the immigrants, old age was seen as a time of sickness in which all their savings and solvency would vanish. Physicians, hospitals, and the general health care system were unfavorably compared to home conditions. These concerns contribute 
to acculturation stress. In training sessions the workings of the health care system works should be clearly spelled out at the beginning of the sojourn.l

\section{Citizenship Training: the}

\section{Reciprocal Relationship}

According to phenomenological assumptions, "Selves can only exist in definite relationships to other selves" (G.H. Mead, 1934, p. 164). As previously suggested, viewed relationally, acculturation is a process whereby the subjective meaning of the acculturation experience emerges, not from only the immigrant, nor from only the host culture, but from relationships. One of the many relationships of acculturation is citizenship.

Part of any relationship includes the need to stabilize and confirm it. One way the immigrant confirms and stabilizes his relationship to the host culture is in citizenship. An immigrant is not eligible for citizenship until after five years in the country. However, initial training sessions should include citizenship awareness at an early period of immigration. This training would prepare the immigrant for the event which, to many, is so traumatic that they never take the step. Some believe the process of receiving citizenship to be too difficult; some are frightened by the paperwork. A subject in this study did not relish the fact that part of the citizenship ceremony demands an oath that immigrants must relinquish all loyalties to their home nation. Often immigrants may 
refuse, or find it difficult to become United States citizens for this very reason because this pushes them into an "either-or" situation. However, if government officials, through training sessions, taught about citizenship from a relational perspective, this last fear may be alleviated as described below.

Relationally, becoming a citizen may be viewed as an act of reciprocity. Reciprocity implies that each side has rights and obligations to each other (Swenson, 1973). And so it is with citizenship. Immigrants should consider that citizenship is an obligation or commitment to the host culture which will, in return, enable them to participate politically in the system. Governmental agencies should recognize and teach that the home culture relationship still provides continuity for the immigrants and can favorably influence the immigrant. This would enable immigrants to accept citizenship as an addition to their life and not necessarily as a negation of their loyalties to the land of their birth.

Most citizenship courses offer a brief survey of United States history, civics, and language. The courses would be of service to the immigrants if the curriculum were designed to include the previously mentioned relational components and skills training that promote understanding of United States values, behaviors, and attitudes. Emphasis should be on tolerance for ambiguity in the immigrant, in others, and in the relationship so that an "either-or" 
mentality is reduced to a level of tolerance, respect, and, ideally, an eventual acceptance of differences.

\section{Intercultural Communication}

\section{Training}

The foregoing suggestions can all be classified as intercultural communication training. The immigrant finds himself in a completely new and strange situation in which much of his social discourse is with people from cultures different from his own. The benefits of intercultural communication training are that the immigrant is guided to become aware of, to be conscious of, the various cultural behaviors, characteristics and patterns of the host culture, and how these factors affect his communication with host culture members. If immigrants should be obliged to take at least one course in intercultural communication, offered by the community it may, perhaps, reduce the anxiety and disorientation associated with culture shock.

Ideally, in these classes, differences between the two cultures should be discussed. The immigrants should be alerted to inappropriate and appropriate behavior for the new culture, contrasting values, and differences in nonverbal behaviors.

The differences in nonverbal communication is an example. Culturally different nonverbal behaviors often communicate mistaken messages to people. Immigrants should be aware that, often, unconscious nonverbal behaviors may be 
misperceived and misunderstood.

One area of nonverbal behavior is paralanguage--how we say what we say. Generally, Scottish paralanguage is quiet and slow. This tends to communicate a message to Americans that the person using it is hesitant and indecisive when, in fact, the opposite might be the case. Understanding the difference between their own nonverbal behaviors and host culture nonverbal style and of how Americans perceive certain nonverbal behaviors would be beneficial to the immigrants. In the case of paralanguage, it would benefit the immigrants to learn new ways speaking that may decrease negative perceptions. Misunderstandings and misperceptions on both sides would tend to decrease, therefore, if part of the training considered nonverbal communication.

of more practical and functional use to immigrants at the onset of their acculturation experience would be culturespecific training, which could enable immigrants to develop coping strategies for their immediate needs.

Culture specific training contains information about only one culture, in this case, the United states. It is a necessary form of training because it alleviates misperceptions about the culture and can be applied to the immigrants' immediate needs. Culture specific training may be useful if it includes the following information:

1. How to deal with, and understand, immigration requirements; for example, the January address report, passports, legal rights and restrictions are oftentimes an anathema to 
immigrants.

2. How to cope with the medical, banking, and postal system.

3. What further education possiblities are available and how to use them. Often immigrants are unaware that in America education is accessible to all. Therefore, many do not avail themselves of the opportunities this type of system offers.

4. The immigrant's social responsibilities.

\section{POTENTIAL PARTICIPANTS IN TRAINING}

Training may help alleviate the problems that immigrants encounter in their adjustment to the host society. Coping strategies may be learned and immigrants may be trained to expand their own cultural awareness to include an awareness and understanding of the host culture. Potential misunderstandings, discomfort, and conflict may then be minimized. Ideally, training would serve to make the overall acculturation experience positive and growthful.

Training may be of use to others in any transitional condition. People undergoing life changes of any type could extrapolate pertinent information to suit their needs. These people may include those dealing in ethnic or multicultural education; therapists; family and marriage counselors; people separated by divorce, death, sickness, retirement; people returning to college in later years; people in 
minority groups; people in transitional crisis of any kind.

\section{Type of Agencies to Participate}

in the Training of Immigrants

The training of immigrants could come under the general auspices of immigrant adjustment agencies (Gordon, 1964). These agencies should be sponsored by the host culture as well as by the ethnic group institutions.

\section{Training by Host Culture}

As the host culture government has a policy of accepting immigrants into the host society, it should also have a policy that would help alleviate the immediate problems of adjustment and to guide the new members of the society toward a satisfying social life.

This type of policy would be more favorable to immigrants than forgetting about immigrants once they arrive. Currently, there are virtually no official programs at this time for immigrants (unless they are refugees) and yet, paradoxically, impermanent foreign nationals of student visa status are aided in their adjustment to the United states by host culture agencies. At state universities in California and oregon known to this author, international student officers serve only foreign students and exclude immigrants. This is a strange phenomenon because the immigrant is considered to be able to "know his own way around" and yet his needs for clarity and understanding in the new education sys- 
tem are as demanding and acute as that of the foreign students. In other words, the system of higher eduction excludes immigrants from the support services they perhaps need the most; the most important service being the special services and training that the international student counsellors offer.

Once host culture agencies are set up they could be represented and staffed by specialists persons skilled in intercultural communication or education. These specialists would teach immigrants, as well as personnel who deal with immigrants such as social workers, therapists, counsellors and teachers.

\section{Intra-Ethnic Training}

As well as the host culture responsibilities, the ethnic group should play a part in training of immigrants, should there be a formal ethnic institution. As we have seen, ethnic groups offer support to the immigrant mainly in informal and social situations. However, a more formalized system of instruction sponsored by fellow immigrants could be utilized.

It is interesting to note that some ethnic group organizations in the United States have formal training schools for children (e.g. the Germans, the Latvians). From this author's experience of ethnic groups in Oregon and California these schools are available only to children of immigrants and children of similar ethnic backgrounds. Lan- 
guage, music, and customs of the home culture are mainly taught. Specific training in immigrant adjustment is not taught by these groups. However, helping to alleviate problems of adjustment could become part of the curriculum.

Formal training sessions could be conducted by fellow immigrants who wish to share their past experience and who have an interest in their peers. These people could also serve as cultural mediators, bridging the gap between home and host culture for the new immigrants.

The Environment of the

Training Session

The sessions, whether or not ethnically sponsored, could be organized in various ways in learning centers, night school classes, or even on community access television. Face-to-face communication, or small group sessions would be of most benefit because immediate and constructive feedback is more possible in sessions such as these. Moreover, these type of sessions allow for experiential learning in which information is given, skills are taught, and the immigrant has an opportunity, through discussion and interaction, to integrate both information and skills into a meaningful pattern.

\section{Cultural Relativity and Diversity}

The overall paradigm of any intercultural communication training should be that of cultural relativity. Kurt 
Vonnegut Jr. believes that everyone should learn about it at an early age:

One thing I would really like to tell them about is cultural relativity. I did not learn until I was in college about all the other cultures, and I should have learned that in the first grade (p. 139).

He goes on to say, "Cultural relativity is defensible and attractive. It's a source of hope. It means we don't have to continue this way if we don't like it" (1974, p.139)

An understanding of cultural relativity is crucial to all successful intercultural and inter-ethnic contact because it should enable people to accept the idea that cultures, values, beliefs and behaviors different from their own are as "valid" as their own, in terms of providing a coherent world view for the members of the culture.

In intercutural communication training sessions, set up for immigrants, cultural relativity should be considered. skills should be taught to increase an awareness in cultural relativity which, ideally, would reduce troublesome ethnocentric attitudes, as well as other problems previously mentioned, to such an extent that no immigrant could be justified in saying, as one person in this study said, "America has no values." Immigrants with this point of view could be made aware that they should evaluate America relative to its own inherent perspective.

With an understanding of cultural relativity may come an appreciation of the diversity of cultural and ethnic groups. Groups need not be assimilated in, consumed by, or 
competitive with other groups. Neither need they be separated or divided from each other. From the phenomenological perspective, cultural relativity and diversity means that all ethnic groups are complementary to, and interconnected with each other, and all the people in the society are involved in multiple relations. People mutually accommodate to the differences of each other with flexibility. In other words, heterogeneity, not homogeneity is encouraged to flourish. 2

According to Margaret Mead (1978) the pursuit of homogeneity or "uniformity" is dangerous because it unbalances the overall cultural system, ignores the differences within it, produces narrowness of vision, and renders it more vulnerable to disruption. Ultimately, the pursuit of homogeneity leads to national competitiveness, to an expansion of in-group/out-group divisions and strenghtens the belief that the outsider is indeed the enemy. Mead reminds her reader that, in present times when cultures have "become one interconnected whole, equipped with lethal powers to destroy life itself," it is essential to recognize the strength of diversity: "Any reduction in diversity represents a hazard." Diversity "brings different visions and different experiences to the decision-making centers of the world" (p. 155). Those who give credence to cultural diversity bring hope to the world because: 
- . with every inclusion of the hitherto excluded--whether it be a paraplegic, a woman, an old man of ninety, a Pygmy from the Ituri forest, a Shaman from the Amazonian jungle, or a dancer from the Nubian desert--the human community, grown richer, more intricately related and diverse, will have a better chance of survival and growth (Mead, 1978, pp. 155-156).

Immigrants, in the process of acculturation, have the opportunity to give credence to cultural relativity and diversity. An immigrant's perceptions of his home culture's values and assumptions are probably extremely limited until he moves to another culture. After he immigrates, he learns that if he judges the host culture from the perspective of his home culture, he may encounter considerable difficulties. He begins to realize that there may be alternatives to life.

Viewing the process of acculturation as a phenomenological relational experience may be a further aid in understanding or achieving cultural relativity. Acculturation as a relational process is an experience which, ideally, should broaden an immigrant's perceptions to include an awareness and understanding that people, including himself, may transcend cultural boundaries and need not be helplessly fixed into one set of cultural beliefs and attitudes. It was interesting to see that several subjects in this study decried the bigotry and narrow mindedness of the home culture people. The subjects in this study said that they were unaware of this bigotry while they were part of the home culture. Perhaps, this implies that their experiences in a 
culture different from their own has brought them to an ethno-relative understanding of cultures, because recognizing bigotry in others may mean that these immigrants have transcended a single culture reality. The potential benefit of ethno-relativism is that ethnocentrism is decreased, and positive attitudes toward people of diverse cultures are increased. Mutual and tolerant inter-ethnic interaction and relationships may ensue. Individuals may participate nonjudgmentally in intra- and inter-ethnic communiction and have meaningful relationships in both. 
lAll people involved in these sessions would benefit from reading books and articles that specifically address the problems. Cultural self-awareness is written of in Margaret Pusch's (1979) Multi-cultural Education. Of particular interest are pages 114-153, which contain exercises that can be used with adult populations in guiding them to assess their own values. A useful book for trainers to acquire is Edward Stewart's (1972) American Cultural Patterns: A Cross Cultural Perspective, in which American cultural values are explicitly stated. For cultural awareness, an interesting article for trainers and immigrants to read is Barna's (1982) "stumbling Blocks in Intercultural Communication." This article analyzes reasons why people have difficulty adjusting to new cultures and offers solutions to the perceived problems.

$2 \mathrm{~A}$ good guide for trainers in cultural relativity theories is the book Cultural Relativism: Perspectives in Cultural Pluralism by Melville Herskovits (1972). For insight into intercultural nonverbal behaviors, trainers should read Non Verbal Behavior: Application and Cultural Implications by Aaron Wolfgang (1979), which is geared toward teaching the understanding of nonverbal behavior from a cultural perspective. 


\section{SELECTED BIBLIOGRAPHY}

Adler, Peter. "The Transitional Experience: An Alternative View of Culture Shock," Journal of Humanistic Psychology, 15 (Fall, 1975), 13-23.

"Beyond Cultural Identity: Reflections on Cultural and Multicultural Man," in Intercultural Communication: A Reader. Edited by L. Samovar and R. Porter. Belmont, California: Wadsworth Publishing Company, $1982,389-406$.

Baldassini, James, and Flaherty, Vincent. "Acculturation Process of Columbian Immigrants into the American Culture in Bergen County, New Jersey." International Journal of Intercultural Relations, 6 , No. 2, 1982, $127-134$.

Barna, LaRay. "Stumbling Blocks in Intercultural Communication," in Intercultural Communication: A Reader. Edited by L. Samovar and R. Porter. Belmont, California: Wadsworth Publishing Company, 1982, 322331 .

Barnlund, Dean. "A Transitional Model of Communication," in Foundations of Communication Theory. Edited by $\mathrm{K}$. Sereno, and D. Mortensen. New York, N.Y.: Harper and Row, 1970 .

"Communication in a Global Village," in Intercultural Communication: A Reader. Edited by L. Samovar and R. Porter. Belmont, California: Wadsworth Publishing Company, 1982, 4-15.

Bemis, J., and Phillips, G. "A Phenomenological Approach to Communication Theory," Speech Teacher, 1, No. 13 (Nov. 1964), 262-266.

Bennett, Janet. "Transition Shock: Putting Culture Shock in Perspective," International and Intercultural Communication Annual, $4(1977), 45-52$. 
Bennett, Milton. "Overcoming the Golden Rule: Sympathy and Empathy," Communication Yearbook, 3. Edited by Dan Nimmo. New Jersey: Transaction Books, 1979, 407-423.

Berlo, David. The Process of Communication. New York, N.Y.: Holt, Rinehart and Winston, 1960.

Berger, Peter, and Luckmann, Thomas. The Social Construction of Reality. Garden City, N.Y.: Doubleday, 1967 .

Bogdan, Robert, and Taylor, Steven. Introduction to Qualitative Research Methodology. New York, N.Y.: Wiley and Sons, 1975 .

Boss, Medard. Psychoanalysis and Daseinalysis. New York: Basic Books, 1963.

Breton, Richard. "Institutional Completeness of Ethnic Community and the Personal Relations of Immigrants," American Journal of Sociology, 70 (1964), 193-205.

Brislin, Richard. Cross-Cultural Encounters. New York: Pergamon Press, 1981 .

Brodbeck, Mary. "Meaning and Action," in The Philosophy of the Social Sciences. Edited by M. Brodbeck, New York, N.Y.: MacMillan and Company, 1968.

Broom, Leonard, and Kitsuse, John. "The Validation of Acculturation: A Condition to Ethnic Assimilation," American Anthropologist, 57 (Feb. 1955), 44-48.

Broome, B. J. "Facilitating Attitudes and Message Characteristics in the Expression of Differences in Intercultural Encounters," International Journal of Intercultural Relations, 5 (1981), 215.

Burkey, R. Ethnic and Racial Groups. New York, N.Y.: The Benjamin Publishing Company, 1978 .

Clark, E. C., Hyde, M.J. and McMahan, E."Developing Instruction in Oral History: A New Avenue for Speech Communication," Communication Education, 1981, 30, 238-244. 
Deetz, Stanley. "Words Without Things: Toward a Social Phenomenology of Language," Quarterly Journal of Speech, 59, No. 1 (Feb. 1973), 40-57.

Dyal, James, and Dyal, Ruth. "Acculturation, Stress, and Coping: Some Implications for Research and Education," International Journal of Intercultural Relations, $7(1981), 301-329$.

Fausti, Remo, and Luker, Aldo. "A Phenomenological Approach to Discussion." in Introductory Readings in Oral Communication. Edited by McGlone and Fausti. Menlo Park, Cal.: Cummings Pub. Co., 1972, 123-131.

Glazer, Nathan, and Moynihan, Peter. Beyond the Melting Pot. Cambridge, Mass.: M.I.T. Press, 1970.

Gordon, Milton. Assimilation in American Life. New York: Oxford University Press, 1964 .

- Human Nature, Class, and Ethnicity. New York: Oxford University Press, 1978.

Greeley, Andrew. Why Can't They Be Like Us? New York: Dutton Press, 1971.

Ethnicity in the United States. A Preliminary Reconnaissance. New York: John Wiley and Sons, 1974.

Gresson, Aaron. "Phenomenology and the Rhetoric of Identification-A Neglected Dimension of Coalition Communication Inquiry," Communcation Quarterly, 26, No.4 (Fall, 1978), 14-41.

Hall, Edward. The Silent Language. New York: Anchor Press, 1973.

Handlin, Oscar. The Uprooted. Boston, Mass.: Little, Brown and Co., 1973 .

Harding, R., and Looney, G. "Problems of Southeast Asian Children in a Refugee Camp," American Journal of Psychiatry, 1, (1977), 31-51. 
Harris, P., and Moran, R. "Understanding Cultural Differences," in Intercultural Communication: A Reader. Edited by L. Samovar and R. Porter. Belmont, Calif.: Wadsworth Publishing Company, 1982, 62-73.

Hawes, Leonard. "Elements of a Model for Communication Processes," Quarterly Journal of Speech, 59, No. 1 (February, 1973), 11-21.

Herberg, Dorothy. "Discovering Ethnic Root Behavior Patterns," International Journal of Intercultural Relations, 6 , No. $2(1982), 155-168$.

Herskovits, Melville. Cultural Relativism: Perspectives in Cultural Pluralism. N.Y.: Random House, 1972.

Husserl, Edmund. Ideas. New York: Collier, 1962.

Jehenson, R. "A Phenomenological Approach to the Study of Formal Organizations." in Phenomenological Sociology: Issues and Applications. Edited by Psathas. New York: Wiley and Sons, 1973, 219-249.

Kelly, George. A Theory of Personality. New York: w. W. Norton and Company, 1963.

Kim, Jin K. "Explaining Acculturation in a Communication Framework: An Emperical Test," Communication Monographs, 47, (Aug. 1980), 155-180.

Kim, Young Yun. "Inter-ethnic and Intra-ethnic Communication: A Study of Korean Immigrants in Chicago," International and Intercultural Communication Annual, 4 $(1977), 53-68$.

"Toward an Interactive Theory of Communication/ Acculturation," in Communication Yearbook. Edited by Dan Nimmo. New Jersey: Transaction Books, 1979, 435-453.

Kohls, Robert. Survival Kit for Overseas Living. Chicago, Ill.: Intercultural Press, Inc., 1979.

Laing, R. D. The Politics of Experience. New York: Pantheon Books, 1967 . 
Laing, R. D., Phillipson, H., and Lee, A. Interpersonal Perception. San Francisco, Ca.: Harper and Row, 1966 .

Lanigan, Richard. Speech Act Phenomenology. The Hague, Netherland: Martinus Nijhoff, 1977.

"Communication Models in Philosophy: Review and Commentary," in Communication Yearbook. Edited by Dan Nimmo. New Jersey: Transaction Books, 1979, $29-45$.

Lauer, Quentin. Phenomenology: Its Genesis and Prospect. New York: Harper and Row, 1965.

Luft, Joseph. of Human Interaction. Palo Alto, Ca.: National Press Books, 1969 .

Lum, John. "Marginality and Multiculturalism: Another Look at Bilingual/Bicultural Education,"in Intercultural Communication: A Reader. Edited by L. Samovar and R. Porter. Belmont, Ca.: Wadsworth Pub. Co., 1982 .

Mansell, Maureen. "Transcultural Experience and Expressive Response," Communication Education, 30 (April 1981), 93-108.

Marden, Charles, and Meyer, Gladys. Minorities in America. New York: Van Nostrand Reinhold Co., 1968.

May, Rollo. "The Origins and Significance of the Existential Movement in Psychology," in Existence: A New Dimension in Psychiatry and Psychology. Edited by May, Angel and Ellenberger. New York: Basic Books, 1958.

McMahan E. "Communicative Dynamics of Hermeneutical Conversation in Oral History Interviews." Communication Quarterly, 31 (1983), 3-11.

Mead, George H. Mind, Self and Society. Chicago, Ill.: University of Chicago Press, 1934. 
Mead, Margaret. Culture and Commitment. Garden City, N.Y.: Anchor Press, 1978 .

Metzger, Janet. "Toward a Phenomenology of Acculturation: An Investigation of Foreign Students' Perception of Competency along Phenomenological Dimensions of Acculturation by Means of Guttman's Scalogram Analysis," M.A. Thesis. Portland State University, 1977.

Oberg, Kalvero. "Culture Shock and the Problems of Adjustment in New Cultural Environments," in Toward Internationalism. Edited by Smith and Luce. Maryland: Newbury House Publishers, Inc., 1979.

Phillips, G., and Metzger, N. Intimate Communication. Boston, Mass: Allyn and Bacon, Inc., 1976.

Prosser, Michael. The Cultural Dialogue. Palo Alto, Ca. Houghton Miffin Co., 1978.

Pusch, Margaret. Multicultural Education: A Cross Cultural Training Program. LaGrange Park, Ill.: Intercultural Network, Inc., 1979.

Rose, Peter. They and We. New York, N.Y.: Random House, Inc., 1981 .

Samovar, L., Porter, R., and Jain, N. Understanding Intercultural Communication. Belmont, Ca.: Wadsworth Publishing Company, 1981.

Sarna, Jonathan. "From Immigrants to Ethnics: Toward a New Theory of Ethnicization," Ethnicity, 5, (1978), $370-378$.

Sauceda, James. "Chicano/a Ethnicity: A Concept in Search of a Content," in Intercultural Communication: A Reader. Edited by L. Samovar and R. Porter. Belmont, Ca.: Wadsworth Publishing Company, 1982, 185-194.

Schutz, Alfred. On Phenomenology and Social Relations. Chicago, I1l: University of Chicago Press, 1970 
Shibutani, T., and Kwan, K. Ethnic Stratification:

A Comparative Approach. New York: MacMillan and Co., 1965 .

Singer, Marshall. "Culture: A Perceptual Approach," in Intercultural Communication: A Reader. Edited by L. Samovar and R. Porter. Belmont, Ca.: Wadsworth Publishing Company, 1982, 54-62.

Steinberg, Stephen. The Ethnic Myth. New York: Atheneum, 1981 .

Stewart, Edward. American Cultural Patterns: A Cross Cultural Perspective. Pittsburg, Pen.: Intercultural Communication Network, 1972.

Stewart, John. Bridges Not Walls. Menlo Park, Ca.: Addison-Wesley, 1973.

"Foundations of Dialogic Communication," Quarterly Journal of Speech, 64, (1978), 183-20l.

Swenson, Clifford. Introduction to Interpersonal Relations. Glenview, Ill.: Scott, Foresman and Co. 1973.

Teske, R., and Nelson, B. "Acculturation and Assimilation: A Clarification," American Ethnologist, 2 (May, $1974), 351-364$.

Ting-Toomey, Stella. "Ethnic Identity and Close Friendship in Chinese-American College Students," International Journal of Intercultural Relations, 5, No. 4 (1981), 383-407.

Vonnegut, K. Jr. "Afterword," in Free to Be...You and Me. Edited by Klagstrum. New York: McGraw-Hill, 1974.

Warner, W., and Srole, L. The Social systems of American Ethnic Groups. New Haven: Yale University Press, 1945 .

Watzlawick, P., Beavin, J., and Jackson, D. Pragmatics of Human Communication. New York: W. W. Norton and Company, 1967. 
Weinstock, Alexander. "Some Factors that Retard or Accelerate the Rate of Acculturation," Human Relations, 17

(November 1974), 321-340.

Wilson, Colin. The New Existentialism. London: Wildwood House Ltd., 1980.

Wolfgang, Aaron. Nonverbal Behavior: Application and Cultural Implication. New York: Academic Press, 1979. 